\title{
Algoritmos Paralelos para Fecho Convexo
}

Emmanuel Kayembe Ilunga

DISSERTAÇÃO APRESENTADA

AO

INSTITUTO DE MATEMÁTICA E ESTATÍSTICA

DA

UNIVERSIDADE DE SÃO PAULO

PARA

OBTENÇÃO DO GRAU DE MESTRE

EM

CIÊNCIA DA COMPUTAÇÃO

Orientador: Prof. Dr. Siang Wun Song

Durante a elaboração deste trabalho o autor recebeu auxilio financeiro da CAPES.

São Paulo, 30 de março de 2001 


\title{
Algoritmos Paralelos \\ para \\ Fecho Convexo
}

\author{
Este exemplar corresponde à redação \\ final da dissertação devidamente corrigida \\ e defendida por Emmanuel Kayembe Ilunga \\ e aprovada pela comissão julgadora.
}

São Paulo, 30 de março de 2001.

Banca examinadora:

- Prof. Dr. Siang Wun Song (orientador) - IME-USP

- Prof. Dr. Alfredo Goldman Vel Lejbman - IME-USP

- Prof. Dr. Jorge Stolfi- IC-UNICAMP 
A minha família,

pelo apoio durante todos estes anos. 


\section{Agradecimentos}

Ao Prof. Dr. Siang Wun Song, pela paciência e excelente orientação durante a realização deste trabalho.

Ao Prof. Dr. Alfredo Goldmann Vel Lejbman, pela amizade e por sua colaboração na realização deste trabalho.

Ao Prof. Dr. Maurice Tchuente, por ter me apresentado a área da computação paralela.

Ao meu pai Grégoire Ilunga Tshisaw, in memoriam, minha mãe Mutoba Katanga e irmãos, por tudo que fizeram por mim.

Ao Prof. Dr. Kabengele Munanga, pelo apoio moral.

Aos irmãos Lukota Kitoko, Richard Kouakou e Crispim C.M.Calonge, pelo acolhimento nessa terra brasileira e todo apoio.

Aos amigos Ricardo Couto Antunes da Rocha e Marco Aurélio Stefanes, pela ajuda e pela troca de idéias.

Aos professores e funcionários do IME-USP, pela formação e serviços prestados.

À CAPES, pelo apoio financeiro.

Finalmente, a todos que de alguma forma contribuiram para a realização deste trabalho. 


\section{Resumo}

O principal objetivo de nossa dissertação é de estudar os algoritmos paralelos e de implementar alguns algoritmos probabilísticos para o problema do fecho convexo.

Nosso estudo começa com os algoritmos seqüenciais que podem ser usados na fase de cálculo local de cada processador. Em seguida apresentamos uma classificação dos modelos de computação paralela. Dois destes modelos são usados para estudar os algoritmos paralelos, um deles foi escolhido pelas características teóricas e outro pelas características práticas ligadas a realidade das máquinas atuais.

Por fim, descrevemos e implementamos dois algoritmos probabilísticos incluindo o algoritmo Quickhull paralelo na máquina paralela Parsytec PowerXplorer. 


\section{Abstract}

The main goal of this dissertation is to study parallel algorithms for the convex hull problem and implement two parallel algorithms.

Our study starts with sequential algorithms that can be used in the local computing phase in each processor. We then present a classification of some parallel computing models. Two of such models are used to study the parallel algorithms, one of which chosen for its theoretical characteristics and the other for its practical characteristics related to actual parallel machines.

At last we describe the implementation of two probabilistic parallel algorithms including the parallel quickhull in a Parsytec PowerXplorer. 


\section{Índice}

Agradecimentos $\quad$ iv

Resumo $\quad$ v

Abstract vi

1 Introdução 1

2 Algoritmos Seqüenciais $\quad 6$

2.1 Introdução . . . . . . . . . . . . . . . . . . 6

2.2 Algoritmo Arestas-Extremas . . . . . . . . . . . . . . . . . . 7

2.3 Algoritmo Embrulho-para-Presente . . . . . . . . . . . . . . . . 8

2.3 .1 Algoritmo . . . . . . . . . . . . . . . . 8

2.3.2 Análise do Algoritmo . . . . . . . . . . . . . . . . 9

2.4 Algoritmo Quickhull . . . . . . . . . . . . . . . . . . . . . 10

2.4.1 Descrição do Algoritmo . . . . . . . . . . . . . . . . . . . 10

2.4.2 Análise de Complexidade. . . . . . . . . . . . . . 11

2.5 Algoritmo Mergehull . . . . . . . . . . . . . . . . . . . . . . . . . . 12

2.5.1 Descrição do Algoritmo . . . . . . . . . . . . . . . . . . . 13

2.5.2 Análise do Algoritmo . . . . . . . . . . . . . . . 15

2.6 Algoritmo de Graham . . . . . . . . . . . . . . . . . . 15

2.6.1 Pré-processamento . . . . . . . . . . . . . 15 
2.6.2 Construção do Fecho Convexo . . . . . . . . . . . . . . . . 16

2.6 .3 Análise do Algoritmo . . . . . . . . . . . . . . . . . 17

3 Modelos de Computação Paralela $\quad 18$

3.1 Introdução . . . . . . . . . . . . . . . . . . . . . . . . . . 18

3.2 Classificação dos Modelos de Computação Paralela . . . . . . . . . . 20

3.2.1 Apresentação dos Principais Modelos . . . . . . . . . . . . . . 20

3.2 .2 Modelos . . . . . . . . . . . . . . . . . 22

3.2 .3 Classificação . . . . . . . . . . . . . . . . . . . . . 27

3.3 Conclusão . . . . . . . . . . . . . . . . . . . . . . . . 30

4 Algoritmo Paralelo PRAM 31

4.1 Estratégia de Divisão-e-Conquista . . . . . . . . . . . . . . . . . . 31

4.2 Um Algoritmo de Tempo Constante para Determinação da Tangente Comum Superior . . . . . . . . . . . . . . . . . . . 33

4.3 Cálculo do Fecho Convexo . . . . . . . . . . . . . . . . . . . 36

5 Algoritmos Paralelos CGM 38

5.1 Algoritmo CGM Probabilístico . . . . . . . . . . . . . 38

5.1 .1 Caso $p \leq \sqrt{n} \ldots \ldots \ldots \ldots$

$5.1 .2 \quad$ Caso $1 \leq p \leq n^{1-\epsilon} \ldots \ldots \ldots \ldots 43$

5.2 Algoritmo Paralelo Determinístico no Modelo CGM . . . . . . . . . . 44

5.2.1 Combinando os Fechos Convexos em Paralelo . . . . . . . . . 46

5.2 .2 Caracterização do Fecho Superior . . . . . . . . . . . . . . 48

5.2.3 Cálculo do $g_{i}^{*}$ e $x_{i}^{*}$ em Paralelo . . . . . . . . . . . . . . . . . 49

5.2 .4 Algoritmo MergeHulls $1 \ldots \ldots 51$

5.2 .5 Algoritmo MergeHulls $2 \ldots \ldots . \ldots . \ldots 52$

5.3 Implementações Paralelas . . . . . . . . . . . . . . . . . . . 54

5.3.1 Implementação do Algoritmo Paralelo Probabilístico . . . . . 54

5.3.2 Implementação do Algoritmo Paralelo Determinístico . . . . . 54

6 Implementações Paralelas $\quad 56$

6.1 Características da Máquina . . . . . . . . . . . . . . 56 
Índice

6.2 Algoritmo Quickhull Paralelo . . . . . . . . . . . . . . . . . . 57

6.3 Resultados . . . . . . . . . . . . . . . . . . 58

7 Considerações Finais $\quad 61$

$\begin{array}{ll}\text { A Implementação } & 63\end{array}$

$\begin{array}{ll}\text { Referências Bibliográficas } & 77\end{array}$ 


\section{Introdução}

A computação paralela é necessária em diversos problemas onde o volume de dados e cálculos é grande e precisa-se de rapidez na obtenção das respostas. Tais problemas podem ser encontrados, por exemplo, na previsão do tempo, na prospecção de petróleo, na dinâmica dos fluidos e na computação gráfica. Algoritmos de geometria computacional, em particular o de fecho convexo, encontram aplicações em diversas áreas como projeto de circuitos VLSI, robótica e computação gráfica, e nos casos práticos a quantidade de dados é grande.

As estratégias usadas em algoritmos seqüenciais para solucionar um problema nem sempre servem para a criação de algoritmos paralelos para o mesmo problema. $\mathrm{Na}$ elaboração dos algoritmos deve-se levar em conta também a natureza dos problemas. Alguns são trivialmente paralelizáveis, outros apresentam um paralelismo não tão transparente, precisando de estratégias mais elaboradas na confeç̧ão dos algoritmos. Existem alguns em que o grau de paralelismo é muito baixo ou igual a um. $\mathrm{O}$ desenvolvimento dos algoritmos paralelos exige que consideremos a arquitetura paralela a ser usada, pois esta afeta diretamente o desempenho dos algoritmos.

A elaboração dos algoritmos paralelos exige a utilização de estruturas de dados que sejam ao mesmo tempo simples para serem calculadas eficientemente, e suficientes para responder as consultas.

Aggarwal et al. [2] mostram algoritmos paralelos para resolver alguns problemas de geometria computacional. O problema do fecho convexo (em inglês convex hull) 2-dimensional é o problema mais fundamental na área de geometria computacional e

\footnotetext{
${ }^{1}$ É o número máximo de processadores que podem estar computacionalmente ativos em um dado instante de tempo, durante a execução de um programa.
} 
também o mais estudado [5]. Além disso, esse problema tem muitas aplicações, por exemplo, reconhecimento de padrões [6, 19], processamento de imagens [45], corte e alocação de estoque $[25,26,46]$. De fato, parece ser o primeiro problema de geometria computacional para o qual algoritmos paralelos foram elaborados.

O desenvolvimento dos algoritmos paralelos depende também do modelo de computação paralela. Por exemplo, um algoritmo de ordenação ou de inversão de matrizes não é tratado da mesma maneira sobre o modelo PRAM (Parallel Random Access Machines) e sobre o modelo BSP (Bulk Synchronous Processors). No primeiro caso, o número de processadores é ligado ao tamanho do problema e os processadores acessam a memória comum. No modelo $B S P$, o número de processadores é um dado do modelo e os processadores se comunicam através da troca de mensagens.

O modelo para a computação paralela deve atender alguns objetivos. Por um lado, tem que ser bastante detalhado para permitir uma predição exata do tempo de execução dos algoritmos. Por outro lado, tem ser bastante simples para fazer uma análise possível dos algoritmos. Um modelo paralelo deve refletir as restrições das máquinas paralelas atuais (existentes e futuras), mas sem perda de portabilidade dos algoritmos feitos nesse modelo. Outro objetivo que deve ser alcançado é a escalabilidade. Isto é, os algoritmos deverão proporcionar ganhos razoáveis para um grande intervalo de número de processadores.

Muitos modelos de computação paralela foram apresentados nos últimos anos [31]. O modelo PRAM [33] é o modelo mais antigo de computação paralela. Esse modelo não é realístico, pois não considera diversas características de máquinas reais. Mas oferece boas diretrizes em um primeiro aspecto da paralelização de um algoritmo. Ele é conveniente também para a análise de classe de complexidade $N C$ [33, 40]. No uso prático, porém, tem igualmente as suposições fortes, por exemplo, ele recomenda somente uma unidade de tempo para comunicação entre os processadores. Algumas variações do modelo PRAM foram propostas as quais tentam aliviar essas limitações, mas ainda estão longe do funcionamento de máquinas paralelas reais.

Dados $n$ pontos no plano, consideramos o problema da obtenção do fecho convexo.

Muitos algoritmos paralelos para este problema são descritos para diferentes arquiteturas tais como: CREW PRAM [11], CRCW PRAM [3], hipercubo [38] e MESH $[37]$.

Um dos algoritmos paralelos estudados, nessa dissertação, foi projetado no modelo PRAM [33]. A sua complexidade de tempo é $O(\log n)$ usando um total de $O(n \log n)$ 
operações. Esse algoritmo usa a estratégia de divisão-e-conquista. O sucesso deste método depende da execução eficiente da primeira e da última fases. A primeira fase consiste em dividir o problema em vários subproblemas. A segunda fase é de resolver os subproblemas recursivamente. Na última fase são combinadas as soluções dos subproblemas para obter uma solução do problema original. Esta estratégia é muito utilizada no desenvolvimento de algoritmos seqüenciais.

Recentemente, alguns modelos mais realistícos como BSP [47] e CGM (CoarseGrained Multicomputers) [15], que levam em conta a comunicação entre os processadores que podem ser um gargalo, têm sido utilizados no desenvolvimento de algoritmos paralelos. Estes modelos são bastante gerais e não consideram a arquitetura específica de interconexão entre os processadores.

O modelo CGM consiste de um conjunto de $p$ processadores, cada um com memória local de tamanho $O\left(\frac{n}{p}\right)$, interconectados através de uma rede de comunicação arbitrária, onde $n$ é o tamanho de entrada do problema. Temos $p<<n$ em geral. O desempenho dos algoritmos no modelo $C G M$ é medido pelo número de rodadas de comunicação. Os algoritmos nesse modelo consistem da alternância entre uma rodada de computação local e uma rodada de comunicação.

No modelo $C G M$, vários resultados foram propostos para o problema do fecho convexo $[13,14,15,17,18]$. Nesses algoritmos, cada processador obtém na primeira etapa o fecho convexo de $\frac{n}{p}$ pontos inicialmente distribuídos em cada processador usando os algoritmos seqüenciais. As etapas seguintes consistem geralmente em fazer a combinação desses fechos convexos.

O algoritmo de Dehne, Fabri e Rau-Chaplin [15] foi o primeiro algoritmo paralelo $C G M$ proposto para o fecho convexo de um conjunto de $n$ pontos. Esse algoritmo é determinístico, aplicável para $n \geq p^{2}$ e requer $O(\log n)$ rodadas de comunicação. A complexidade de tempo desse algoritmo é $O\left(\frac{T_{\text {sequencial }}}{p}+T_{s}(n, p)\right)$ onde $n$ é o tamanho do problema, $p$ o número de processadores e $T_{s}(n, p)$ refere-se a complexidade de tempo de ordenação de $n$ pontos armazenados em $p$ processadores. O algoritmo é ótimo se $\frac{T_{\text {sequencial }}}{p}$ domina $T_{s}(n, p)$ ou $T_{s}(n, p)$ é ótimo. A vantagem dele é de ser simples, determinístico e escalável sobre um grande intervalo dos valores do fator $\frac{n}{p}$. Mas a desvantagem é de possuir um número não constante de rodadas de comunicação.

No ano seguinte, Dehne, Fabri e Kenyon [14] apresentaram um algoritmo paralelo que requer, com alta probabilidade, um número constante de rodadas de comunicação. Esse algoritmo é ótimo e aplicável para $n \geq p^{3+\epsilon}$ onde $\epsilon$ é uma constante fixa tal que 
$\epsilon>0$. Ele tem complexidade $(k+2)\left(\frac{T_{1}(n)}{p}+O\left(\frac{n}{p}\right)\right)$ para o tempo de computação local e $(k+1)\left(T_{p \text { Sum }}(p)+T_{\text {compr }}(p, n)\right)$ para o tempo de comunicação, onde $k=$ $\left\lceil\frac{1}{2 \epsilon}+\frac{1}{2}\right\rceil$ é uma constante. $T_{1}(n)$ denota a complexidade de tempo seqüencial e $T_{p S u m}(p)$ é a complexidade paralela para calcular a soma parcial de $p$ números, cada um armazenado em um processador. $T_{\text {compr }}(p, n)$ é o tempo para comprimir um subconjunto de dados de tamanho $n^{\prime} \leq n$ em $p^{\prime} \leq p$ processadores. A vantagem é que esse algoritmo resolve o problema do fecho convexo para os pontos em qualquer dimensão maior que dois, supondo a distribuição uniforme de pontos. Este algoritmo será apresentado de modo detalhado nesta dissertação.

No mesmo ano, Deng e Gu [17] publicaram dois algoritmos para fecho convexo bidimensional aplicável para $n \geq p^{3+\epsilon}$. Esse algoritmo determinístico requer $O(\log p)$ rodadas de comunicação, enquanto a versão probabilística requer com alta probabilidade $O(1)$ de rodadas de comunicação. A complexidade de tempo desses algoritmos é $O\left(\frac{n \log n}{p}\right)$. A vantagem é de não ter restrição da distribuição uniforme de conjunto de pontos.

Num outro trabalho recente, Diallo, Ferreira, Rau-Chaplin e Ubéda [18] obtiveram um algoritmo determinístico, que requer somente um número constante de rodadas de comunicação no pior caso. Esse algoritmo, aplicável para $n \geq p^{1+\epsilon}$, é o terceiro estudado neste trabalho. O algoritmo proposto tem complexidade de tempo local $O\left(\frac{n \log n}{p}+T_{s}(n, p)\right)$ onde $n$ é o tamanho do problema, $p$ o número de processadores e $T_{s}(n, p)$ refere a complexidade de tempo de ordenação de $n$ pontos armazenados em $p$ processadores. Este algoritmo é ótimo se $\frac{n \log n}{p}$ domina $T_{s}(n, p)$ [18].

Zhou, Deng e Dymond, em um trabalho ainda não publicado, propõem um algoritmo paralelo para o fecho convexo de um conjunto de $n$ pontos no plano, de complexidade de tempo local $\left(O\left(\frac{n \log n}{p}\right)\right)$ com o número de rodadas de comunicação ótimo.

O algoritmo seqüencial Quickhull foi paralelizado por nós e implementado utilizando a máquina paralela Parsytec PowerXplorer. Essa máquina tem 16 processadores, interligados por uma topologia de grade bidimensional. Cada nó é composto de um processador PowerPC 601 para a computação, um processador Transputer T805 para a comunicação e uma memória local de 32 MBytes. O sistema operacional usado é o PARIX. Sua complexidade de tempo da computação local é $O\left(\frac{n}{p} \log \frac{n}{p}\right)$ com um número constante de rodadas de comunicação.

$\mathrm{Na}$ implementação do algoritmo, utilizamos os conjuntos de $n$ pontos segundo 
uma distribuição normal. Com esses tipos de dados, conseguimos eliminar quase 97 porcento dos pontos na primeira fase do cálculo local em cada processador. Implementamos também o algoritmo probabilístico de Dehne [14]. Os resultados mostram que as comunicações do algoritmo de Dehne são melhores. O código da implementação do algoritmo Quickhull paralelo pode ser encontrado no Apêndice A.

No capítulo 2, enunciaremos o problema do fecho convexo estudado neste trabalho. No mesmo capítulo, descreveremos os algoritmos seqüenciais que resolvem o problema com complexidade $O(n \log n)$. Esses algoritmos podem ser usados no modelo de computação $C G M$ durante a rodada de computação local e são os melhores conhecidos até hoje.

O capítulo 3 apresenta a classificação dos modelos de computação paralela, destacando as características principais.

O capítulo 4 terá a descrição completa do algoritmo paralelo no modelo PRAM. Esse algoritmo é um dos primeiros para resolver o problema do fecho convexo em paralelo.

No capítulo 5, vamos descrever detalhadamente os algoritmos paralelos probabilístico de Dehne [14] e determinístico de [18], repectivamente. Esses algoritmos são escaláveis e facilmente implementáveis em máquinas paralelas existentes.

Nosso capítulo 6 trata da implementação na máquina paralela. Nesse mesmo capítulo apresentamos um algoritmo Quickhull paralelo, as características da máquina e o resultado. Implementamos também o algoritmo probabilístico de Dehne.

Por fim, apresentamos no capítulo 7 as considerações finais de nosso trabalho. 


\section{Algoritmos Seqüenciais}

\subsection{Introdução}

Antes de apresentarmos os algoritmos seqüenciais, vamos definir o problema do fecho convexo.

Definição: Dado um conjunto $S=\left\{p_{1}, p_{2}, \cdots, p_{n}\right\}$ de $n$ pontos no plano ou num espaço de dimensão qualquer maior que dois, o fecho convexo de $S$, denotado $C H(S)$, é o menor polígono convexo que contém todos os pontos de $S$.

Seja $\mathbb{E}^{d}$ um espaço euclidiano $d$-dimensional. Um conjunto $S$ em $\mathbb{E}^{d}$ é convexo se $\forall x, y \in S$, o segmento $x y \subseteq S$.

Problema do fecho convexo [39]: Dado um conjunto $S=\left\{p_{1}, p_{2}, \cdots, p_{n}\right\}$ de pontos no plano, encontrar $C H(S)$, o fecho convexo dos pontos de $S$.

Existem vários algoritmos seqüenciais para encontrar o fecho convexo de um conjunto $S$ de pontos no plano. Vamos examinar alguns deles, especialmente, aqueles de complexidade $O(n \log n)$ que servirão na computação local do modelo de granularidade grossa $C G M$.

Considere um ponto $p$ no plano, de coordenadas $(x, y)$. A abscissa de $p$ será denotada por $x(p)$ e a ordenada denotada por $y(p)$. 


\subsection{Algoritmo Arestas-Extremas}

O algoritmo [39] identifica arestas do fecho convexo ao invés de vértices extremos. Uma aresta $x y$ é uma aresta extrema de um conjunto de pontos $S$ se $x$ e $y$ forem vértices extremos e todos os pontos de $S$ estão sobre ou de um mesmo lado da aresta.

Considere o segmento $(a, b)$ e um ponto $c$ (Figura 2.1). Se a tripla $(a, b, c)$ forma um circuito anti-horário como mostra a figura 2.1, então $c$ é dito à esquerda de $(a, b)$. Analogamente, $c^{\prime}$ é dito à direita de $(a, b)$ se $\left(a, b, c^{\prime}\right)$ forma um circuito horário.

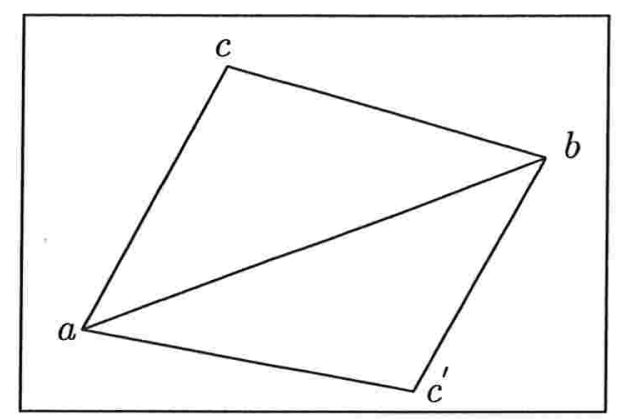

Figura 2.1: O ponto $c$ está à esquerda do segmento $(a, b)$ e o ponto $c$ está à direita do segmento $(a, b)$.

\section{Algoritmo Arestas-Extremas}

Entrada: Um conjunto finito $S=\left\{p_{1}, \ldots, p_{n}\right\}$ de pontos no plano.

Saída: As arestas extremas de $C H(S)$

for cada $i$ do

for cada $j, j \neq i$ do

for cada $k, k \neq i, k \neq j$ do

if $p_{k}$ não está à esquerda ou sobre $\left(p_{i}, p_{j}\right)$

then $p_{i}, p_{j}$ não é aresta de $C H(S)$.

O algoritmo acima tem complexidade de tempo $O\left(n^{3}\right)$, pois existem três laços encaixados e cada um desses laços fará $O(n)$ iterações. 


\subsection{Algoritmo Embrulho-para-Presente}

O algoritmo Embrulho-para-Presente (Gift-Wrapping) também é conhecido como algoritmo de Jarvis $[32,39,43]$ e pode ser visto como uma variação do algoritmo Arestas-Extremas [39]. Ele usa a aresta extrema mais recentemente encontrada para achar a próxima aresta. A idéia funciona, pois sabemos que no fecho convexo, uma aresta está conectada a outra, que por sua vez está ligada a uma outra aresta e assim por diante. Para achar a próxima aresta extrema, testamos $O(n)$ candidatas para cada aresta extrema encontrada. Logo a complexidade do algoritmo é $O\left(n^{2}\right)$, que reduz por um fator de $n$ a complexidade do algoritmo Arestas-Extremas.

\subsubsection{Algoritmo}

Seja $S$ um conjunto de $n$ pontos no plano. Suponhamos que não existem três pontos em $S$ que sejam colineares. Seja a uma aresta de $C H(S)$ ligando o ponto $p$ e o ponto $q$ onde $x(p)<x(q)$. A idéia chave do algoritmo [32] é achar o ponto $r$ tal que o ângulo polar $\theta_{r}$ entre $r q$ e a reta passando pela aresta $a$ seja mínimo. Essa observação é do algoritmo Arestas-Extremas que busca colocar todos pontos de mesmo lado, como mostra Figura 2.2. No início não temos nenhuma aresta de

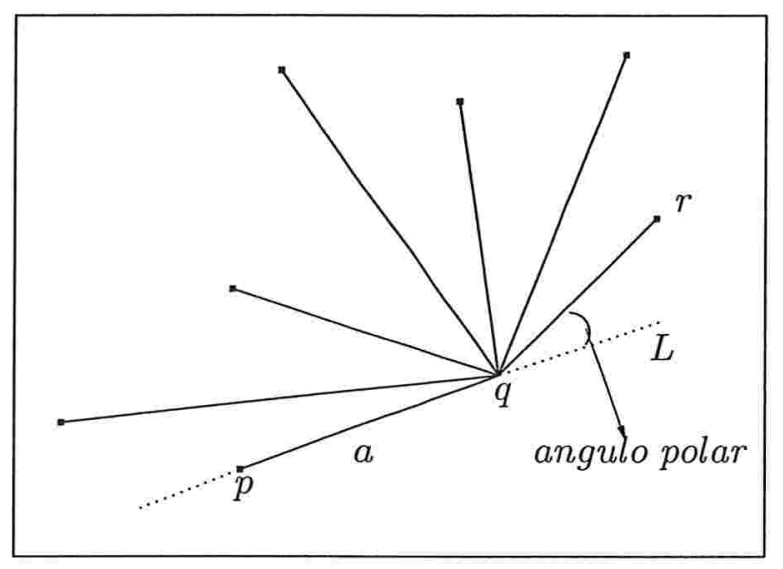

Figura 2.2: A aresta $q r$ e a reta passando pela aresta $a$ tem o menor ângulo polar.

$C H(S)$. Basta escolher o mais baixo ponto $p_{0}$ em $S$ (isto é, com menor $y\left(p_{0}\right)$ ). A Figura 2.3 mostra como encontrar o ponto $p_{1}$ em $S$ de menor ângulo polar (sentido anti-horário) em relação a $p_{0}$ e a reta horizontal. 
Abaixo encontra-se o algoritmo Embrulho-Para-Presente.

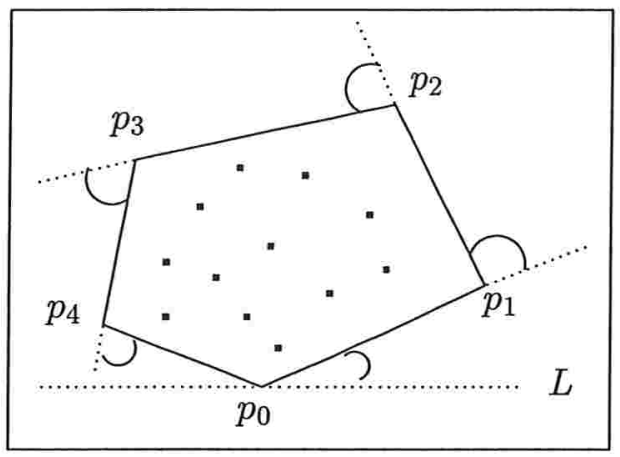

Figura 2.3: As operações feitas pelo algoritmo Embrulho-para-Presente.

\section{Algoritmo Embrulho-Para-Presente}

Entrada: Um conjunto finito $S=\left\{p_{1}, \ldots, p_{n}\right\}$ de pontos no plano.

Saída: As arestas extremas de $C H(S)$ tais que elas aparecem na fronteira de $C H(S)$ no sentido anti-horário.

1. Encontre o ponto em $S$ de menor ordenada.

2. Seja $i_{0}$ o índice desse ponto. $i \leftarrow i_{0}$.

3. Seja $L$ a reta horizontal passando por $p_{i_{0}}$.

4. repeat

a. for cada $j, j \neq i$ do

Calcule o ângulo polar $\theta_{j}$ do ponto $p_{j}$ em relação ao ponto $p_{i}$ e a reta $L$.

b. Seja $k$ o índice do ponto $p_{k}$ tal que $\theta_{k}=\min _{j} \theta_{j}$

c. Output $p_{i} p_{k}$ como uma aresta de $C H(S)$.

d. $L \leftarrow$ reta passando por $p_{i} p_{k}$.

e. $i \leftarrow k$.

until $i=i_{0}$.

\subsubsection{Análise do Algoritmo}

Seja $h$ o número de arestas extremas de $C H(S)$. Então, no pior caso, o algoritmo tem complexidade de tempo $O(h n)=O\left(n^{2}\right)$. Se $h$ é pequeno, por exemplo, $h=O(\log n)$, a complexidade fica $O(n \log n)$. 


\subsection{Algoritmo Quickhull}

O problema de ordenação tem sido uma constante fonte de inspiração para o desenvolvimento de algoritmos do fecho convexo. O algoritmo que vamos ver nesta seção, com algumas variações, foi proposto independentemente por vários autores quase ao mesmo tempo $[10,20,30]$. Devido a semelhança com o algoritmo Quicksort, o algoritmo que vamos descrever foi batizado de Quickhull [24, 39, 43].

\subsubsection{Descrição do Algoritmo}

A idéia básica é tentar descartar uma grande parte dos pontos que estão no interior do fecho convexo. O trabalho então concentra nos pontos que estão próximos à fronteira. No início, o algoritmo busca os pontos extremos que estão na posição mais acima, mais abaixo, mais à esquerda e mais à direita. No caso de empate, devem ser escolhidos os pontos com menor abscissa ou ordenada. Note que os pontos no interior do quadrilátero são dispensáveis para a construção do fecho convexo, como mostra Figura 2.4. Para achar o fecho convexo, devemos concatenar os quatro subproblemas correspondentes às regiões triangulares que resultam após eliminar os pontos interiores ao quadrilátero.

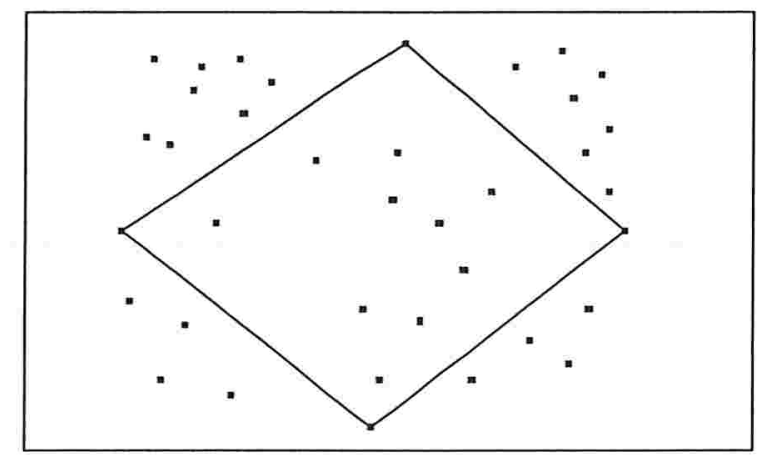

Figura 2.4: $\mathrm{O}$ algoritmo descarta os pontos que se encontram no quadrilátero formado pelos quatro pontos extremos.

Cada um dos quatro triângulos tem dois pontos que certamente estão no fecho convexo. O algoritmo resolve recursivamente cada um dos quatro subproblemas obtidos. Para isso, sejam $a$ e $b$ os pontos extremos do conjunto que formam a base do triângulo. O algoritmo encontra um ponto $c$ mais distante do segmento $\overline{a b}$ (que es- 
tará no fecho convexo), descarta os pontos que estão no interior do triângulo formado pelos pontos $a, b$ e $c$ e particiona o problema em dois subproblemas idênticos menores. Esses dois subproblemas são resolvidos recursivamente. A Figura 2.5 mostra os pontos $a, b$ e $c$.

O algoritmo está descrito abaixo.

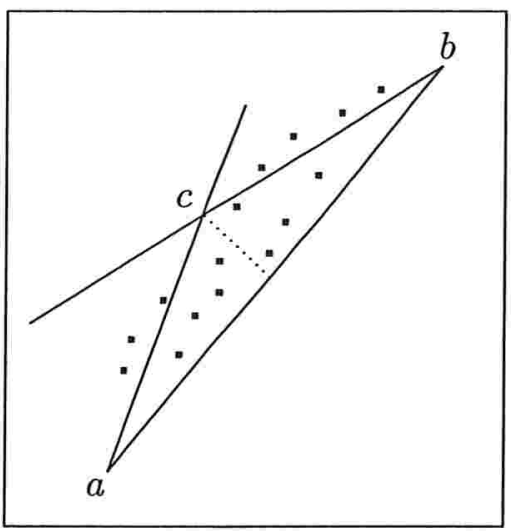

Figura 2.5: O Quichull descarta os pontos que estão no interior do triângulo formado pelos pontos $a, b$ e $c$.

\section{Algoritmo Quickhull}

Entrada: Dois pontos distintos $a$ e $b$ e um conjunto $S$ de pontos no plano tal que todo ponto de $S$ está à esquerda da reta passando por $a$ e $b$.

Saída: Fecho convexo $C H(S)$ de $S$.

1. if $S=\emptyset$ then return $\overline{a b}$.

2. else

a. $c \leftarrow$ ponto com distância máxima ao segmento $\overline{a b}$.

b. $A \leftarrow$ os pontos de $S$ à esquerda do segmento $\overline{a c}$.

c. $B \leftarrow$ os pontos de $S$ à esquerda do segmento $\overline{c b}$.

d. return Quickhull $(a, c, A)$ concatenado com Quickhull $(c, b, B)$.

\subsubsection{Análise de Complexidade.}

Na descrição do algoritmo acima, temos uma fase do pré-processamento que consiste em achar os quatro pontos extremos. Essa fase custa $O(n)$ operações elementa- 
res, onde $n$ é o número de pontos.

A análise de complexidade é semelhante à do Quicksort, depende do número de elementos nos conjuntos $A$ e $B$. Seja $\alpha=|A|$ e $\beta=|B|$. Se $T(n)$ denota o tempo para achar o fecho convexo de $n$ pontos. A complexidade é dada por:

$$
T(n) \leq T(\alpha)+T(\beta)+d n,
$$

onde $d$ é uma constante. O termo $d n$ corresponde ao número de operações gastas pelo algoritmo Quickhull para encontrar o ponto $c$ e construir os conjuntos $A$ e $B$.

Se $\alpha=\lfloor n / 2\rfloor$ e $\beta=\lceil n / 2\rceil$, a metade dos pontos estão em $A$ e outra metade em $B$, teremos que:

$$
T(n) \leq T(\lfloor n / 2\rfloor)+T(\lceil n / 2\rceil)+d n .
$$

Isto é uma relação de recorrência cuja a solução é:

$$
T(n)=O(n \log n) .
$$

No pior caso, a partição deixa $n-1$ pontos de um mesmo lado e $\alpha=1$ e $\beta=n-1$. A equação de recorrência fica:

$$
T(n) \leq T(n-1)+d n .
$$

Ao resolver essa recorrência chegamos a:

$$
T(n) \leq d+d 2+\cdots+d(n-2)+d(n-1)+d n=O\left(n^{2}\right) .
$$

\subsection{Algoritmo Mergehull}

O algoritmo Mergehull é chamado assim por causa da sua similaridade com o algoritmo MergeSort. Ele usa a técnica de divisão-e-conquista [12] para encontrar o fecho convexo de um conjunto de $n$ pontos. A estratégia de divisão-e-conquista é composta de três passos principais:

- Divisão: O problema é dividido em um número de subproblemas de tamanho menor.

- Conquista: Os subprolemas são resolvidos recursivamente. Quando o subproblema tem o tamanho suficientemente pequeno, ele é resolvido de maneira direta.

- Combinação: As soluções dos subproblemas são combinadas para obter uma solução do problema original. 
Em Geometria Computacional, muitos problemas são resolvidos, seqüencialmente, através do paradigma de divisão-e-conquista. Um destes problemas é a determinação do fecho convexo de um conjunto de pontos no plano, que pode ser resolvido através desta estratégia em tempo ótimo $O(n \log n)$. Na resolução seqüencial deste problema, as fases de divisão e conquista são simples de se obter, a fase de combinação é a mais trabalhosa.

\subsubsection{Descrição do Algoritmo}

Antes de aplicarmos o algoritmo a um conjunto $S$ de pontos dados, a primeira fase será de fazer um certo pré-processamento que consiste em ordenar os pontos dados em relação as suas abscissas.

A próxima fase do Mergehull consiste em dividir o conjunto de pontos em dois subconjuntos $A$ e $B$ de tamanho $\lfloor n / 2\rfloor$ e $\lceil n / 2\rceil$, pela abscissa (em caso de empate considera-se a ordenada). Isso significa dividir o problema em dois subproblemas de tamanho menor. Na fase seguinte são resolvidos recursivamente os subproblemas independentemente. A última fase permite combinar as soluções dos subproblemas para obter a solução do problema inicial.

Para que o fecho convexo seja construído em tempo $O(n \log n)$, deve-se ter certeza que a última fase seja executada em tempo $O(n)$. A idéia é escolher o ponto mais à direita de $A$ e mais à esquerda de $B$, chamaremos de pontos $u_{i}$ e $v_{j}$. Para achar a aresta do fecho "de baixo" escorregue o segmento $u_{i} v_{j}$ para baixo, de um lado e depois do outro, até que as extremidades do segmento tangente procurado sejam encontradas, como mostra Figura 2.6. A aresta de cima é encontrada da maneira análoga. Essa idéia foi sugerida por Preparata e Hong [42].

Temos a seguir os algoritmos Acha Tangente-Inferior e Mergehull.

\section{Algoritmo: Acha Tangente-Inferior}

Entrada: Dois fechos convexos $C H(A)$ e $C H(B)$.

Saída: O segmento 'tangente' inferior a $C H(A)$ e $C H(B)$.

1. $v_{i} \leftarrow$ vértice mais à direita de $C H(A)$.

2. $u_{j} \leftarrow$ vértice mais à esquerda de $C H(B)$.

3. while $T=u_{i} v_{j}$ não é tangente inferior de $C H(A)$ e $C H(B)$ do

a. while $T$ não é tangente inferior de $C H(B)$ do $j \leftarrow j+1$. 


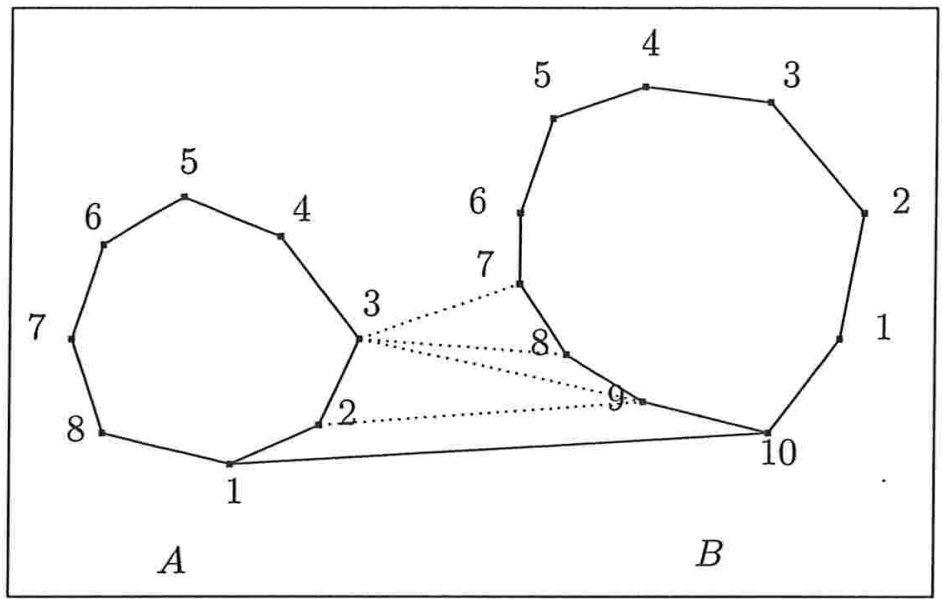

Figura 2.6: O algoritmo Acha Tangente-Inferior começa com $\left(u_{i}, v_{j}\right)=(3,7)$ e termina com $\left(u_{i}, v_{j}\right)=(1,10)$.

b. while $T$ não é tangente inferior de $C H(A)$ do $i \leftarrow i-1$.

4. return $T$.

O algoritmo supõe que os pontos $v_{i}$ de $C H(A)$ e os pontos $u_{j}$ de $C H(B)$ estão em sentido anti-horário. A aritmética envolvendo os índices é módulo o tamanho do respectivo conjunto $A$ ou $B$.

No algoritmo acima, dizer que " $T=u_{i} v_{j}$ " não é tangente inferior de $C H(A)$ é equivalente a $u_{i-1}$ está à direita do segmento $u_{i} v_{j}$. Da maneira análoga, " $T=u_{i} v_{j}$ " não é tangente inferior de $C H(B)$ é equivalente a $v_{j+1}$ está à direita do segmento $u_{i} v_{j}$.

\section{Algoritmo: Mergehull}

Entrada: Um conjunto finito $S=\left\{p_{1}, \ldots, p_{n}\right\}$ de pontos no plano.

(Suponha que estão ordenados pela abscissa.)

Saída: O fecho convexo de $S$.

1. if $|S| \leq k_{0}$, onde $k_{0}$ é uma constante pequena, construa o fecho convexo diretamente por algum método e return.

2. Particione o conjunto $S$ em conjuntos $A$ com $\lfloor n / 2\rfloor$ pontos e $B$ com $\lceil n / 2\rceil$.

3. Recursivamente construa o fecho convexo de $A$ e $B$.

4. Construa o fecho convexo de $A \cup B$. 


\subsubsection{Análise do Algoritmo}

O pré-processamento do algoritmo Mergehull consiste em ordenar os pontos do conjunto $S$. Se usarmos o algoritmo Heapsort ou Mergesort [12], a complexidade de tempo dessa fase é $O(n \log n)$. Na fase de combinação, os laços são executados $O(n)$ vezes. Isto significa que as tangentes inferior e superior podem ser construídas em tempo $O(n)$. Então, a complexidade de tempo da fase de combinação é $O(n)$.

Se $T(n)$ é a complexidade de tempo do algoritmo Mergehull, ao resolver uma instância de tamanho $n$, teremos:

$$
T(n) \leq T(\lfloor n / 2\rfloor)+T(\lceil n / 2\rceil)+c n=O(n \log n),
$$

onde $c$ é uma constante.

Portanto, a complexidade de tempo do algoritmo Mergehull é $O(n \log n)$.

\subsection{Algoritmo de Graham}

O construção do fecho convexo de um conjunto $S$ de pontos pelo algoritmo de Graham [29] é feita em duas fases. Primeiramente, um pré-processamento é realizado para selecionar um ponto $p_{0}$ em $S$ de ordenada mínima e ordenar os pontos restantes pelo ângulo ao redor de $p_{0}$. A segunda fase do algoritmo consiste em processar iterativamente os pontos, construido uma seqüência de fechos convexos que converge para $C H(S)$.

\subsubsection{Pré-processamento}

A fase de pré-processamento consiste em achar um ponto $p_{0}$ de $S$. O ponto $p_{0}$ vai ser o ponto em $S$ com a menor ordenada. Em caso de empate, escolheremos entre os pontos com a menor ordenada, o ponto com a maior abscissa.

O passo seguinte de pré-processamento consiste em ordenar os pontos de $S \backslash\left\{p_{0}\right\}$ em relação ao ângulo polar que estes pontos formam ao redor do ponto $p_{0}$. Se dois pontos têm o mesmo ângulo polar (colineares), descarta o ponto mais próximo de $p_{0}$. Veja a figura 2.7. 


\subsubsection{Construção do Fecho Convexo}

A segunda fase constrói o fecho convexo. Nesta fase, os pontos são examinados na ordem que estes foram colocados pelo pré-processamento. Em cada iteração, os pontos de fecho convexo já encontrados estão em uma pilha identificada pela variável topo. Para cada ponto $p_{i}$, se o ângulo entre $T_{\text {topo-1 }} T_{\text {topo }}$ e $T_{\text {topo }} p_{i}$ for menor que $180^{\circ}$, empilha $p_{i}$ senão desempilha. Note que alguns pontos que eram pontos do fecho convexo anterior, podem não ser pontos do fecho convexo corrente. No final da última iteração do algoritmo, a pilha contém os pontos do fecho convexo.

A seguir o algoritmo de Graham.

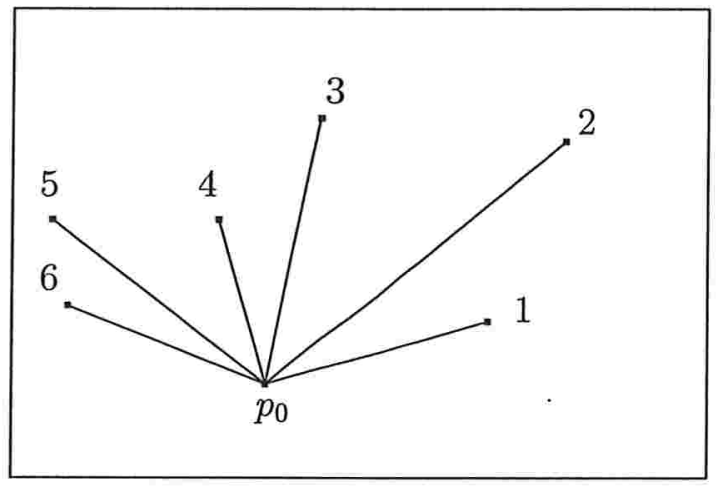

Figura 2.7: Os pontos ordenados conforme o ângulo polar que estes formam ao redor do ponto $p_{0}$.

Algoritmo: Graham

Entrada: Um conjunto finito $S$ de pontos no plano $(n>3)$.

Saída: O fecho convexo de $S$.

1. Encontre $p_{0}$ o ponto em $S$ com ordenada mínima, em caso de empate tome o ponto mais à direita.

2. Ordene pontos pelo ângulo (elimine os empates escolhendo o ponto mais distante). Sejam $p_{1}, \cdots, p_{n-1}$ os pontos de $S$ ordenados.

3. $T \leftarrow \emptyset$

4. Empilhe $p_{0}, p_{1}, p_{2}$ na pilha $T$.

5. $i \leftarrow 3$.

6. while $i<n$ do

a. if $p_{i}$ está à esquerda de $\left(p_{\text {topo-1 }}, p_{\text {topo }}\right)$ then 
Empilhe $p_{i}$ e $i \leftarrow i+1$

b. else Desempilhe $p_{\text {topo }}$.

7. return $T$.

\subsubsection{Análise do Algoritmo}

A análise de complexidade de tempo depende das fases do algoritmo. O primeiro passo do algoritmo, na fase de pré-processamento, pode ser feito em tempo $O(n)$. O custo total da fase de pré-processamento é dominado pelo custo da ordenação dos pontos que é $O(n \log n)$ no segundo passo.

A segunda fase do algoritmo vai da linha 3 até 7 . As linhas 3, 4 e 5 são executadas em tempo constante $(O(1))$. O número total de execuções do comando while da linha 6 será $O(n)$. Portanto, o número de operações Empilha e Desempilha na execução do algoritmo é $O(n)$.

Assim, a complexidade de tempo total do algoritmo é $O(n \log n)$. 


\section{Modelos de Computação Paralela}

Neste capítulo apresentamos uma visão geral sobre alguns modelos de computação paralela. Os modelos $P R A M$ e $C G M$ vão ser usados no nosso trabalho para o desenvolvimento dos algoritmos paralelos que resolvem o problema do fecho convexo. Esse capítulo é baseado no capítulo 20 do livro de Capa Rumeur [1].

\subsection{Introdução}

Um dos principais objetivos deste capítulo é expor os diferentes modelos de computação paralela, do PRAM ao modelo CGM. A diversidade dos modelos de computação paralela apresentados na literatura é tal que uma apresentação exaustiva é hoje quase impossível. Vamos apresentar as grandes classes de modelos e focar nossa apresentação ao redor de uma classificação. A classificação que apresentaremos será eficaz pois continua compatível com os outros modelos da literatura.

O segundo objetivo desse capítulo é mostrar a influência do modelo de computação paralela no desenvolvimento dos algoritmos paralelos. Por exemplo, um algoritmo de ordenação ou de inversão de matrizes não é tratado da mesma maneira sobre o modelo $P R A M$ e sobre o modelo $B S P$. No primeiro caso, o número de processadores é ligado ao tamanho do problema e os processadores acessam uma memória comum. No modelo $B S P$, o número de processadores é um dado do modelo e os processadores se comunicam por troca de mensagens.

O destaque vai também na adequação do modelo com a realidade das máquinas parạlelas atuais. É conveniente, entretanto, de não se focalizar sobre esse parâmetro. Por um lado a tecnologia evolui tão rapidamente, que não se pode afirmar que as 
máquinas atuais são representativas das máquinas da próxima geração. A definição de novos modelos pode ser vista de fato como uma maneira de determinar os funcionamentos dos algoritmos paralelos no futuro. Como no caso de modelo de von Neumann para a computação seqüencial, o modelo de computação paralela deve estabelecer uma ponte entre o software e o hardware [31, 34]. Por outro lado, existem outros parâmetros que vão determinar a importância de um modelo tais como:

- a portabilidade;

- a escalabilidade;

- a capacidade de desenvolver uma teoria da complexidade;

- a facilidade de utilização;

- a ampla aplicabilidade com respeito às máquinas existentes e futuras.

Cada um desses critérios tem importância variada conforme a utilização feita do modelo. A teoria de complexidade prefere certamente o modelo PRAM ao modelo mais próximo das máquinas, porém mais dificilmente tratável. Contrariamente, um programador de uma aplicação específica sobre uma categoria de máquinas específica usaria um modelo correspondente a todas as características da máquina tais como entrada/saída, cache, etc.

O custo de tempo é um outro fator que pode influenciar uma possível classificação linear de modelos. Por exemplo, para resolver os problemas como a predição meteorológica ou o cálculo de trajetória de uma sonda sobre Marte, é importante se aproximar da máquina. Assim, adaptar-se-ia um produto de matrizes à estrutura da máquina para executá-lo o mais rapidamente possível. Entretanto, se a pergunta sobre a complexidade do produto de matrizes for levada em conta, uma tal aproximação não permite resposta satisfatória, pois uma máquina é muito pouco estável no tempo para que possa desenvolver uma teoria da complexidade sobre essas características. Esta é uma das razões pelas quais em teoria da complexidade o modelo PRAM é o melhor adaptado.

Muitos modelos de computação paralela foram apresentados nos últimos anos. A seção 3.2 descreve e classifica os modelos de computação paralela. Nessa seção, vamos falar do modelo PRAM [33] que vai ser usado para desenvolver um algoritmo paralelo para o problema do fecho convexo. Nessa mesma seção veremos um outro 
modelo mais recente e realístico, o $\operatorname{CGM}[13,14,15,16]$. Esse modelo servirá para o desenvolvimento de outros algoritmos paralelos de nosso trabalho. A seção 3.3 conclui o capítulo com as perspectivas dos modelos de paralelismo.

\subsection{Classificação dos Modelos de Computação Pa- ralela}

O objetivo dessa seção não é listar o conjunto de modelos de computação paralela apresentado na literatura nesses últimos anos. Procura-se concentrar sobre alguns principais modelos para compreender as suas características mais importantes.

\subsubsection{Apresentação dos Principais Modelos}

Por principais modelos, entendemos os modelos cujo impacto sobre a análise dos algoritmos é considerável em termos de número de publicações usando esses modelos como base da descrição e do estudo das suas complexidades. Todos esses modelos têm vantagens e desvantagens, as quais discutiremos. Muitos modelos são, aliás, as variações ao redor de modelos descritos abaixo. Na subseção 3.2.3, classificaremos os modelos apresentando suas principais propriedades.

\section{Modelo PRAM}

O modelo PRAM é historicamente o primeiro a aparecer. Ele corresponde a visão de uma máquina paralela como um conjunto de máquinas seqüenciais acessando a uma memória comum.

Da maneira formal, no modelo $P R A M$ estão disponíveis um conjunto arbitrariamente grande de processadores, cada um possuindo um conjunto finito de registradores e tendo acesso a memória comum, de tamanho também arbitrário. O número de processadores e o tamanho da memória são os parâmetros do modelo e a complexidade dos problemas será expressa em função desses parâmetros. Em geral o número de processadores é considerado da mesma grandeza que o tamanho da memória. Uma máquina PRAM de $n$ processadores pode potencialmente executar $n$ instruções simultanemente. Essas instruções podem ser idênticas ou não em cada processador. 
Todos os processadores acessam a memória comum em tempo constante, pois não há o custo de comunicação.

O modelo PRAM foi usado para o estudo da complexidade paralela dos problemas fundamentais. Esse modelo permite a definição formal de classes de complexidade como a classe $N C$, correspondendo ao conjunto de problemas do tamanho $n$ solucionáveis em tempo polilogarítmico sobre um número polinomial de processadores. Uma das conjecturas mais famosas de algoritmos paralelos é de saber se $P=N C$, o que significa, se o conjunto dos problemas solucionáveis seqüenciamente em tempo polinomial podem ser resolvidos em tempo polilogarítmico sobre uma máquina PRAM com um número polinomial de processadores. Note que o contrário é trivial pela simples simulação de $n$ processadores em um único processador: cada etapa paralela necessitando $O(n)$ etapas seqüenciais.

\section{Modelo de topologias explícitas}

O modelo PRAM deveria ser um padrão para a computação paralela, mas apesar da sua importância no desenvolvimento de algoritmos, ele não consegue atingir a exata noção do paralelismo. A principal desvantagem desse modelo é de não considerar a estrutura das máquinas disponíveis. Hoje, a maioria das máquinas tem memória distribuída, uma estrutura bem diferente do PRAM. Um outro problema sério do modelo $P R A M$ é ligado à memória global e à hipótese de leitura/escrita em tempo constante, que não correspondem às máquinas existentes. O acesso à memória local é mais rápido que o acesso à memória do processador vizinho, que por sua vez é menos caro que o acesso à memória de um processador distante (não conectado diretamente).

Foram introduzidos novos modelos, com topologias explícitas tais como grade, hipercubo, etc. As arquiteturas MIMD (Multiple Instructions Multiple Data) e SIMD (Single Instruction Multiple Data) levaram a dois tipos de modelos: os modelos de granularidade fina modelando as máquinas SIMD, em particular os Connection $M a-$ chines CM1 e CM2 [23], e os modelos de granularidade grossa modelando as máquinas tais como iPC'S de Intel, ou as máquinas a base de Transputers [4] na Europa.

Esses modelos permitiram o desenvolvimento de um número grande de algoritmos. Emergiram os paradigmas de programação paralela tais como pipeline, partição de dados, balanceamento de carga e agrupamento de mensagens. Também foram colocadas em evidência técnicas de programação complexas e problemas fundamentais 
ainda não resolvidos.

\section{Modelo sem topologias}

Dois fatores influenciaram o comportamento dos algoritmos em relação aos modelos de topologia explícita. Por um lado, as comunicações das máquinas paralelas modernas tendem dissimular a distância entre os processadores que se comunicam. Isto é, dois processadores vizinhos ou distantes não modificam, na teoria, o custo da comunicação. Por outro lado, o paradigma de troca de mensagem compete com outros paradigmas, como a memória virtualmente compartilhada; na qual a topologia não é mais um critério a considerar na concepção de um algoritmo. Nenhuma topologia emergiu como candidata universal de rede de interconexão de processadores de uma máquina paralela.

As observações acima fazem aparecer os modelos que não consideram a topologia, ou seja, a topologia se dá de maneira implícita através de outros parâmetros. Um dos modelos mais conhecidos é o modelo $B S P$ [47]. Nesse modelo, a máquina paralela é considerada como um conjunto de $p$ processadores que se comunicam, dispondo de um processo de sincronização. Os algoritmos no modelo $B S P$ consistem de uma seqüência de superpassos. Em cada superpasso temos duas fases: uma fase de computação local e uma fase de comunicação. A cada final de computação local, cada processador efetua as trocas de mensagens com os demais processadores. Recebendo informações necessárias para a computação no próximo superpasso. Esse modelo não considera a topologia de rede, só nos custos de comunicação e sincronização que a topologia pode ficar aparente.

Os modelos sem topologias tais como $B S P$ e $C G M$ (uma variante do $B S P$, a ser visto em seguinte) fizeram um grande sucesso na área de computação paralela. $O$ fato de não considerar a topologia faz com que a análise dos algoritmos tenha um resultado considerável. A portabilidade dos algoritmos é um outro fator positivo. A riqueza desses modelos se dá também através das simulações formais de outros modelos, como o PRAM.

\subsubsection{Modelos}

Agora vamos focalizar nossa atenção sobre os modelos seguintes: PRAM, BSP, $C G M$ e $G-R A M$ de granularidade fina ou de granularidade grossa. Esses modelos 
fixam as principais características dos modelos do paralelismo.

\section{Modelo PRAM}

No modelo de memória compartilhada existem dois modos básicos de operação. De um lado, o modo chamado síncrono, onde todos processadores processam sincronamente sob o controle de um mesmo relógio. O nome padrão para o modelo de memória compartilhada síncrono é modelo de máquina paralela de acesso aleátório ou PRAM. Por outro lado, há o modelo chamado assíncrono, onde cada processador opera sob relógios separados. Nesse modo de operação, os pontos de sincronização apropriados são de responsabilidade do programador, sempre que necessários. A figura 3.1 mostra uma visão geral do modelo de memória compartilhada.

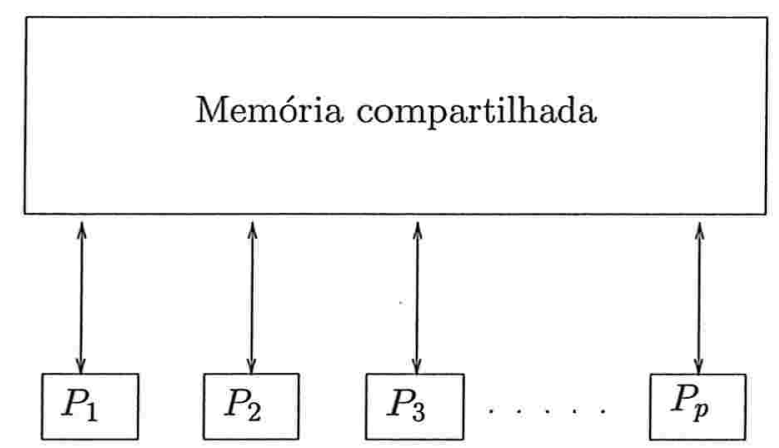

Figura 3.1: O modelo de memória compartilhada.

O modelo PRAM é o mais usado para computação paralela. Apesar de ser um modelo muito importante e usado para o desenvolvimento de algoritmos, não é um modelo realístico e não é adequado na prática. Esse modelo oferece uma excelente plataforma para estudar o paralelismo, uma vez que se abstrai de detalhes de implementação como acesso a dados. Ele usa o modo de comunicação síncrono, ou seja os processadores executam as instruções com um mesmo relógio. Cada processador é uma $R A M$ seqüencial. Os processadores podem executar diferentes instruções em conjuntos de dados diferentes.

Como a memória é compartilhada, os processadores trabalham concorrentemente. Pode ocorrer de dois ou mais processadores tentarem acessar (para leitura ou escrita) simultaneamente uma mesma posição de memória. O acesso é feito das seguintes formas: 
- EREW (Exclusive Read, Exclusive Write). Não é permitido o acesso concorrente para leitura ou para escrita em uma mesma posição de memória.

- CREW (Concurrent Read, Exclusive Write). O acesso é permitido para leitura simultânea de uma mesma posição de memória por vários processadores.

- CRCW (Concurrent Read, Concurrent Write). A leitura e a escrita concorrente são permitidas na mesma posição de memória. Para administrar os possíveis conflitos temos os critérios seguintes:

- modelo CRCW com escrita arbitrária: um dos processadores deve ter sucesso na escrita, não importando qual deles.

- modelo CRCW com escrita comum: é necessário que todos os processadores em conflito escrevam o mesmo valor.

- modelo CRCW com escrita prioritária: o processador com índice menor tem prioridade para escrever.

\section{Modelo G-RAM}

O modelo G-RAM é um modelo para as máquinas paralelas à memória distribuída. A rede de interconexão da máquina paralela é representada por um grafo $G$, onde os vértices são os processadores e as arestas representam os canais de comunicação. Nesse modelo existem duas categorias principais. Por um lado, há o modelo de granularidade grossa, que tem dois parâmetros distintos: o número de processadores $p$ e o tamanho do problema $n$. Por outro lado, o modelo $G-R A M$ de granularidade fina supõe-se que a identidade desses dois parâmetros, pelo menos uma relação espécifica em termo de ordem de grandeza. Geralmente, supõe-se que a máquina tem $\theta(n)$ processadores. Como no modelo $P R A M$, o número de processadores é arbitrariamente grande no modelo $G$-RAM de granularidade fina.

Nos dois casos, o modelo é síncrono. No modelo de granularidade fina, cada etapa consiste de uma computação local e de trocas de dados com outros processadores. Como para o PRAM, este modelo pode distinguir diferentes hipóteses conforme a capacidade dos processadores de se comunicar, simultaneamente ou não, com vários vizinhos. No modelo $G$-RAM de granularidade grossa, cada processador efetua um grande número de cálculos locais antes de agrupar os dados a enviar durante a fase de comunicação. 
Não há possibilidade de comunicações distantes e/ou globais nos dois tipos de granularidade. Assim, se um dado deve ir para um processador não vizinho, esse dado deve passar pelos processadores ou caminhos intermediários. Do mesmo modo, se um processador deve mandar uma mensagem a um conjunto de outros processadores, todos os processadores deverão participar. As comunicações necessitarão de várias etapas $^{1}$. O número de etapas depende fortemente da topologia de rede e do grafo $G$.

\section{Modelo BSP}

O modelo $B S P$, proposto por L. G. Valiant [47], é um dos principais modelos realísticos, que busca abstrair a topologia de rede e apresentar uma descrição através de parâmetros numéricos. Ele é um modelo de propósito geral e um candidato a se tornar o padrão para a computação paralela, com resultados eficientes tanto para o projeto quanto para execução prática de algoritmos.

A máquina $B S P$ consiste de um conjunto de $p$ processadores com memória local. Os processadores se comunicam através de algum meio de interconexão, controlados por um roteador com facilidade de sincronização periódica global.

Um algoritmo no modelo $B S P$ consiste de uma seqüência de superpassos (supersteps). Nestes, os processadores operam independentemente realizando cálculos locais e trocas de mensagens através de operações de envio e recebimento. Uma mensagem enviada é recebida no próximo superpasso. No final de um superpasso, uma barreira de sincronização é realizada. Os custos de comunicação dependem de dois parâmetros, a saber:

- $L$ : a latência, que é o tempo máximo de um superpasso;

- g: que descreve a vazão (throughput) do roteador, medida como a razão entre o número de operações de computação local por segundo pelo número de palavras transmitidas pelo roteador por segundo (computação / comunicação).

Se um processador envia $h$ dados e recebe $h^{\prime}$ durante a fase de comunicação, o custo dessa comunicação será de $L+\max \left(h, h^{\prime}\right) g$. Então, o custo total da fase de comunicação é $\max _{i=1, \cdots, p}\left\{L+\max \left(h_{i}, h_{i}^{\prime}\right) g\right\}$, onde $h_{i}$ e $h_{i}^{\prime}$ representam os números de dados enviados e recebidos, respectivamente. O modelo $B S P$ permite que o valor de $L$ seja

\footnotetext{
${ }^{1}$ Falaremos sobre isso na seção 3.2 .3 .
} 
controlado pelo programa, mesmo em tempo de execução. As restrições de software e de hardware devem ser consideradas na escolha de $L$.

A simulação de algoritmos $P R A M$ no modelo $B S P$ foi também discutida por L. G. Valiant [47].

\section{Modelo CGM}

O modelo $C G M$ para computadores paralelos com memória distribuída foi proposto por F. Dehne $[13,14,15]$ com a inspiração no modelo $B S P$ [47]. Ele privilegia a computação local, minimizando as operações globais. Nesse modelo, os processadores possuem uma memória local de tamanho $O(n / p)$, onde $n$ é o tamanho da entrada e $p$ é o número de processadores. Em geral, $p<<n$. Veja a figura 3.2. A preocupação é aumentar a granularidade das máquinas paralelas. Isto significa aumentar a quan-

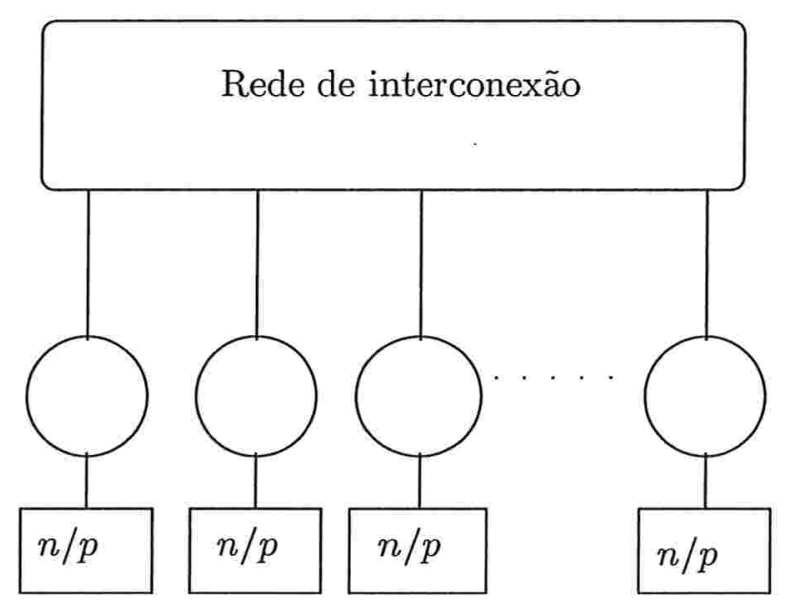

Figura 3.2: O modelo $C G M$ de memória distribuída.

tidade de operações locais executadas por um processador sem se comunicar com outros. Cada processador é conectado por um roteador que pode trocar mensagens ponto a ponto.

Um algoritmo em $C G M$ consiste da alternância entre fases de computação local e rodadas de comunicação separadas por uma barreira de sincronização. Seja $R$ o número de rodadas, o esquema genérico é:

For $i=1$ to $R$ do

\{ 


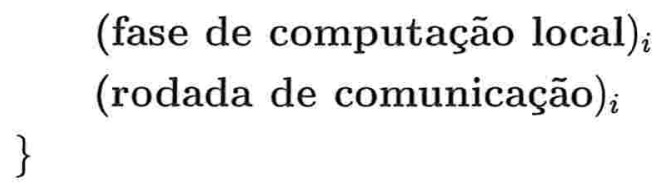

Uma fase de computação local mais uma rodada de comunicação é equivalente a um superpasso no modelo $B S P$. Nessa rodada, usualmente devemos utilizar o melhor algoritmo seqüencial em cada processador e processar os seus dados localmente.

Em uma rodada de comunicação, cada processador pode enviar e receber no máximo um total de $O(n / p)$ dados de outros processadores. Além disso, o modelo $C G M$ exige que todos os dados enviados de um processador para outro em uma fase de comunicação sejam empacotados em uma mensagem.

O custo de comunicação no modelo $C G M$ é medido pelo número de rodadas de comunicação. Vários algoritmos $C G M$ conhecidos para problemas geométricos necessitam de um número de rodadas de comunicação constante ou $O(\log p)$ [18]. O modelo $C G M$ é particularmente adequado para máquinas paralelas atuais, onde a velocidade da computação local é consideravelmente maior que a velocidade de comunicação entre processadores.

As implementações dos algoritmos neste modelo, nas máquinas atualmente disponíveis, se comportam bem e os speedups exibidos são similares àqueles previstos em suas análises. Assim, o objetivo do modelo $C G M$ é construir algoritmos que minimizam o número de rodadas de computação local e de comunicação.

\subsubsection{Classificação}

A classificação dos modelos foi baseada em função de três critérios: a granularidade, a topologia e a maneira como o custo de comunicação é avaliado.

A granularidade é o primeiro fator de aproximação dos modelos. Ela pode ser fina ou grossa. No primeiro caso, o número de processadores é arbitrário e geralmente ligado ao tamanho do problema. No segundo caso, o tamanho do problema $n$ e o número de processadores $p$ são dois parâmetros distintos. Em geral, os algoritmos funcionam então em relação entre essas duas quantidades: $n \simeq p$ permite o acesso rápido na memória local mas multiplica as comunicações, ao contrário, $n>>p$ limita o número de comunicação, mas pode sobrecarregar a memória local de processador. A granularidade é uma medida do paralelismo disponível e possível de ser extraída 
de um problema.

A topologia da máquina parece ser um parâmetro essencial na computação paralela. Como sugere o modelo $B S P$, a topologia pode não estar explicitamente representada, mas pode aparecer de maneira implícita através de outros parâmetros. $O$ modelo da topologia explícita permite refinar o algoritmo mas pode se tornar muito dependente da arquitetura. Contrariamente, o modelo da topologia implícita é portável, mas pode talvez se revelar pouco confiável com os resultados experimentais sobre a máquina.

O custo de comunicação pode ser avaliado de diferentes formas. Vamos considerar as comunicações fixas e as comunicações paramétricas. No modelo das comunicações fixas, uma comunicação é uma operação atômica de custo unitário. No modelo da granularidade fina, por exemplo, poderia ser uma troca de um dado entre dois processadores vizinhos; ao contrário, na granularidade grossa, a noção de custos fixos é delicada. O modelo das comunicações paramétricas é um modelo no qual todas comunicações não são contabilizadas de maneira idêntica. Uma das medidas mais usadas é a quantidade de dados enviadas. Mas outras medidas podem ser consideradas tais como: o tempo de inicialização e a distância entre processadores.

Antes de classificar os diferentes modelos descritos acima, conforme os três critérios, lembramos que o objetivo não é de julgar. Não se tem, por enquanto, um modelo universal satisfazendo todos os critérios de um bom modelo. Do ponto de vista fundamental, um bom modelo é aquele em que podemos construir uma teoria rica, permitindo exprimir formalmente um grande número de resultados considerados naturalmente como de primeira importância. Como exemplo, a questão de $P=N C$ do modelo $P R A M$ é crucial e natural, pois é legítimo perguntar até quando um problema solúvel seqüencialmente em tempo polinomial pode ser paralelizado. Na prática, um bom modelo poderia ser um modelo em que o comportamento de muitas máquinas reais poderia ser expresso. É conveniente buscar a qualificação dos modelos em função de sua utilidade, visto que é ilusório quantificar seu valor intrínseco sobre uma escala linear forçosamente arbitrária.

A figura 3.3 apresenta a classificação dos modelos em função dos critérios acima. No modelo $P R A M$ a granularidade é fina. A topologia é implícita no sentido que ela não é considerada. Poderia ser estimado, ao contrário, que o PRAM tem intrinsecamente uma topologia de grafo completo, ou ainda que a memória compartilhada é uma forma de topologia explícita. Consideramos o modelo PRAM com a topologia 
implícita, pois do ponto de vista da análise de algoritmos, a topologia não interfere.

\begin{tabular}{|c|c|c|c|c|}
\hline Topologia & \multicolumn{2}{|c|}{ Granularidade grossa } & \multicolumn{2}{|c|}{ Granularidade fina } \\
\hline \multirow{2}{*}{ Explícita } & $\begin{array}{l}\text { Comunicacãa } \\
\text { paramétrica }\end{array}$ & $\begin{array}{c}\text { Comunicação } \\
\text { fixa }\end{array}$ & $\begin{array}{l}\text { Comunicacãão } \\
\text { paramétrica }\end{array}$ & $\begin{array}{l}\text { Comunicação } \\
\text { fixa }\end{array}$ \\
\hline & $\begin{array}{l}\text { G-RAM } \\
\text { "MIMD" }\end{array}$ & $\begin{array}{c}\text { G-RAM } \\
\text { Granularidade } \\
\text { grossa }\end{array}$ & & $\begin{array}{l}\text { G-RAM } \\
\text { "SIMD" }\end{array}$ \\
\hline \multirow[b]{2}{*}{ Implícita } & $\begin{array}{l}\text { Comunicação } \\
\text { paramétrica }\end{array}$ & $\begin{array}{c}\text { Comunicação } \\
\text { fixa }\end{array}$ & $\begin{array}{l}\text { Comunicacãa } \\
\text { parametrica }\end{array}$ & $\begin{array}{c}\text { Comunicação } \\
\text { fixa }\end{array}$ \\
\hline & BSP & CGM & & PRAM \\
\hline
\end{tabular}

Figura 3.3: A classificação dos modelos. As comunicações em relação ao custo são fixas ou paramétricas, as topologias são implícitas ou explícitas e a granularidade grossa ou fina.

O modelo G-RAM SIMD é um modelo de granularidade fina, comunicação fixa e topologia explícita. O termo SIMD faz referência a toda uma gama de máquinas massivamente paralelas, possuindo um único sequenciador distribuindo as instruções ao conjunto de processadores. Nesse modelo, a topologia é explícita, tais como grade e hipercubo. A natureza de granularidade fina implica quase necessariamente em considerar as comunicações atômicas de custo unitário.

Os modelos BSP e CGM são de granularidade grossa e de topologia implícita. Os custos de comunicação fazem a diferença entre eles. O BSP modela seus custos considerando os parâmetros $L$ e $g$. De fato, a topologia da máquina poderia ser ocultada atrás dos parâmetros $L$ e $g$ do modelo $B S P$. O modelo $C G M$ é uma variante de modelo $B S P$. O objetivo dos algoritmos $C G M$ é de minimizar as fases de comunicação.

Os modelos G-RAM MIMD e granularidade grossa são ambos de topologia explícita e de granularidade grossa. A diferença entre eles é como no caso dos modelos $B S P$ e $C G M$, baseada no custo de comunicação. No modelo G-RAM MIMD, as comunicações são modeladas finamente. Por exemplo, no modelo de troca de mensagem, o custo de comunicação de vizinho a vizinho é modelado por uma função linear do tamanho $L$ das mensagens: $\beta+L \tau$, onde $\beta$ representa um tempo de inicialização e $\frac{1}{\tau}$ a largura da banda de comunicação. No modelo por comutação de circuitos, esse 
mesmo tempo é representado por $\beta+d(x, y) \delta+L \tau$, onde $d(x, y)$ denota a distância entre a origem $x$ e o destino $y$, e $\delta$ é função de tempo de comutação dos caminhos intermediários. As comunicações no modelo granularidade fina são atômicas com custo unitário.

Observamos que duas casas são vazias que correspondem aos modelos de granularidade fina, às comunicações paramétricas e à topologia explícita ou implícita. Isso vem simplesmente do fato de que um modelo de granularidade fina supõe que muitas vezes as comunicações são atômicas e de custos unitários. As fases de comunicação são calculadas onde cada fase tem um custo constante. A quantidade de dados transferidos é constante a cada fase.

\subsection{Conclusão}

A definição de um modelo resulta da escolha a priori de aspectos a serem considerados. Assim, a concepção de um modelo com determinadas funcionalidades é sempre feita em detrimento de outras características. O modelo PRAM é simples e permite extrair o paralelismo. O modelo $G-R A M$ de topologia explícita garante a boa previsibilidade de custos medidos. O modelo $B S P$ permite o desenvolvimento dos algoritmos genéricos. É recomendável conhecer todas as grandes classes de modelos e estar apto a analisar e comparar os algoritmos, não somente do ponto de vista intra-modelos, mas também inter-modelos. 


\section{Algoritmo Paralelo PRAM}

Neste capítulo, descrevemos um algoritmo paralelo [33], no modelo $P R A M$, que resolve o problema de fecho convexo. A estratégia, usada geralmente na computação paralela, é de divisão-e-conquista [8, 9, 12, 36]. Essa estratégia nos leva a uma forma natural de explorar o paralelismo: os subproblemas gerados podem ser executados independentemente e, portanto, em paralelo. O algoritmo paralelo usando esta estratégia, a ser apresentado, leva tempo ótimo $O(\log n)$ em uma PRAM CREW. A maior dificuldade em garantir esta complexidade de tempo está na fase em que os resultados dos subproblemas são combinados. O algoritmo paralelo de busca e de ordenação [33] é utilizado no desenvolvimento desse algoritmo.

\subsection{Estratégia de Divisão-e-Conquista}

Considere um conjunto $S=\left\{p_{1}, p_{2}, \cdots, p_{n}\right\}$ de pontos no plano, onde $n$ é uma potência de 2 . O algoritmo começa a ordenar os pontos de $S$ pela sua abscissa, através de um algoritmo paralelo que leva tempo $O(\log n)$ usando $O(n)$ processadores $[33,44]$.

Com isto temos os pontos $p$ e $q$ de menor e maior abscissa respectivamente. Sabemos que esses pontos pertencem ao fecho convexo $C H(S)$. Eles particionam $C H(S)$ nos fechos superior e inferior. O fecho superior, denotado $U H(S)$, consiste dos pontos de $p$ até $q$, no sentido horário. Os pontos do $q$ até $p$ formam o fecho inferior e denotado $L H(S)$. A Figura 4.1 mostra os fechos superior e inferior. A idéia é determinar separadamente o fecho convexo superior $U H(S)$ e inferior $L H(S)$ para então achar o fecho convexo.

Para obter o fecho convexo superior $U H(S)$, precisa-se combinar $U H\left(S_{1}\right)$ e $U H\left(S_{2}\right)$ 


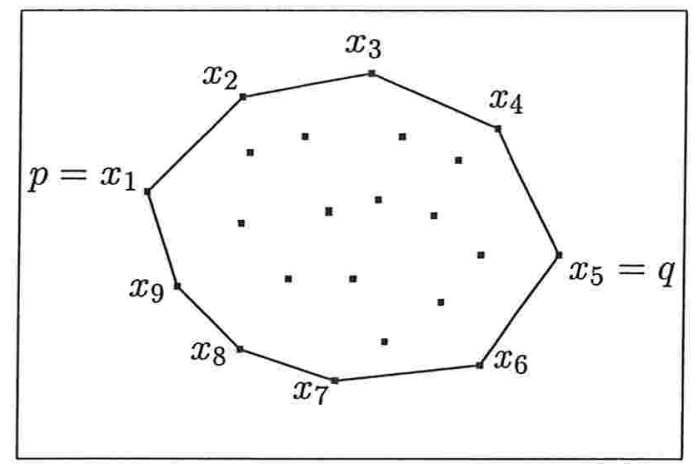

Figura 4.1: Um fecho convexo para um conjunto de pontos. $\mathrm{O}$ fecho superior é $\left(x_{1}, x_{2}, x_{3}, x_{4}, x_{5}\right)$ e o fecho inferior é $\left(x_{5}, x_{6}, x_{7}, x_{8}, x_{9}, x_{1}\right)$.

através de sua tangente comum superior, onde onde $S_{1}=\left\{p_{1}, p_{2}, \cdots, p_{n / 2}\right\}$ e $S_{2}=$ $\left\{p_{(n / 2)+1}, p_{(n / 2)+2}, \cdots, p_{n}\right\}$. O algoritmo paralelo PRAM acha a tangente comum superior dos $U H\left(S_{1}\right)$ e $U H\left(S_{2}\right)$ em tempo constante, usando um número linear de operações. A tangente comum inferior é encontrada de maneira análoga.

A complexidade deste algoritmo é dada por:

$$
T(n) \leq T(n / 2)+c T_{t a n}
$$

onde $T_{\text {tan }}$ é o tempo para determinar em paralelo a tangente comum superior de $U H\left(S_{1}\right)$ e $U H\left(S_{2}\right)$.

\section{Algoritmo: FECHO CONVEXO SUPERIOR}

Entrada: Um conjunto $S=\left\{p_{1}, p_{2}, \cdots, p_{n}\right\}$ de pontos ordenados pela abscissa no plano.

Saída: O fecho convexo superior $U H(S)$.

1. Se $n \leq 4$ então encontra o fecho convexo destes pontos e termine.

2. Sejam $S_{1}=\left\{p_{1}, p_{2}, \cdots, p_{n / 2}\right\}$ e $S_{2}=\left\{p_{(n / 2)+1}, p_{(n / 2)+2}, \cdots, p_{n}\right\}$.

Calcule recursivamente $U H\left(S_{1}\right)$ e $U H\left(S_{2}\right)$.

3. Encontre a tangente superior comum entre $U H\left(S_{1}\right)$ e $U H\left(S_{2}\right)$ e obtenha $U H(S)$. 


\subsection{Um Algoritmo de Tempo Constante para De- terminação da Tangente Comum Superior}

Como queremos um algoritmo de complexidade de tempo $O(\log n)$, a tangente comum superior deve ser determinada em tempo constante. Abaixo descrevemos como obtê-la com este tempo desejado.

Seja $S=\left\{p_{1}, p_{2}, \cdots, p_{n}\right\}$ um conjunto de pontos do plano ordenados pela abscissa e sejam $S_{1}=\left\{p_{1}, p_{2}, \cdots, p_{n / 2}\right\}$ e $S_{2}=\left\{p_{(n / 2)+1}, p_{(n / 2)+2}, \cdots, p_{n}\right\}$. A tangente comum superior entre $C H\left(S_{1}\right)$ e $C H\left(S_{2}\right)$ é a tangente comum tal que $C H\left(S_{1}\right)$ e $C H\left(S_{2}\right)$ estão abaixo dela. A tangente comum inferior é definida de maneira analoga.

Sejam $U H\left(S_{1}\right)=\left(r_{1}, \cdots, r_{s}\right)$ e $U H\left(S_{2}\right)=\left(q_{1}, \cdots, q_{t}\right)$ os fechos superiores do $S_{1}$ e $S_{2}$, respectivamente, dados no sentido horário, onde $r_{i}, q_{j} \in S$ para $1 \leq i \leq s$ e $1 \leq j \leq t$. Nosso problema é determinar os pontos $u=r_{i}$ e $v=q_{j}$ de $U H\left(S_{1}\right)$ e $U H\left(S_{2}\right)$, respectivamente, com $1 \leq i \leq s$ e $1 \leq j \leq t$, tais que $u v$ é a tangente superior comum. O fecho resultante é dado pela seqüencia $\left(r_{1}, \cdots, r_{i}, q_{j}, \cdots, q_{t}\right)$. Assim, se tivermos determinado $u$ e $v$, o fecho pode ser determinado em tempo paralelo $O(1)$ usando $n$ processadores.

Nosso foco agora é justamente determinar estes pontos de tangência. A idéia é muito parecida com aquela do algoritmo seqüencial de divisão e conquista para determinar as tangentes comuns. Antes de apresentarmos o algoritmo, vamos relacionar alguns resultados que motivam e justificam a idéia.

Primeiramente, vamos ver como a tangente entre um ponto $r_{i}$ de $U H\left(S_{1}\right)$ e $U H\left(S_{2}\right)$ pode ser determinada; isto é, queremos determinar um ponto $q_{j(i)}$ de $U H\left(S_{2}\right)$ tal que $U H\left(S_{2}\right)$ está abaixo da linha determinada por $r_{i}$ e $q_{j(i)}$. O lema seguinte mostra como podemos obter esta tangente usando um algoritmo de busca paralela.

Lema 4.2.1 Seja $r_{i}$ um ponto qualquer de $U H\left(S_{1}\right)$. Então, dado um ponto qualquer $q_{l}$ de $U H\left(S_{2}\right)$, pode-se determinar, em tempo seqüencial $O(1)$ se $q_{j(i)}$ está à direita, é igual a, ou está à esquerda de $q_{l}$, onde $q_{j(i)}$ é o ponto de $U H\left(S_{2}\right)$ tal que $r_{i} q_{j(i)}$ é a tangente a $U H\left(S_{2}\right)$.

Prova. Seja $L$ uma reta determinada por $r_{i}$ e $q_{l}$, e $L^{\prime}$ (respectivamente $L^{\prime \prime}$ ) a parte de $L$ estritamente à esquerda (respectivamente à direita) de $q_{l}$, como indicado na figura 4.2. Então, se $L^{\prime}$ está acima do segmento $q_{l-1} q_{l}$ e $L^{\prime \prime}$ está abaixo do segmento 


\subsection{Um Algoritmo de Tempo Constante para Determinação da Tangente Comum Superior34}

$q_{l} q_{l+1}$, então $q_{j(i)}$ está à direita de $q_{l}$. Se $q_{l}=q_{j(i)}$ então $q_{l-1}$ e $q_{l+1}$ estão abaixo de $L$ senão $q_{j(i)}$ está à esquerda de $q_{l}$. Uma vez que $r_{i}$ e $q_{l}$ são dados, podemos determinar cada uma das três condições em tempo seqüencial $O(1)$.

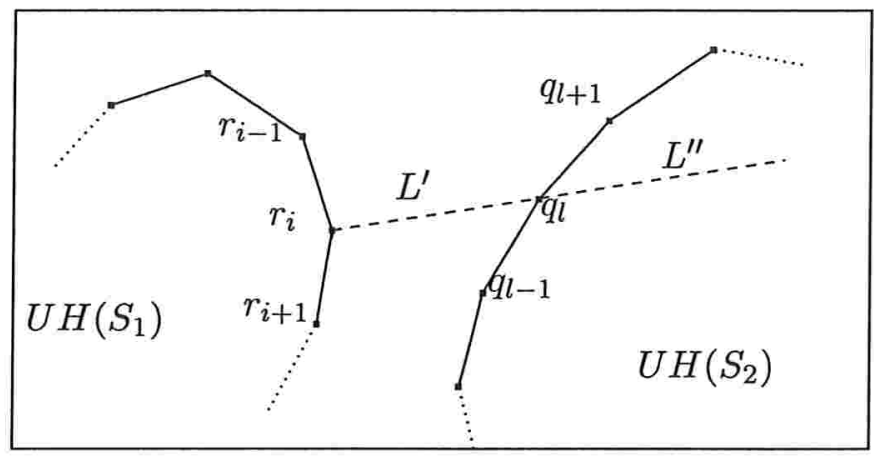

Figura 4.2: Determinação da tangente a $U H\left(S_{2}\right)$ passando por $r_{i}$. Nesse caso, $L^{\prime}$ está acima do segmento $q_{l-1} q_{l}$, e $L^{\prime \prime}$ está abaixo do segmento $q_{l} q_{l+1}$. Assim, a tangente de $r_{i}$ a $U H\left(S_{2}\right)$ cruza o ponto de $U H\left(S_{2}\right)$ que está à direita de $q_{l}$.

Corolário 4.2.2 Dados dois fechos superiores $U H\left(S_{1}\right)$ e $U H\left(S_{2}\right)$, e um ponto $r_{i}$ do $U H\left(S_{1}\right)$, a tangente $r_{i} q_{j(i)}$ a UH( $\left.S_{2}\right)$ pode ser determinada em tempo $O\left(\frac{\log t}{\log k}\right)$ usando $k$ processadores, onde $t$ é o número de pontos de $U H\left(S_{2}\right)$ e $1<k \leq t$.

Prova. Lembrando que os pontos de $U H\left(S_{2}\right)$ são ordenados no sentido horário, podemos usar o algoritmo paralelo de busca [33] para encontrar o ponto $q_{j(i)}$. Escolhemos $k$ pontos de $U H\left(S_{2}\right)$ que o dividem em $k+1$ partes, cada um com aproximadamente o mesmo número de pontos. Para cada um dos $k$ pontos $q_{t_{1}}, \cdots, q_{t_{k}}$, determinamos em paralelo e em tempo $O(1)$, a posição relativa entre o segmento $r_{i} q_{h}$ e o sucessor de $q_{h}$ em $U H\left(S_{2}\right)$, com $t_{1} \leq h \leq t_{k}$. Repetimos o processo até que $q_{j(i)}$ seja encontrado. O tempo é dado por $T(n)=T(n / k)+c$, o que dá $T(n)=O\left(\frac{\log t}{\log k}\right)$.

Lema 4.2.3 Seja $(u, v)$ a tangente comum superior aos fechos convexos superiores $U H\left(S_{1}\right)$ e UH $\left(S_{2}\right)$. Suponhamos que, para qualquer ponto $r_{i}$ de $U H\left(S_{1}\right)$, seja dado $q_{j(i)}$ de $U H\left(S_{2}\right)$ tal que o segmento de reta $r_{i} q_{j(i)}$ seja a tangente a $U H\left(S_{2}\right)$. Então, em tempo seqüencial $O(1)$, podemos determinar se u está à esquerda, é igual a, ou está à direita de $r_{i}$.

Note que, se $r_{i} q_{j(i)}$ é tangente a $U H\left(S_{1}\right)$, então $u$ é igual a $r_{i}$, pois $r_{i} q_{j(i)}$ já é 
tangente a $U H\left(S_{2}\right)$. Senão, $u$ está à esquerda de $r_{i}$ se e somente se $r_{i-1}$ está acima de $r_{i} q_{j(i)}$. Veja Figura 4.3.

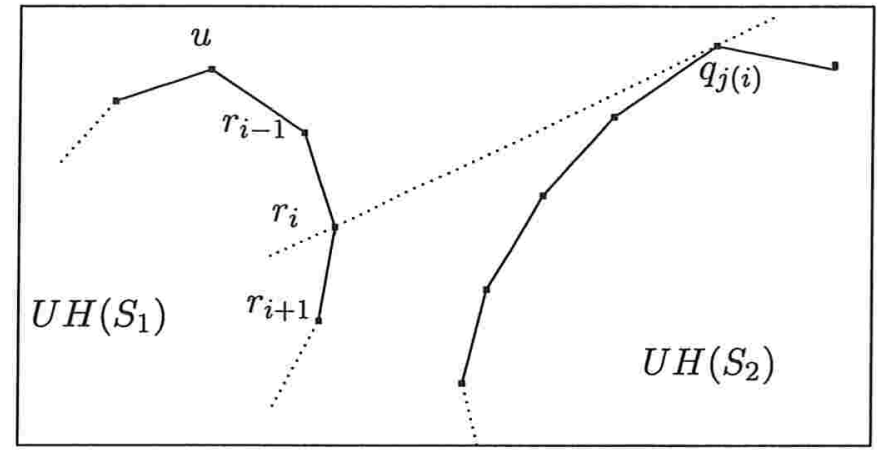

Figura 4.3: Determinação da posição do ponto $u$ onde a tangente comum superior cruza $U H\left(S_{1}\right)$, dada a tangente $r_{i} q_{j(i)}$ a $U H\left(S_{2}\right)$. Na figura, $r_{i-1}$ está acima da tangente, e então $u$ deve estar à esquerda de $r_{i}$.

Com esses dois lemas, podemos determinar, para qualquer ponto $r_{i}$ de $U H\left(S_{1}\right)$, se o ponto $u$ aparece à esquerda de, à direita de, ou é igual a $u_{i}$ em tempo $O\left(\frac{\log t}{\log k}\right)$ usando $k$ processadores. Se escolhemos $k$ aproximadamente igual a $\sqrt{t}$, temos um algoritmo paralelo de tempo $O(1)$ que determina, para qualquer ponto $r_{i}$, sua posição relativa em relação a $u$.

Essas observações nos levam a um algoritmo paralelo de busca para isolar $u$ da seguinte maneira. Escolhemos $\sqrt{s}$ pontos de $U H\left(S_{1}\right)$, que dividem $U H\left(S_{1}\right)$ em partes aproximadamente do mesmo tamanho. Podemos então isolar $u$ em uma destas partes em tempo $O(1)$ usando $\sqrt{s} \sqrt{t}$ processadores. Da maneira análoga podemos isolar $v$ em uma parte de $U H\left(S_{2}\right)$ contendo aproximadamente $\sqrt{t}$ pontos em tempo $O(1)$ usando $\sqrt{s} \sqrt{t}$ processadores. Assim, o tempo desta busca em paralelo é $O(1)$, com um total de $O(\sqrt{s} \sqrt{t})=O(n)$ operações.

Temos agora no máximo $\sqrt{s}$ candidatos para o ponto $u$ e $\sqrt{t}$ candidatos para o ponto $v$. Para cada par de candidatos, podemos verificar em tempo seqüencial $O(1)$, se ele forma uma tangente comum superior entre $U H\left(S_{1}\right)$ e $U H\left(S_{2}\right)$. Portanto, podemos testar todos os pares em paralelo e, então, identificar a única tangente comum superior em tempo $O(1)$ usando $O(n)$ operações. O algoritmo a seguir encontra a tangente comum superior.

Algoritmo: Tangente Comum Superior 
Entrada: Os fechos superiores $U H\left(S_{1}\right)=\left(r_{1}, r_{2}, \cdots, r_{s}\right)$ e $U H\left(S_{2}\right)=\left(q_{1}, q_{2}, \cdots, q_{t}\right)$ ordenados no sentido horário, onde $S_{1}=\left\{p_{1}, p_{2}, \cdots, p_{n / 2}\right\}$ e $S_{2}=\left\{p_{n / 2+1}, p_{n / 2+2}, \cdots, p_{n}\right\}$ são tais que $x\left(p_{1}\right)<x\left(p_{2}\right)<\cdots<x\left(p_{n}\right)$. Suponha que $\sqrt{s}$ e $\sqrt{t}$ são inteiros.

Saída: Os pontos $u$ e $v$ tais que a reta determinada por $u$ e $v$ é a tangente comum superior entre $U H\left(S_{1}\right)$ e $U H\left(S_{2}\right)$.

1. Para cada $i$ tal que $1 \leq i \leq \sqrt{s}$, achar $q_{j(i \sqrt{s})}$ tal que $r_{i \sqrt{s}} q_{j(i \sqrt{s})}$ seja tangente a $U H\left(S_{2}\right)$.

2. Para cada $i$ tal que $1 \leq i \leq \sqrt{s}$, determinar se $u$ está à esquerda, é igual a, ou está à direita de $r_{i \sqrt{s}}$. Se $u=r_{i \sqrt{s}}$, para algum $i$, então fim. Senão, determinar o bloco $A=\left(r_{l \sqrt{s}+1}, \cdots, r_{(l+1) \sqrt{s}-1}\right)$ contendo $u$.

3. Para cada $r_{i}$ no bloco $A$, determinar $q_{j(i)}$ tal que $r_{i} q_{j(i)}$ seja a tangente a $U H\left(S_{2}\right)$, faça $u:=r_{i}$ e $v:=q_{j(i)}$ se $r_{i} q_{j(i)}$ é também tangente a $U H\left(S_{1}\right)$.

Teorema 4.2.4 O algoritmo Tangente Comum Superior calcula corretamente a tangente comum superior entre $U H\left(S_{1}\right)$ e $U H\left(S_{2}\right)$. Ele executa em tempo $O(1)$ utilizando um número linear de operações.

Prova. Suponha que temos $s+t$ processadores disponíveis. O passo 1 pode ser executado em $O(1)$ utilizando $\sqrt{t}$ processadores para cada $i$ (Lema 4.2 .1 e seu Corolário 4.2.2). Como $\sqrt{s t} \leq s+t$, todos pontos $q_{j(i \sqrt{s})}$ podem ser encontrados em tempo $O(1)$ usando $s+t$ processadores. $O$ passo 2 pode ser realizado em tempo $O(1)$ com $O(\sqrt{s})$ processadores. O passo 3 é análogo. Portanto, o algoritmo pode ser executado em tempo $O(1)$ usando $s+t$ processadores. O número total de operações é $O(s+t)=O(n)$.

\subsection{Cálculo do Fecho Convexo}

O fecho convexo é obtido usando a estratégia de divisão-e-conquista com o cálculo das tangentes comum superior e inferior.

Teorema 4.3.1 O fecho convexo de um conjunto de $n$ pontos no plano pode ser calculado em tempo $O(\log n)$, usando $O(n \log n)$ operações. Assim, o algoritmo para encontrar o fecho convexo é ótimo ${ }^{1}$.

\footnotetext{
${ }^{1}$ Um algoritmo paralelo é ótimo se $p T_{p}(n)=O\left(T^{*}(n)\right)$, onde $T^{*}(n)$ é o tempo do melhor algoritmo
} 
Prova. Seja $S=\left\{p_{1}, p_{2}, \cdots, p_{n}\right\}$ um conjunto de $n$ pontos no plano. O algoritmo ordena os pontos de $S$ de acordo com suas abscissas. Esse procedimento pode ser feito em tempo $O(\log n)[33,44]$. Então, para os pontos vale a relação: $x\left(p_{1}\right)<$ $x\left(p_{2}\right)<\cdots<x\left(p_{n}\right)$.

Para determinar o fecho convexo $C H(S)$ usaremos a estratégia da divisão e conquista da seguinte maneira. Se $n \leq 4$, calcula diretamente $C H(S)$. Senão, o algoritmo acha recursivamente $C H\left(S_{1}\right)$ e $C H\left(S_{2}\right)$. A última fase é a combinação de $C H\left(S_{1}\right)$ e $C H\left(S_{2}\right)$ com as tangentes superior e inferior comum e obtenção de $C H(S)$.

O algoritmo executa $O(\log n)$ iterações, cada uma levando tempo $O(1)$, com um número linear de operações. Assim o algoritmo todo leva tempo $O(\log n)$ e $O(n \log n)$ operações.

O modelo PRAM usa o modo de acesso a memória $C R E W$ pois apenas a leitura concorrente é necessária pelos algoritmos de ordenação e pelo algoritmo de busca paralela. A escrita concorrente é não necessária.

seqüencial para o problema, $T_{p}(n)$ o tempo do algoritmo paralelo usando $p$ processadores para resolver o mesmo problema e $n$ o tamanho da entrada do problema. 


\section{Algoritmos Paralelos CGM}

Neste capítulo apresentaremos dois algoritmos, no modelo $C G M$, para resolver o problema do fecho convexo. Um deles é probabilístico e outro é determinístico.

Os algoritmos que veremos nesse capítulo são escaláveis, de complexidade ótima na computação local, portáveis e independentes de arquitetura. Eles são desenvolvidos no modelo de computação paralela $C G M$, com as características seguintes:

- Há $p$ processadores $P_{1}, \cdots, P_{p}$ interligados por alguma rede de interconexão;

- Cada processador $P_{i}$ tem memória local $O(n / p)$;

- Para alguma constante arbitrária pequena e fixa $\alpha>0, n / p \geq p^{\alpha}$. Isso é equivalente a $1 \leq p \leq n^{1-\epsilon}$ onde $\epsilon=\frac{\alpha}{1+\alpha}$;

- O tamanho total de dados $n$ é um número grande mas $p$ não é necessariamente grande.

Como vimos no capítulo 3 , o modelo $C G M$ é realístico em termo de máquinas existentes. Por isso, as características enumeradas acima são em geral verificadas.

Na seção 5.1 descrevemos o algoritmo paralelo probabilístico e na seção 5.2 apresentamos o algoritmo paralelo determinístico.

\subsection{Algoritmo CGM Probabilístico}

O algoritmo probabilístico que vamos ver nessa seção se encontra em [14]. Com o modelo de distribuição de dados uniforme, a complexidade dos algoritmos abaixo 
é, com alta probabilidade ${ }^{1},(k+2)\left(\frac{T_{1}(n)}{p}+O\left(\frac{n}{p}\right)\right)$ para tempo de computação local e $(k+1)\left(T_{p S u m}(p)+T_{\text {compr }}(p, n)\right)$ para tempo de comunicação, onde $k=\left\lceil\frac{1}{2 \alpha}+\frac{1}{2}\right\rceil$ é uma constante e $\alpha>0$ uma constante fixa. $T_{1}(n)$ denota a complexidade de tempo seqüencial, e $T_{p S u m}(p)$ é a complexidade paralela para calcular a soma parcial de $p$ números cada um armazenado em um processador. $T_{\text {compr }}(p, n)$ é o tempo para comprimir um subconjunto de dados de tamanho $n^{\prime} \leq n$ em $p^{\prime} \leq p$ processadores.

Estes algoritmos abaixo requerem, com alta probabilidade, somente um número pequeno e fixo de rodadas de comunicação, independentemente do tamanho do problema. Cada rodada de comunicação corresponde a uma soma parcial ou operação de comprimir. Os restantes dos cálculos são locais.

Em [14] dois casos são considerados. O primeiro caso é para $p \leq \sqrt{n}$ e o segundo caso que generaliza o primeiro é dado para $1 \leq p \leq n^{1-\epsilon}$ onde $\epsilon=\frac{\alpha}{1+\alpha}$.

Recordamos o problema: dado um conjunto aleatório $S$ de $n$ pontos em $\mathbb{R}^{2}$, encontrar seu fecho convexo $C H(S)$. Prova-se que este fecho $C H(S)$ verifica as propriedades seguintes:

P1. $C H\left(A_{1} \cup \cdots \cup A_{i}\right)=C H\left(C H\left(A_{1}\right) \cup \cdots \cup C H\left(A_{i}\right)\right)$ para cada $A_{1}, \cdots, A_{i} \subseteq S$, e P2. Existe uma função $h(n)$ tal que:

(a) para cada subconjunto aleatório $A \subseteq S, \mathrm{E}(|C H(A)|) \leq h(|A|)$.

Observação: Para alguma váriavel aleatória $\mathrm{X}, \mathrm{E}(\mathrm{X})$ e $\operatorname{Pr}\{\mathrm{X}=\mathrm{y}\}$ denotam o valor esperado de $\mathrm{X}$ e a probabilidade que $\mathrm{X}$ toma um certo valor $\mathrm{y}$, respectivamente.

(b) $h(n) \leq n^{\delta}$ para $0<\delta<\min \{\epsilon, 1 / 8\}$.

As provas destas propriedades estão em [14] e são omitidas neste trabalho.

\subsubsection{Caso $p \leq \sqrt{n}$}

O algoritmo abaixo resolve o problema para o caso $p \leq \sqrt{n}$.

Algoritmo: Algoritmo 1.

Entrada: Um conjunto finito $S=\left\{p_{1}, \ldots, p_{n}\right\}$ de pontos. Cada processador $P_{i}$ armazena um subconjunto aleatório $S_{i}$ de $n / p$ pontos de $S . S_{i}$ são

\footnotetext{
${ }^{1} X=O(f(n))$ com "alta probabilidade", se e somente se $\forall c>c_{0}>1, \operatorname{Prob}\{X \geq c f(n)\} \leq \frac{1}{n^{g(c)}}$, onde $c_{0}$ é uma constante fixa e $g(n)$ é um polinômio em $c \operatorname{com} g(c) \rightarrow \infty$ para $c \rightarrow \infty$.
} 
disjuntos.

Saída: O fecho convexo de $S$.

1. Cada processador $P_{i}$ calcula sequencialmente $C H\left(S_{i}\right)$.

Seja $S^{\prime}=C H\left(S_{1}\right) \cup \cdots \cup C H\left(S_{p}\right), n^{\prime}=\left|S^{\prime}\right|$.

2. If $n^{\prime} \leq n / p$ Then $S^{\prime}$ é comprimido dentro do processador $P_{1}$, o qual calcula sequencialmente $C H(S)=C H\left(S^{\prime}\right)$. Fim.

3. O conjunto $S^{\prime}$ é comprimido em $p^{\prime} \leq \frac{2 n^{\prime} p}{n}$ processadores da seguinte forma:

a seqüência $C H\left(S_{1}\right), \cdots, C H\left(S_{p}\right)$ é dividida em $p^{\prime}$ subseqüências maximais de $C H\left(S_{j}\right)$ consecutivas, tal que o tamanho total de cada subseqüência é no máximo $n / p$. Seja $S_{i}^{\prime}$ o conjunto de pontos na subseqüência $i$ tal que $1 \leq i \leq p^{\prime}$. O conjunto $S_{i}^{\prime}$ é armazenado no processador $P_{i}$.

4. Cada processador $P_{i}\left(1 \leq i \leq p^{\prime}\right)$ calcula sequencialmente $C H\left(S_{i}^{\prime}\right)$. Seja $S^{\prime \prime}=C H\left(S_{1}^{\prime}\right) \cup \cdots \cup C H\left(S_{p^{\prime}}^{\prime}\right), n^{\prime \prime}=\left|S^{\prime \prime}\right|$.

5. If $n^{\prime \prime} \leq n / p$ Then $S^{\prime \prime}$ é comprimido dentro do processador $P_{1}$ o qual calcula sequencialmente $C H(S)=C H\left(S^{\prime \prime}\right)$.

Else continua com qualquer algoritmo determinístico.

A corretude desse algoritmo vem da propriedade que o fecho convexo da união dos conjuntos é igual o fecho convexo da união dos fechos convexos (Propriedade P1). Notemos que para o caso da linha 5, qualquer algoritmo paralelo determinístico pode ser aplicado. Um caso trivial seria de usar o algoritmo seqüencial no processador $P_{1} \mathrm{e}$ com a memória acessando as memórias de outros processadores, através de passagem de mensagens.

Os lemas e teorema seguintes são de [14].

Lema 5.1.1 Com alta probabilidade, vale $n^{\prime} \leq n / p$ ou $n^{\prime \prime} \leq n / p$.

Prova. Consideramos alguns $\delta$ tal que $0<\delta<1 / 4$. Então, segue da propriedade P2 que $h(n) \leq n^{\delta}$. Três casos são considerados para provar o lema.

Caso 1: $p \leq n^{\frac{1-\delta}{3}}$

A partir da desigualidade de Chebyshev [22] e da suposição acima, como $\delta \leq \frac{1}{4}$, temos que:

$$
\begin{aligned}
\operatorname{Pr}\left\{\exists i 1 \leq i \leq p:\left|C H\left(S_{i}\right)\right|>n^{\frac{2}{3}\left(\frac{1}{2}-\delta\right)} h(n)\right\} & \leq p \operatorname{Pr}\left\{\left|C H\left(S_{i}\right)\right|>n^{\frac{2}{3}\left(\frac{1}{2}-\delta\right)} h(n)\right\} \\
& \leq \frac{p}{n^{\frac{4}{3}\left(\frac{1}{2}-\delta\right)}} \\
& \leq \frac{n^{\frac{1-\delta}{3}}}{n^{\frac{4}{3}\left(\frac{1}{2}-\delta\right)}}
\end{aligned}
$$




$$
\leq \frac{1}{n^{\frac{1}{3}-\delta}} \rightarrow 0 \text { para } n \rightarrow \infty
$$

Logo, depois do passo 1 do Algoritmo 1 e com probabilidade de, no mínimo, $1-\frac{1}{n^{\frac{1}{3}-\delta}} \rightarrow 1$ (para $n \rightarrow \infty$ ), é obtido um conjunto $S^{\prime}$ de tamanho:

$$
\begin{aligned}
n^{\prime} & \leq p n^{\frac{2}{3}\left(\frac{1}{2}-\delta\right)} h(n) \\
& \leq n^{\frac{1-\delta}{3}} n^{\frac{2}{3}\left(\frac{1}{2}-\delta\right)} n^{\delta} \\
& =n^{\frac{2}{3}} .
\end{aligned}
$$

Como $p \leq n^{\frac{1-\delta}{3}}$ segue que $\frac{n}{p} \geq n^{\frac{2}{3}}$. Portanto, $n^{\prime} \leq \frac{n}{p}$ com alta probabilidade, $\mathrm{e}$ segue o lema 5.1.1 para o caso 1 .

Caso 2: $n^{\frac{1-\delta}{3}} \leq p \leq \frac{1}{\sqrt{2}} n^{\frac{1-\delta}{2}}$

Como $n^{\frac{1-\delta}{3}} \leq p$, temos que $p \rightarrow \infty$ para $n \rightarrow \infty$. Neste caso, segue da lei dos grandes números [22] que $\operatorname{Pr}\left\{n^{\prime} \leq 2 p h(n)\right\} \rightarrow 1$ para $n \rightarrow \infty$. Observamos que $2 p h(n) \leq \frac{n}{p}$ se $p \leq \frac{\sqrt{n}}{\sqrt{2 h(n)}}$. A última expresão é válida se $p \leq \frac{\sqrt{n}}{\sqrt{2 n^{\delta}}}$, o qual é verdadeiro se $p \leq \frac{1}{\sqrt{2}} n^{\frac{1-\delta}{2}}$. Conseqüentemente, $n^{\prime} \leq \frac{n}{p}$ com alta probabilidade, e segue $o$ lema 5.1.1 para o caso 2 .

Caso 3: $\frac{1}{\sqrt{2}} n^{\frac{1-\delta}{2}} \leq p \leq \sqrt{n}$

Como $\frac{1}{\sqrt{2}} n^{\frac{1-\delta}{2}} \leq p$, vale $p \rightarrow \infty$ para $n \rightarrow \infty$. De novo neste caso, segue da lei dos grandes números que, com alta probabilidade:

$$
\begin{aligned}
\frac{1}{2} p h(n) & \leq n^{\prime} \\
& \leq 2 p h(n) \\
& \leq 2 \sqrt{n} n^{\delta} .
\end{aligned}
$$

Como $p^{\prime} \leq \frac{2 n^{\prime}}{\frac{n}{p}}$ e $p \leq \sqrt{n}$, temos com alta probabilidade:

$$
\begin{aligned}
p^{\prime} & \leq \frac{4 p h(n)}{\frac{n}{p}} \\
& \leq 4 h(n) \\
& \leq 4 n^{\delta} .
\end{aligned}
$$

Vamos agora estudar os passos 3 e 4 do Algoritmo 1. Para cada $S_{i}^{\prime}, 1 \leq i \leq$ $p^{\prime}$, existem conjuntos $S_{t_{i}}, S_{t_{i}+1}, \cdots, S_{u_{i}}$ tais que $S_{i}^{\prime}=C H\left(S_{t_{i}}\right) \cup C H\left(S_{t_{i}+1}\right) \cup \cdots \cup$ $\mathrm{CH}\left(S_{u_{i}}\right)$. Conseqüentemente, pela propriedade $\mathrm{P} 1$ : 


$$
\begin{aligned}
C H\left(S_{i}^{\prime}\right) & =C H\left(C H\left(S_{t_{i}}\right) \cup C H\left(S_{t_{i}+1}\right) \cup \cdots \cup C H\left(S_{u_{i}}\right)\right) \\
& =C H\left(S_{t_{i}} \cup S_{t_{i}+1} \cup \cdots \cup S_{u_{i}}\right) .
\end{aligned}
$$

Defina $\operatorname{orig}\left(S_{i}^{\prime}\right)=S_{t_{i}} \cup S_{t_{i}+1} \cup \cdots \cup S_{u_{i}}$, então $C H\left(S_{i}^{\prime}\right)=C H\left(\operatorname{orig}\left(S_{i}^{\prime}\right)\right)$.

Lema 5.1.2 Para cada $1 \leq i \leq p^{\prime}$, orig $\left(S_{i}^{\prime}\right)$ é um subconjunto aleatório de $S$ e, portanto, $E\left(\left|C H\left(S_{i}^{\prime}\right)\right|\right)=E\left(\left|C H\left(\operatorname{orig}\left(S_{i}^{\prime}\right)\right)\right|\right) \leq h(n)$.

Prova. Vamos apresentar o esboço da prova. $\operatorname{orig}\left(S_{i}^{\prime}\right)=S_{t_{i}} \cup S_{t_{i}+1} \cup \cdots \cup S_{u_{i}}$. Claramente, $S_{t_{i}}$ é um conjunto aleatório de $\frac{n}{p}$ pontos. Para cada $l \in\left[t_{i}, u_{i}\right], S_{t_{i}} \cup S_{t_{i}+1} \cup \cdots \cup S_{l} \cup \cdots \cup S_{u_{i}}$ é na bijeção com $S_{l} \cup S_{t_{i}} \cup S_{t_{i}+1} \cup \cdots \cup S_{l-1} \cup S_{l+1} \cup \cdots \cup S_{u_{i}}$, nessa ordem. Conseqüentemente, segue que $S_{l}$ tem a mesma distribuição como $S_{t_{i}}$. Portanto, orig $\left(S_{i}^{\prime}\right)$ é a união de subconjuntos aleatórios de $S$, e o lema 5.1.2 é provado.

Conseqüentemente, segue da desigualidade de Chebyshev que:

$$
\begin{aligned}
\operatorname{Pr}\left\{\exists i 1 \leq i \leq p^{\prime}:\left|C H\left(S_{i}^{\prime}\right)\right|>n^{\frac{1}{3}-2 \delta} h(n)\right\} & \leq p^{\prime} \operatorname{Pr}\left\{\left|C H\left(S_{i}\right)\right|>n^{\frac{1}{3}-2 \delta} h(n)\right\} \\
& \leq \frac{p^{\prime}}{n^{\frac{2}{3}-2 \delta}} \\
& \leq \frac{4 n^{\delta}}{n^{\frac{2}{3}-4 \delta}} \rightarrow 0 \text { pois } \delta<\frac{1}{8}
\end{aligned}
$$

Portanto, depois o passo 4 do Algoritmo 1 obtemos, com alta probabilidade, um conjunto $S^{\prime \prime}$ de tamanho:

$$
\begin{aligned}
n^{\prime \prime} & \leq p^{\prime} n^{\frac{1}{3}-2 \delta} h(n) \\
& \leq 4 n^{\delta} n^{\frac{1}{3}-2 \delta} n^{\delta} \\
& \leq n^{\frac{1}{2}} .
\end{aligned}
$$

Como $p \leq \sqrt{n}$ então $\frac{n}{p} \geq \sqrt{n}$. Conseqüentemente, $n^{\prime \prime} \leq \frac{n}{p}$ com alta probabilidade, e segue o lema 5.1.1 para o caso 3. Isto conclui a prova do lema 5.1.1.

Teorema 5.1.3 Dado um multicomputador com $p$ processadores, $p \leq \sqrt{n}$, então, com alta probabilidade, o Algoritmo 1 calcula $C H(S),|S|=n$, com tempo de comunicação no máximo $2\left(T_{p S u m}(p)+T_{\text {compr }}(p, n)\right)$ e tempo de cálculo local no máximo $3 \frac{T_{1}(n)}{p}+O\left(\frac{n}{p}\right)$. 


\subsubsection{Caso $1 \leq p \leq n^{1-\epsilon}$}

Podemos agora generalizar o algoritmo Algoritmo 1 para resolver o problema do fecho convexo. Seja $k$ uma constante inteira positiva fixa tal que $k \geq \frac{1}{2(\epsilon-\delta)}-\frac{1}{6}=$ $\frac{1+\alpha}{2 \alpha-2 \delta(1+\alpha)}-\frac{1}{6}$.

\section{Algoritmo: Algoritmo 2.}

Entrada: Um conjunto finito $S=\left\{p_{1}, \ldots, p_{n}\right\}$ do pontos. Cada processador $P_{i}$ armazena um subconjunto aleatório $S_{i}$ de $n / p$ pontos de $S$.

Saída: O fecho convexo de $S$.

$$
\text { Seja } n^{(0)}=n, p^{(0)}=p \text { e } S^{(0)}=S .
$$

1. For $j=0 \cdots k$ do

a. Cada processador $P_{i}, 1 \leq i \leq p^{(j)}$, calcula sequencialmente $C H\left(S_{i}^{(j)}\right)$.

Seja $S^{(j+1)}=C H\left(S_{1}^{(j)}\right) \cup \cdots \cup C H\left(S_{p^{(j)}}^{(j)}\right), n^{(j+1)}=\left|S^{(j+1)}\right|$.

b. If $n^{(j+1)} \leq n / p$ Then $S^{(j+1)}$ é comprimido dentro do processador $P_{1}$

o qual calcula sequencialmente $C H(S)=C H\left(S^{(j+1)}\right)$. Fim.

c. O conjunto $S^{(j+1)}$ é comprimido em $p^{(j+1)} \leq \frac{2 n^{(j+1)} p}{n}$ processadores da seguinte forma: a seqüência $C H\left(S_{1}^{(j)}\right), \cdots, C H\left(S_{p^{(j)}}^{(j)}\right)$ é dividida em $p^{(j+1)}$ subseqüências maximais de $C H\left(S_{i}^{(j)}\right)$ consecutivas, tal que o tamanho total de cada subseqüência é no máximo $n / p$. Seja $S_{i}^{(j+1)}$ o conjunto de pontos na subseqüência $i$, tal que $1 \leq i \leq p^{(j+1)}$. O conjunto $S_{i}^{(j+1)}$ é armazenado no processador $P_{i}$.

2. If $n^{(k+1)} \leq n / p$ Then no passo anterior 1.c., $S^{(k+1)}$ foi comprimido no processador $P_{1}$ o qual pode agora calcular sequencialmente $C H(S)=C H\left(S^{(k+1)}\right)$.

Else continua com qualquer algoritmo determinístico.

Lema 5.1.4 Com alta probabilidade, vale $n^{(j)} \leq n / p$ para algum $j \leq k+1$.

Prova. Consideramos dois casos.

Se $p \leq \sqrt{n}$ então aplicamos a análise do Algoritmo 1 dada na seção anterior. Suponhamos agora que $\sqrt{n} \leq p \leq n^{1-\epsilon}$.

A ideia básica é de usar o lema 5.1 .2 em cada iteração e a análise de caso 3 do lema 5.1.1. Obtemos, com alta probabilidade:

$$
\begin{aligned}
& p^{(j+1)} \leq \frac{4 p^{(j)} h(n)}{\frac{n}{p}} \\
& \quad \leq p^{(j)} \frac{4 n^{\delta}}{n^{\epsilon}} \forall j \geq 0 .
\end{aligned}
$$


Conseqüentemente, com alta probabilidade, $p^{(j)} \leq p\left(\frac{4 n^{\delta}}{n^{\epsilon}}\right)^{j} \forall j \geq 0$. Observamos que $p\left(\frac{4 n^{\delta}}{n^{\epsilon}}\right)^{j} \leq n^{\frac{\epsilon-\delta}{3}}$ se $i \geq \frac{1}{2(\epsilon-\delta)}-\frac{1}{6}$. A menos que o laço do Algoritmo 2 seja parado para $j<k$, temos:

$$
\begin{aligned}
\operatorname{Pr}\left\{\exists i 1 \leq i \leq p:\left|C H\left(S_{i}^{(k)}\right)\right|>n^{\frac{2}{3}(\epsilon-\delta)} h(n)\right\} & \leq \frac{p^{(k)}}{n^{\frac{4}{3}(\epsilon-\delta)}} \\
& \leq \frac{n^{\frac{1}{3}}(\epsilon-\delta)}{n^{\frac{4}{3}(\epsilon-\delta)}} \\
& \leq \frac{1}{n^{\epsilon-\delta}} \rightarrow 0 \text { para } n \rightarrow \infty, \text { pois } \delta<\epsilon .
\end{aligned}
$$

Portanto, com alta probabilidade:

$$
\begin{aligned}
n^{(k+1)} & \leq p^{(k)} n^{\delta} n^{\frac{2}{3}(\epsilon-\delta)} \\
& \leq n^{\frac{1}{3}(\epsilon-\delta)} n^{\delta} n^{\frac{2}{3}(\epsilon-\delta)} \\
& \leq n^{\epsilon} \\
& \leq \frac{n}{p}
\end{aligned}
$$

Isso conclui a prova do lema 5.1.4.

Teorema 5.1.5 Dado um multicomputador com $p$ processadores, então, com alta probabilidade, o Algoritmo 2 calcula $C H(S),|S|=n$, com tempo de comunicação no máximo $(k+1)\left(T_{p \text { Sum }}(p)+T_{\text {compr }}(p, n)\right)$ e tempo de cálculo local no máximo $(k+2)\left(\frac{T_{1}(n)}{p}+O\left(\frac{n}{p}\right)\right)$, onde $T_{1}(n)$ é o tempo seqüencial e $k \geq \frac{1}{2(\epsilon-\delta)}-\frac{1}{6}=\frac{1+\alpha}{2 \alpha-2 \delta(1+\alpha)}-\frac{1}{6}$ uma constante inteira positiva determinada.

Aplicamos Algoritmo 2 e teorema $5.1 .5 \operatorname{com} k=\left\lceil\frac{1}{2 \alpha}+\frac{1}{2}\right\rceil$. Temos então:

Teorema 5.1.6 Dado um multicomputador com $p$ processadores, então, com alta probabilidade, o Algoritmo 2 calcula $C H(S),|S|=n$, com tempo de comunicação no máximo $(k+1)\left(T_{p S u m}(p)+T_{\text {compr }}(p, n)\right)$ e tempo de cálculo local no máximo $(k+2)\left(\frac{T_{1}(n)}{p}+O\left(\frac{n}{p}\right)\right)$, onde $T_{1}(n)$ é o tempo seqüencial e $k=\left\lceil\frac{1}{2 \alpha}+\frac{1}{2}\right\rceil$ uma constante inteira positiva determinada.

\subsection{Algoritmo Paralelo Determinístico no Modelo CGM}

O algoritmo que vamos ver agora é determinístico e escalável [18]. No pior caso, a complexidade de tempo é $O\left(\frac{n \log n}{p}+T_{s}(n, p)\right)$ e o número de rodadas de comunicação 
é $O(1)$, onde $n$ é o tamanho do problema, $p$ o número de processadores e $T_{s}(n, p)$ o tempo de ordenação de $n$ números usando $p$ processadores. O algoritmo é ótimo. A idéia chave, como no caso do algoritmo probabilístico, é de particionar os dados em dados locais, que são executados seqüencialmente em cada processador.

A estrutura do algoritmo é a seguinte. Os dados de problema estão distribuídos em memórias locais, onde ficam até o final da solução. Dados um conjunto $S$ de $n$ pontos e $p$ processadores, o algoritmo mostra como encontrar o fecho superior $U H(S)$. O fecho inferior $L H(S)$ é calculado de maneira análoga. Sem perda da generalidade, suponha que os pontos estão no primeiro quadrante, isto é, suas coordenadas cartesianas são não negativas.

\section{Algoritmo: CGM UPPER HULL(S)}

Entrada: Cada processador armazena um conjunto de $\frac{n}{p}$ pontos escolhidos arbitrariamente de $S$.

Saída: A representação distribuída do fecho superior de $S$. Todos os pontos do fecho superior estão identificados e numerados da esquerda para a direita.

1. Ordena todos os pontos de $S$ pela abscissa. Seja $S_{i}$ o conjunto de $\frac{n}{p}$ pontos ordenados e armazenados no processador $i$.

2. Independentemente e em paralelo, cada processador $i$ calcula o fecho superior de $S_{i}$. Seja $X_{i}$ o resultado no processador $i$.

3. Cada processador calcula para $X_{i}, 1 \leq i \leq p$, as linhas de tangente comum superior entre ele e todos $X_{j}, i<j \leq p$, e identifica o fecho superior de $S$ usando as retas de tangente superior. (Este passo será detalhado adiante.)

O passo 1 pode ser executado usando a operação de ordenação global descrito em [18]. O passo 2 é totalmente seqüencial e pode ser completado em tempo $O\left(\frac{n \log n}{p}\right)$, usando os algoritmos seqüenciais conhecidos [43]. O desafio principal está no passo 3. Neste passo, um algoritmo de merge combina os $p$ fechos superiores disjuntos em um único fecho superior. Apresentaremos dois algoritmos de merge diferentes: MergeHulls 1 e MergeHulls 2 ambos. O primeiro, descrito na subseção 5.2.4, é o merge simples ou direto requerendo um número constante de rodadas de comunicação global e $\frac{n}{p} \geq p^{2}$ de memória local por processador. O segundo merge, descrito na subseção 5.2.5, é mais complexo e usa o primeiro como um subprocedimento. Mas tem o grau alto de escalabilidade e pode ser implementado com somente $\frac{n}{p} \geq p^{\epsilon}$ de memória local, onde $\epsilon$ é uma constante fixa tal que $0<\epsilon \leq 1$ e também requer um número constante de rodadas de comunicação. Os dois algoritmos usam a idéia de 
conjuntos divisores selecionados, que foi introduzida em [38].

Antes de apresentarmos os algoritmos vamos relacionar alguns resultados que motivam e justificam a idéia.

\subsubsection{Combinando os Fechos Convexos em Paralelo}

Vamos ver como podemos combinar, em um único fecho superior, os $p$ fechos superiores disjuntos armazenados em $p$ processadores. Isso corresponde ao desafio no passo 3 do algoritmo $C G M$ UPPER $H U L L(S)$. Para isso, precisamos de algumas definições.

Definição 5.2.1 Seja $\overline{a b}$ o segmento de reta ligando os pontos a e b. Vamos denotar por $(a b)$ a reta passando por a e b. Dizemos que o ponto c está dominado pelo segmento de reta $\overline{a b}$ se e somente se a abscissa de $c$ está estritamente entre as abscissas de a e b, e c está localizado abaixo do segmento $\overline{a b}$.

Definição 5.2.2 Seja $\left\{S_{i}\right\}, 1 \leq i \leq p$, uma partição de $S$ tal que $\forall x \in S_{j}, y \in$ $S_{i}, j>i$, a abscissa de $x$ é maior que de $y$.

Definição 5.2.3 Seja $X_{i}=\left\{x_{1}, x_{2}, \cdots, x_{m}\right\}$ um fecho superior. Então, pred ${ }_{X_{i}}\left(x_{i}\right)$ denota $x_{i-1}$ e $\operatorname{suc}_{X_{i}}\left(x_{i}\right)$ denota $x_{i+1}$. Veja Figura 5.1.

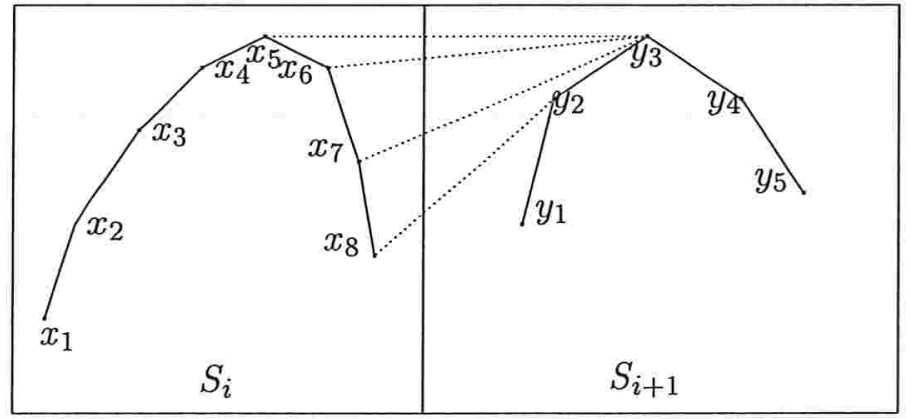

Figura 5.1: Seja $S^{\prime}=S_{i} \cup S_{i+1}$ então $\operatorname{suc}\left(x_{j}\right)=x_{j+1}, x_{3}=\operatorname{Next}_{S^{\prime}}\left(x_{2}\right), x_{4}=$ $\operatorname{Next}_{S^{\prime}}\left(x_{3}\right), x_{5}=\operatorname{Next}_{S^{\prime}}\left(x_{4}\right), \operatorname{Next}_{S^{\prime}}\left(x_{5}\right)=\operatorname{Next}_{S^{\prime}}\left(x_{6}\right)=\operatorname{Next}_{S^{\prime}}\left(x_{7}\right)=$ $y_{3}, \operatorname{Next}_{S^{\prime}}\left(x_{8}\right)=y_{2}$, e $\operatorname{lm}\left(S_{i}\right)=x_{5}$.

Dados dois fechos superiores $X_{i}=U H\left(S_{i}\right)$ e $X_{j}=U H\left(S_{j}\right)$, onde todos os pontos em $S_{j}$ estão à direita de todos os pontos em $S_{i}$. A operação do merge consiste em 
achar para um ponto $p \in X_{i}$, o ponto $q \in X_{i} \cup X_{j}$ que segue $p$ no $U H\left(X_{i} \cup X_{j}\right)$. Veja Figura 5.1.

Definição 5.2.4 Seja $Q \subseteq S$. Então, Next $\sec _{S} Q \longrightarrow S$ é a função tal que $\operatorname{Next}_{S}(p)=$ $q$ se e somente se $q$ está a direita de $p$ e $\overline{p q}$ está acima de $\overline{p q^{\prime}}$ para todo $q^{\prime} \in S, q^{\prime}$ a direita de $p$.

Definição 5.2.5 Seja $Y \subseteq S_{i}$. Então, $\operatorname{lm}(Y)$ é uma função tal que $\operatorname{lm}(Y)=y^{*}$ se e somente se $y^{*}$ é o ponto mais à esquerda em $Y$ tal que $N$ ext $t_{Y \cup S_{j}, j>i}\left(y^{*}\right) \notin S_{i}$.

Seja $X$ um fecho superior de um conjunto de $n$ pontos e $c$ um ponto localizado à esquerda desse conjunto. Apresentamos um algoritmo seqüencial chamado QueryFindNext que busca $q=N e x t_{X}(c)$. A busca binária processa em tempo $O(\log |X|)$ [43]. Veja Figura 5.2.

Algoritmo: QueryFindNext $(X, c, q)$

Entrada: Um fecho superior $X=\left\{x_{1}, \cdots, x_{m}\right\}$ ordenado pela abscissa e

o ponto $c$ à esquerda de $x_{1}$.

Saída: Um ponto $q \in X, q=\operatorname{Next}_{X}(c)$.

1. Se $X=\{x\}$ então $q \longleftarrow x$ e pára.

2. Se $\overline{x_{\lceil m / 2\rceil} \operatorname{suc}\left(x_{\lceil m / 2\rceil}\right)}$ está localizado abaixo da reta $\left(c x_{\lceil m / 2\rceil}\right)$

então QueryFindNext $\left(\left\{x_{1}, \cdots, x_{\lceil m / 2\rceil}\right\}, c, q\right)$,

senão QueryFindNext $\left(\left\{x_{\lceil m / 2\rceil}, \cdots, x_{m}\right\}, c, q\right)$

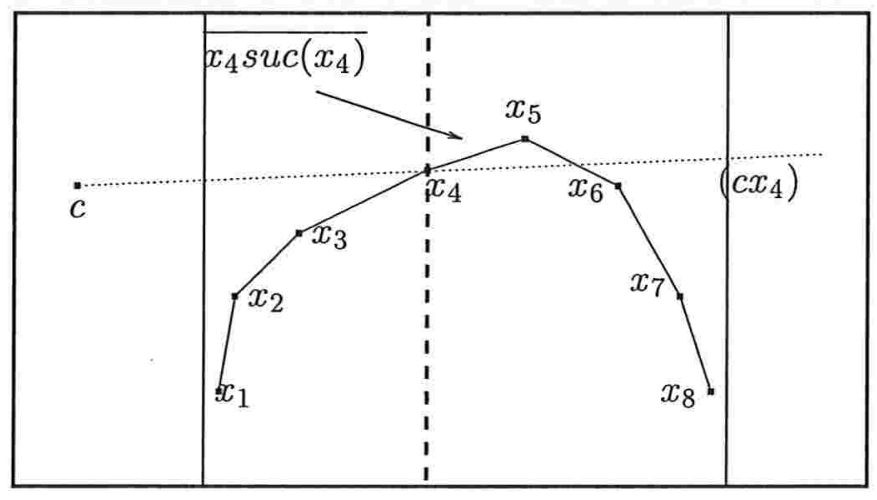

Figura 5.2: Um passo da busca binária de QueryFindNext. O segmento de reta $\overline{x_{4} s u c\left(x_{4}\right)}$ está acima da reta $\left(c x_{4}\right)$ e o algoritmo busca sobre $\left\{x_{4}, \cdots, x_{8}\right\}$. 


\subsubsection{Caracterização do Fecho Superior}

Uma caracterização do fecho superior de um conjunto $S$ de pontos é baseada na observação seguinte [43]: O segmento de reta $\overline{a b}$ é uma aresta do fecho superior de um conjunto $S$ do pontos localizado no primeiro quadrante se e somente se todos os $n-2$ pontos restantes caem abaixo da reta (ab). Vamos trabalhar com uma nova caracterização do fecho superior de $S$ baseada na mesma observação, mas definida em termos da partição de $S$ dada nas definições 5.2 .2 e 5.2.5.

Consideramos os conjuntos $S, S_{i}$ e $X_{i}$ como definidos anterioramente.

Definição 5.2.6 Seja $S^{\prime}=\left\{c \in \cup X_{i} \mid c\right.$ não está dominado pelo segmento de reta $\left.\overline{x_{i}^{*} N e x t_{\cup X_{j}, j>i}\left(x_{i}^{*}\right)}, 1 \leq i<p\right\}$, onde $x_{i}^{*}=\operatorname{lm}\left(X_{i}\right)$.

O teorema seguinte caracteriza o fecho superior $U H(S)$.

Teorema 5.2.1 $S^{\prime}=U H(S)$.

Prova. Consideremos dois casos.

- $U H(S) \subseteq S^{\prime}$.

Suponha $y \in U H(S), y \notin S^{\prime}$. Então, existe $i$ tal que $\overline{x_{i}^{*} N e x t_{X_{j}, j>i}\left(x_{i}^{*}\right)}$ domina $y$. Portanto, $y \notin U H(S)$, o que é uma contradição.

- $S^{\prime} \subseteq U H(S)$.

Suponha $y \in S^{\prime}, y \notin U H(S)$. Então existem $p, q$ com $p \in \operatorname{UH}(S), q \in U H(S)$, e $q=N e x t_{S}(p)$, tais que $\overline{p q}$ domina $y$. Portanto, ambos $p$ e $q$ não podem pertencer a $S_{i}$, uma vez que $y \in X_{i}$ significa que $y$ não está dominado por qualquer segmento de reta com pontos extremos em $S_{i}$. Assim, $p \in X_{j}$ e $q \in X_{k}$ com $j \neq k$. Consequentemente, como $q=\operatorname{Next}_{S}(p), p \in \mathrm{UH}(S)$, e $q \in U H(S)$, então existe $i$ tal que $p=x_{i}^{*}$, onde $x_{i}^{*}=\operatorname{lm}\left(X_{i}\right)$. Portanto, $y$ está dominado pelo segmento $\overline{x_{i}^{*} N e x t_{X_{j}, j>i}\left(x_{i}^{*}\right)}$, o que é uma contradição.

As definições e o lema seguintes são necessários na descrição dos dois algoritmos paralelos do merge nas subseções 5.2.4 e 5.2.5. Eles ajudam não somente na descrição do algoritmo mas também na análise das complexidade de tempo e de espaço. 
Definição 5.2.7 Seja $G_{i} \subseteq X_{i}$ e $g_{i}^{*}=\operatorname{lm}\left(G_{i}\right)$. Seja $R_{i}^{-} \subseteq X_{i}$ composto dos pontos

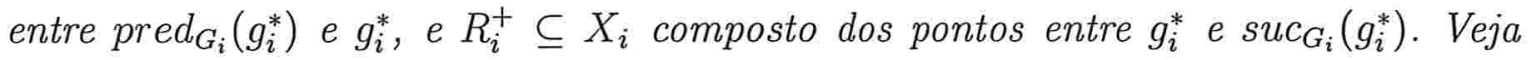
Figura 5.3.

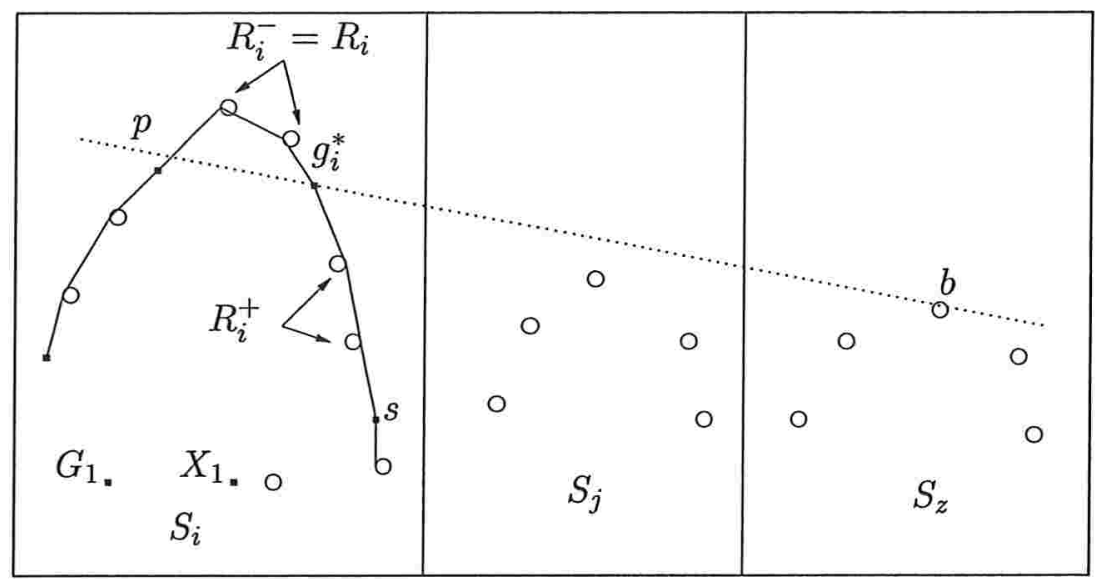

Figura 5.3: Os pontos pretos são elementos de $G_{i}$ que é um subconjunto de $X_{i}$ composto de pontos circulares e pretos. Seja $p=\operatorname{pred}_{G_{i}}\left(g_{i}^{*}\right)$ e $s=\operatorname{suc}_{G_{i}}\left(g_{i}^{*}\right)$. Temos $R_{i}=R_{i}^{-}$porque $R_{i}^{+}$não tem nenhum ponto acima da $\operatorname{reta}\left(g_{i}^{*} b\right)$.

Lema 5.2.2 Os pontos de $R_{i}^{+}$ou $R_{i}^{-}$, ou ambos, estão abaixo da reta $\left(g_{i}^{*} N \operatorname{ext} t_{X_{j, j>i}}\left(g_{i}^{*}\right)\right)$.

A prova desse lema é direta, senão $g_{i}^{*} \notin X_{i}$.

Definição 5.2.8 $R_{i}$ denota o conjunto $R_{i}^{+}$ou $R_{i}^{-}$que tem pelo menos um ponto acima da reta $\left(g_{i}^{*} N e x t_{X_{j, j>i}}\left(g_{i}^{*}\right)\right)$.

Os conjuntos $R_{i}^{+}, R_{i}^{-}$e $R_{i}$ são mostrados na figura 5.3.

Observamos que o tamanho de cada um dos conjuntos $R_{i}$ é limitado pelo número de pontos cercados entre dois pontos consecutivos em $G_{i}$.

\subsubsection{Cálculo do $g_{i}^{*}$ e $x_{i}^{*}$ em Paralelo}

Mostraremos como calcular $g_{i}^{*}=\operatorname{lm}\left(G_{i}\right)$, onde $G_{i} \subseteq X_{i}$. O algoritmo, descrito abaixo, funciona da seguinte forma. Os elementos de $G_{i}$ são enviados, no passo 2 , aos processadores com numeração maior de maneira que eles, recebendo $G=\cup G_{j}, j<i$, 
podem calcular seqüencialmente $N \operatorname{ext}_{\Delta_{i}}(g)$ para cada $g \in G$. No passo 3, estes pontos são calculados usando o algoritmo QueryFindNext, que são mandados de volta no passo 4. Então, os processadores podem calcular independentemente os $g_{i}^{*}$. Quando os processadores estão divididos em grupos, faça $q_{z}^{i}$ denotar o $z$-ésimo processador do grupo $i$.

Algoritmo: FindLMSubset $\left(\triangle_{i}, k, w, G_{i}, g_{i}^{*}\right)$

Entrada: Fechos superiores $\Delta_{i}, 1 \leq i \leq p^{k}$ representando cada um em $p^{w}$

processadores numerados consecutivamente $q_{z}^{i}, 1 \leq z \leq p^{w} \mathrm{e}$

o conjunto $G_{i} \subseteq \Delta_{i}$.

Saída: O ponto $g_{i}^{*}=\operatorname{lm}\left(G_{i}\right) \cdot g_{i}^{*}$ vai estar em cada $q_{z}^{i}, 1 \leq z \leq p^{w}$

1. Junte $G_{i}$ no processador $q_{1}^{i}$, para todo $i$.

2. Cada processador $q_{1}^{i}$ manda seu $G_{i}$ a todos processadores $q_{z}^{j}, j>i, 1 \leq z \leq p^{w}$. Cada processador $q_{z}^{i}$, para todo $i, z$, recebe $\mathcal{G}^{i}=\cup G_{j}, \forall j<i$.

3. Cada processador $q_{z}^{i}, \forall i, z$, calcula seqüencialmente $N \operatorname{ext}_{\Delta_{i}}(g)$ para cada $g \in \mathcal{G}^{i}$, usando o algoritmo QueryFindNext.

4. Cada processador $q_{z}^{i}, \forall i, z$, manda de volta a todos processadores $q_{1}^{j}, j<i$, o $\operatorname{Next}_{\triangle_{i}}(g)$ calculado, $\forall g \in G_{j}$.

Cada processador $q_{1}^{i}, \forall i$, recebe para cada $g \in G_{i}$, o $N e x t_{\triangle_{j}}(g)$ calculado, $\forall j>i$.

5. Cada processador $q_{1}^{i}, \forall i$, calcula para cada $g \in G_{i}$ o segmento de reta com a maior inclinação entre $\overline{g s u c_{G_{i}}(g)}$ e $\overline{g N e x t_{\Delta_{j}}(g)}, j>i$, achando $\operatorname{Next}_{G_{i} \cup \Delta_{j}, j>i}(g)$. Então, calcula $g_{i}^{*}=\operatorname{lm}\left(G_{i}\right)$.

6. Cada processador $q_{1}^{i}, \forall i$, faz broadcasts de $g_{i}^{*}$ a $q_{z}^{i}, 1 \leq z \leq p^{w}$.

Lema 5.2.3 O algoritmo FindLMSubset calcula $g^{*}=\operatorname{lm}\left(G_{i}\right)$ em um número constante de rodadas de comunicação. Requer um espaço de memória local $\frac{n}{p} \geq p^{k}\left|G_{i}\right|$.

Prova. A corretude desse algoritmo depende das definições 5.2.4, 5.2.5 e do algoritmo de busca QueryFindNext. Os espaços de memórias requeridos são: $\left|G_{i}\right|$ no passo 1, $p^{k}\left|G_{i}\right|$ no passo $2, p^{k}$ no passo 4 equivalendo a um espaço total de $O\left(p^{k}\left|G_{i}\right|\right)$. A complexidade das operações seqüencias é $O\left(p^{k}\left|G_{i}\right| \log n\right)$ e precisa somente de quatro rodadas de comunicação. 


\subsubsection{Algoritmo MergeHulls 1}

Esse algoritmo combina $p$ fechos superiores, armazenados numa $C G M$ de $p$ processadores, em um único fecho superior usando um número constante de rodadas de comunicação global. Ele requer $\frac{n}{p} \geq p^{2}$ e isso limita a escalabilidade.

Para achar a tangente comum superior entre os fechos superiores $X_{i}$ e $X_{j}$ (à sua direita), o algoritmo calcula a função $N e x t$, não para todo $X_{i}$ mas apenas para o subconjunto de $p$ pontos igualmente espaçados de $X_{i}$. Chamamos esse subconjunto de pontos igualmente espaçados um divisor de $X_{i}$. Essa estratégia baseada no divisor reduz bastante o total de dados que deve ser comunicado entre processadores sem aumentar muito o número de rodadas de comunicação global.

Algoritmo: MergeHulls $1\left(X_{i}(1 \leq i \leq p), S, n, p, U H\right)$

Entrada: O conjunto de $p$ fechos superiores $X_{i}$ consistindo, no máximo, de $n$ pontos de $S$, onde $X_{i}$ é armazenado no processador $q_{i}, 1 \leq i \leq p$.

Saída: A representação do fecho superior de $S$. Todos os pontos sobre

o fecho superior estão identificados e numerados da esquerda à direita.

1. Cada processador $q_{i}$ identifica sequencialmente um conjunto divisor $G_{i}$ composto de $p$ pontos espaçados igualmente de $X_{i}$.

2. Os processadores acham em paralelo $g_{i}^{*}=\operatorname{lm}\left(G_{i}\right)$. Isso é feito via FindLMSibset.

3. Cada processador $q_{i}$ calcula seus próprios $R_{i}^{-}$e $R_{i}^{+}$de acordo com a definição 5.2 .7 , e o conjunto $R_{i}$ de pontos que estão acima da reta $\left(g_{i}^{*} N e x t_{G_{i} \cup X_{j}, j>i}\left(g_{i}^{*}\right)\right)$, de acordo com o Lema 5.2.2.

4. Os processadores acham em paralelo $x_{i}^{*}=\operatorname{lm}\left(R_{i} \cup g_{i}^{*}\right)$, usando o algoritmo FindLMSubset. Note que por definição $\operatorname{Next}_{S}\left(x_{i}^{*}\right) \notin X_{i}$.

5. Cada processador $q_{i}$ faz broadcasts de seu ponto $N e x t_{S}\left(x_{i}^{*}\right)$ a $q_{j}, j>i$, e calcula seu próprio $S_{i}^{\prime}$ de acordo a definição 5.2.6.

Lema 5.2.4 O algoritmo MergeHulls 1 calcula $U H(S)$ em tempo $O\left(\frac{n \log n}{p}+T_{s}(n, p)\right)$, requer um espaço de memória local igual $a \frac{n}{p} \geq p^{2}$ e um número constante de rodadas de comunicação.

Prova. Pelo teorema 5.2.1, os conjuntos calculados $S_{i}^{\prime}$ no passo 5 são uma representação do fecho superior $U H(S)$. O algoritmo MergeHulls 1 chama o procedimento FindLMSubset duas vezes. No passo 2 , os parâmetros são $\Delta_{i}=X_{i}, k=1, w=0 \mathrm{e}$ 
$G_{i}=G_{i}$, implicando que $\left|G_{i}\right|=p$. No passp 4, têm novamente os mesmos parâmetros, mas para $G_{i}=R_{i} \cup g_{i}^{*}$. Portanto, $\left|G_{i}\right|=\left|R_{i} \cup g_{i}^{*}\right|=\frac{\left|X_{i}\right|}{p} \leq \frac{n}{p^{2}}$. Com isso, o espaço de memória local requerido é $\frac{n}{p} \geq p^{2}$, pelo lema 5.2.3 O mesmo lema garante que a complexidade das operações seqüenciais no algoritmo MergeHulls 1 é $O\left(p^{2} \log n\right)=$ $O\left(\frac{n}{p} \log n\right)$ e que um número constante de rodadas de comunicação é usado.

\subsubsection{Algoritmo MergeHulls 2}

Ao contrário do MergeHulls 1 , esse algoritmo requer somente $\frac{n}{p} \geq p^{\epsilon}$ de espaço de memória por processador, $0<\epsilon \leq 1$. Para simplificar usamos $\epsilon=1$. O algoritmo funciona assim:

1. Na primeira fase, o algoritmo MergeHulls 1 é utilizado para encontrar o fecho superior de grupo de $\sqrt{p}$ processadores, com $\left|G_{i}\right|$ igual a $\sqrt{p}$. A complexidade dessa fase é $O(p)$.

2. A segunda fase combina esses $\sqrt{p}$ fechos superiores, cada um de tamanho máximo $\frac{n \sqrt{p}}{p}$, no lugar dos $p$ fechos iniciais. Então, com $\left|G_{i}\right|=\sqrt{p}$, o passo 2 requer somente espaço de tamanho $p$. Porém, precisamos ser mais cuidadosos, porque o tamanho de cada conjunto $R_{i}$ é, no pior caso, $\frac{n \sqrt{p}}{p\left|G_{i}\right|}$, implicando que o passo 4 vai precisar de espaço até $\frac{n \sqrt{p}}{p}$, o que é muito. Por isso, uma nova redução desses tamanhos é necessária. Sabemos que os conjuntos $R_{i}$ também são de fechos superiores e podemos aplicar recursivamente a todos os $R_{i}$, o mesmo método usado no algoritmo MergeHulls 1 para achar $x_{i}^{*}=\operatorname{lm}\left(R_{i} \cup g_{i}^{*}\right)$.

Algoritmo: BuildHulls $\left(\Phi_{i}, \Psi_{j}, p, k, w, \epsilon\right)$

Entrada: Fechos superiores $\Phi_{i}, 1 \leq i \leq \frac{p}{p^{w}}$, representado cada em $p^{w}$ processadores númerados consecutivamente $q_{z}^{i}, 1 \leq z \leq p^{w}$. O parâmetro $\epsilon$ reflete o tamanho da memória local de cada um dos $p$ processadores.

Saída: Fechos convexos $\Psi_{j}=\mathrm{UH}\left(\cup_{i=(j-1) p^{k}+1}^{j p^{k}} \Phi_{i}\right)$, para $1 \leq j \leq \frac{p}{p^{w+k}}$.

1. $G_{i} \longleftarrow \Phi_{i}$.

2. While $\left|G_{i}\right| p^{k}>p^{\epsilon}$ do

(a)Cada grupo de processadores $q_{z}^{i}, 1 \leq z \leq p^{w}$, identifica sequencialmente um conjunto divisor $G_{i}^{\prime}$ composto de $p^{\epsilon / 2}$ pontos espaçados igualmente de $G_{i}$

(b)FindLMSubset $\left(\Phi_{i}, k, w, G_{i}^{\prime}, g_{i}^{*}\right)$.

(c)Se $\overline{g_{i}^{*} s u c_{\Phi_{i}}\left(g_{i}^{*}\right)}$ está acima do $\overline{g_{i}^{*} N e x t_{\Phi_{i}, j>i}\left(g_{i}^{*}\right)}$ então $R_{i}$ é composto 
de todos pontos de $\Phi_{i}$ entre $g_{i}^{*}$ e $s u c_{G_{i}}\left(g_{i}^{*}\right)$; senão $R_{i}$ é composto de todos pontos de $\Phi_{i}$ entre $g_{i}^{*}$ e $\operatorname{pred}_{G_{i}}\left(g_{i}^{*}\right)$.

(d)Seja $G_{i} \longleftarrow R_{i} \cup\left\{g_{i}^{*}\right\}$.

3. FindLMSubset $\left(\Phi_{i}, k, w, G_{i}, x_{i}^{*}\right)$.

4. Cada processador $q_{1}^{i}$ faz broadcasts de seu $x_{i}^{*}$ a todos $q_{j}^{h}, h=\left(i \bmod \left(p^{k}+1\right)\right) p^{k}+1, \cdots,\left(i \bmod \left(p^{k}+1\right)\right) p^{k}+p^{k}$ e $1 \leq j \leq p^{w}$.

5. Cada processador calcula seu próprio $S_{i}^{\prime}$ de acordo a definição 5.2.6.

Lema 5.2.5 O algoritmo BuildHulls calcula $\Psi_{j}=U H\left(\cup_{i=(j-1) p^{k+1}}^{j p^{k}} \Phi_{i}\right)$, para $1 \leq j \leq$ $\frac{p}{p^{w+k}}$ em tempo $O\left(\frac{n \log n}{p}+T_{s}(n, p)\right)$. Seja $\alpha=\max \{(k+\epsilon / 2), \epsilon\}$. Entâa o algoritmo requer um espaço de memória local igual a $\frac{n}{p} \geq p^{\alpha}$ e um número constante de rodadas de comunicação.

Prova. O algoritmo BuildHulls exige a memória como seguir. No passo 2(b), $\frac{n}{p} \geq$ $p^{k+\epsilon / 2}$. No passo $3, \frac{n}{p} \geq p^{\epsilon}$ e no passo $4, \frac{n}{p} \geq p^{k}$. A complexidade de tempo da computação é $O\left(\frac{n}{p} \log n+p^{k}\left|G_{i}\right|\right)=O\left(\frac{n}{p} \log n\right)$. Com respeito ao número de rodadas de comunicação, note que no passo 2 existem no máximo $p^{\alpha+w}$ pontos em $\Phi_{i}$. Cada passagem no passo 2 (a) reduz esse tamanho pelo fator de $p^{\epsilon / 2}$. Com isso, existem $\frac{2(\alpha+w)}{\epsilon}$ fases, onde uma fase é chamada no procedimento FindLMSubset.

Algoritmo: MergeHulls $2\left(X_{i}(1 \leq i \leq p), S, n, p, U H(S), \epsilon\right)$

Entrada: O conjunto de $p$ fechos superiores $X_{i}$ consistindo, no máximo, de $n$ pontos de $S$, onde $X_{i}$ está armazenado no processador $p_{i}, 1 \leq i \leq p$. O parâmetro $\epsilon$ reflete o tamanho da memória local.

Saída: A representação do fecho superior de $S$. Todos os pontos sobre

o fecho superior são identificados e numerados da esquerda à direita.

1. Seja $k=\frac{\epsilon}{2}, w=0$, e $X_{i}^{0}=X_{i}$.

2. Do

(a) BuildHulls $\left(X_{i}^{w}, X_{j}^{w+k}, p, k, w, \epsilon\right)$.

(b) $w \longleftarrow w+k$.

Until $w \geq 1$.

Teorema 5.2.6 O algoritmo MergeHulls 2 calcula UH(S) em tempo $O\left(\frac{n \log n}{p}+T_{s}(n, p)\right)$, requer um espaço de memória local $\frac{n}{p} \geq p^{\epsilon}$ e um número constante de rodadas de comunicação. 
Prova. O lema 5.2 .5 implica que $\frac{n}{p} \geq p^{k+\epsilon / 2}$, somente $\frac{n}{p} \geq p^{\epsilon}$. Com respeito ao número de rodadas de comunicação, o procedimento BuildHulls é chamada $\frac{2}{\epsilon}$ vezes. Pelo lema 5.2.5, existe $\frac{2(\epsilon+w)}{\epsilon}$ fases, em cada chamada. Conseqüentemente, como $w=(t-1) \frac{\epsilon}{2}$ na t-ésima execução do passo 2(a), o número total de rodadas de comunicação é $\sum_{t=1}^{2 / \epsilon} t=O\left(\left(\frac{2}{\epsilon}\right)^{2}\right)$. Finalmente, isso implica que a complexidade de tempo da computação local é $O\left(\frac{1}{\epsilon^{2}} \frac{n}{p} \log n\right)$.

Corolário 5.2.7 O fecho convexo de n pontos no plano pode ser calculado no $C G M(n, p)$ em tempo $O\left(\frac{T_{\text {sequencial }}}{p}+T_{s}(n, p)\right)$, onde $T_{s}(n, p)$ se refere ao tempo de ordenação global de $n$ dados sobre $p$ processadores. Além disso, envolve só um número constante de rodadas de comunicaçãa e $\frac{n}{p} \geq p^{\epsilon}$, para $\epsilon>0$ constante e arbitrariamente pequeno.

\subsection{Implementações Paralelas}

\subsubsection{Implementação do Algoritmo Paralelo Probabilístico}

O algoritmo Algoritmo 2 foi implementado [14] sobre a máquina CM5, com 32 processadores, cada um com $40 \mathrm{MB}$ de memória. Foi usado como algoritmo seqüencial, o algoritmo Quickhull. As implementações foram feitas para achar o fecho convexo nas dimensões 3 e 4 .

O número de rodadas de comunicação observado, para todos os pontos, foi sempre idêntico para os 20 testes.

Quando $\frac{n}{p}$ está entre 256 e $2 \mathrm{~K}$, ou $1 \mathrm{~K}$ e $8 \mathrm{~K}$, foi observado para o fecho convexo 3D ou $4 \mathrm{D}$, respectivamente, que o Algoritmo 2 requer entre 2 e 3 rodadas de comunicação.

Se $\frac{n}{p} \geq 4 \mathrm{~K}$ (em dimensão 3 ) ou $\frac{n}{p} \geq 16 \mathrm{~K}$ (em dimensão 4), respectivamente, o algoritmo termina sempre depois de uma rodada de comunicação.

\subsubsection{Implementação do Algoritmo Paralelo Determinístico}

As implementações do algoritmo paralelo determinístico foram feitas [18] na máquina T3D-CRAY, com 128 processadores, usando as rotinas PVM (Parallel Virtual Machine) para as comunicações.

A primeira versão foi implementada com $\frac{n}{p} \geq p^{2}$. No caso de conjuntos de pontos 
aleatórios, foi constatado que a complexidade total aumenta proporcionalmente a $n$, desde que $p$ é fixo, enquanto a complexidade de comunicação é quase constante.

No pior caso (conjunto linear de pontos), o tempo de computação local cresce proporcionalmente a $n \log n$. O tempo de comunicação total aumenta linearmente com $n$. O valor de $p$ foi igual a 64 .

Com o número de pontos fixos, os conjuntos de pontos aleatórios apresentam um bom comportamento quando $p$ é pequeno. Quando $p \geq 64$, foi observado uma inversão completa da inclinação da curva de tempo total de execução, isto significa que o algoritmo precisa de um grande número de processadores para resolver um problema de tamanho pequeno.

O Speedup $p^{2}$ observado, no pior caso, é melhor desde que a quantidade de computação local é suficientemente grande comparada com a comunicação.

O algoritmo foi implementado também no caso onde o número de dados por processador é fixo. No caso de conjunto aleatório, a curva de tempo total é quase paralela àquela de tempo de comunicação. Isto mostra o impacto de comunicação sobre a escalabilídade do algoritmo.

\footnotetext{
${ }^{2}$ O Speedup de um algoritmo paralelo é definido pela seguinte fórmula: $S_{p}(n)=T^{*}(n) / T_{p}(n)$, onde $T^{*}(n)$ é o tempo do melhor algoritmo seqüencial do problema, $T_{p}(n)$ o tempo de um algoritmo paralelo para o problema usando $p$ processadores e $n$ o tamanho da entrada do problema.
} 


\section{Implementações Paralelas}

Na seção 2.4 apresentamos o algoritmo seqüencial Quickhull. Nesse capítulo paralelizamos este algoritmo e mostrarmos a nossa implementação, na máquina paralela Parsytec PowerXplorer, do algoritmo Quickhull paralelizado para achar o fecho convexo. Esse algoritmo é descrito no modelo CGM. A topologia considerada é uma estrela onde os processadores filhos são ligados ao processador raiz. Os pontos usados obedecem a distribuição normal ou de Gauss.

Implementamos também o algoritmo paralelo (Algoritmo 1) de Dehne [14]. Fazemos ainda uma comparação entre os resultados dos dois algoritmos implementados.

$\mathrm{Na}$ seção 6.1 descrevemos as características da máquina Parsytec PowerXplorer do $L C P D$ do IME/USP (Laboratório de Computação Paralela e Distribuída do IME/USP ). A seção 6.2 trata da descrição do algoritmo Quickhull Paralelo. Na seção 6.3 apresentamos os resultados. Há um Apêndice $A$ nesse trabalho que contém o código da implementação do algoritmo Quickhull paralelizado.

\subsection{Características da Máquina}

A implementação do algoritmo foi feita na máquina paralela Parsytec PowerXplorer. Essa máquina tem 16 processadores, interconectados por uma topologia de grade bidimensional. Cada nó é formado por um PowerPC 601 para a computação e de um Transputer T805 para a comunicação, que compartilham uma memória local de 32 MBytes.

Os processadores são agrupados em 4 partições de 4 nós cada, chamadas A, B, C 
e D. Uma vez alocada, uma partição (ou mais) é dada para se rodar uma aplicação e permanece exclusiva para esta aplicação. As outras partições não usadas ficam livres para outras aplicações.

A máquina Parsytec PowerXplorer usa o sistema operacional PARIX que é uma extensão paralela para o sistema operacional UNIX. O sistema fornece as ferramentas necessárias para o desenvolvimento de aplicações paralelas. Essas ferramentas rodam em um computador hospedeiro (host) e o código produzido roda na Parsytec Power $X$ plorer. O PARIX oferece uma extensão para a linguagem $\mathrm{C}$ para o desenvolvimento de aplicações paralelas.

O PARIX permite que o mesmo código seja executado por todos os processadores, de forma que cada nó executa uma cópia do programa até o fim. O comportamento de cada processador depende do conteúdo do código, da posição de processador e dos dados locais. Como não existe memória global, as informações são trocadas via troca de mensagens.

No ambiente PARIX, as comunicações são feitas através de links virtuais. As conexões são ponto-a-ponto entre processadores arbitrários da grade. Um conjunto bem definido de links virtuais pode ser combinado para construir a topologia virtual como anel, árvore, pipelines, hipercubo, etc.

\subsection{Algoritmo Quickhull Paralelo}

Paralelizar o algoritmo sequêncial quickhull que resolve o problema do fecho convexo já estava no plano original da dissertação. Essa paralelização é feita no modelo de computação paralela CGM. Apesar de parecer trivial a sua paralelização, não se encontra nenhum resultado de paralelização deste algoritmo na literatura.

A idéia do algoritmo é de achar primeramente os quatro pontos extremos em cada processador. Os pontos que estão no interior de quadrilatero são eliminados. Esses pontos extremos são trocados em cada processador para encontrar os verdadeiros quatro pontos extremos. A fase seguinte consiste a colocar os pontos que sobram em um único processador e achar o fecho convexo. Esse algoritmo precisa de três rodadas de comunicação.

Algoritmo: Quickhull Paralelo

Entrada: Um conjunto finito $S=\left\{p_{1}, \ldots, p_{n}\right\}$ de pontos. Cada processador $P_{i}$ 
armazena um subconjunto aleatório $S_{i}$ de $n / p$ pontos de $S . S_{i}$ são disjuntos.

Saída: O fecho convexo de $S$.

1. Cada processador acha os quatro pontos extremos.

2. Um processador determinado $\left(P_{1}\right)$ recebe dos outros processadores seus quatro pontos extremos, acha os novos quatro pontos extremos e manda de volta aos demais processadores.

3. Os processadores eliminam os pontos que estão no interior de quadrilátero.

4. Processador $P_{1}$ recebe dos outros processadores os pontos que sobram e calcula o fecho convexo.

O algoritmo acima tem complexidade de tempo de computação local $O\left(\frac{n}{p} \log n\right)$ e um número constante de rodadas de comunicação.

\subsection{Resultados}

Utilizamos os dados de entrada segundo uma distribuição normal ou de Gauss. Nessa distribuição, são eliminados quase $97 \%$ de pontos depois de achar os quatro pontos extremos.

As tabelas listadas a seguir apresentam os tempos $\left(T_{1}, T_{4}, T_{8}\right)$ obtidos na nossa implementação com a máquina usando um, quatro e oito processadores, do algoritmo Quickhull paralelo e do algoritmo de Dehne.

\begin{tabular}{|r|r|r|r|r|r|}
\hline \multicolumn{1}{|c|}{$n$} & \multicolumn{1}{|c|}{$T_{1}$} & \multicolumn{2}{|c|}{$T_{4}$} & \multicolumn{2}{|c|}{$T_{8}$} \\
\hline & & Tempo & Speedup & Tempo & Speedup \\
\hline \hline 8000 & 93825 & 46223 & 2,029 & 34442 & 2,724 \\
\hline 40000 & 472804 & 135078 & 3,500 & 80802 & 5,851 \\
\hline 80000 & 922457 & 271032 & 3,403 & 198921 & 4,637 \\
\hline 120000 & 1382823 & 376272 & 3,675 & 210574 & 6,566 \\
\hline 160000 & 1844777 & 509180 & 3,623 & 366931 & 5,027 \\
\hline
\end{tabular}

Tabela 6.1: Tempos em $\mu$ s e Speedup para achar o fecho convexo de $n$ pontos segundo a distribuição normal com o algoritmo Quickhull paralelo. 


\begin{tabular}{|r|r|r|r|r|r|}
\hline \multicolumn{1}{|c|}{$n$} & \multicolumn{1}{|c|}{$T_{1}$} & \multicolumn{2}{|c|}{$T_{4}$} & \multicolumn{2}{c|}{$T_{8}$} \\
\hline & & Tempo & Speedup & Tempo & Speedup \\
\hline \hline 8000 & 93825 & 26036 & 3,603 & 16390 & 5,724 \\
\hline 40000 & 472804 & 119773 & 3,947 & 63596 & 7,434 \\
\hline 80000 & 922457 & 232947 & 3,959 & 119194 & 7,739 \\
\hline 120000 & 1382823 & 348541 & 3,967 & 175525 & 7,878 \\
\hline 160000 & 1844777 & 467269 & 3,947 & 234199 & 7,876 \\
\hline
\end{tabular}

Tabela 6.2: Tempos em $\mu$ s e Speedup para achar o fecho convexo de $n$ pontos segundo a distribuição normal com o algoritmo de Dehne.

\begin{tabular}{|r|r|r|r|r|}
\hline \multicolumn{1}{|c|}{$n$} & \multicolumn{2}{|c|}{$T_{4}$} & \multicolumn{2}{c|}{$T_{8}$} \\
\hline & computação & comunicação & computação & comunicação \\
\hline \hline 8000 & 34647 & 11576 & 20941 & 13501 \\
\hline 40000 & 123547 & 11531 & 67033 & 13769 \\
\hline 80000 & 248588 & 22444 & 153033 & 45888 \\
\hline 120000 & 356089 & 20183 & 186683 & 23891 \\
\hline 160000 & 482293 & 26887 & 276435 & 90496 \\
\hline
\end{tabular}

Tabela 6.3: Tempos em $\mu s$ da computação e comunicação para achar o fecho convexo de $n$ pontos segundo a distribuição normal com o algoritmo Quickhull paralelo.

Os resultados de nossa implementação mostram que as comunicações do algoritmo de Dehne são melhores. Com alta probabilidade, o algoritmo de Dehne necessita de apenas uma rodada de comunicação, em que apenas são transmitidos os pontos dos fechos convexos armazenados em cada processador. Esse número de pontos transmitidos é menor que $\frac{n}{p}$. No algoritmo de Quickhull paralelo, são transmitidos os quatro pontos extremos e os pontos que não são eliminados em cada processador. 


\begin{tabular}{|r|r|r|r|r|}
\hline \multicolumn{1}{|c|}{$n$} & \multicolumn{2}{|c|}{$T_{4}$} & \multicolumn{2}{c|}{$T_{8}$} \\
\hline & computação & comunicação & computação & comunicação \\
\hline \hline 8000 & 24676 & 1360 & 13335 & 3055 \\
\hline 40000 & 118499 & 1274 & 60569 & 3027 \\
\hline 80000 & 231583 & 1364 & 115985 & 3209 \\
\hline 120000 & 347060 & 1481 & 172217 & 3308 \\
\hline 160000 & 465340 & 1929 & 228187 & 6012 \\
\hline
\end{tabular}

Tabela 6.4: Tempos em $\mu s$ da computação e comunicação para achar o fecho convexo de $n$ pontos segundo a distribuição normal com o algoritmo de Dehne. 


\section{Considerações Finais}

O problema do fecho convexo é um dos problemas da geometria computacional mais estudados em computação paralela. Esse problema tem muitas aplicações em diversas áreas que motivam o estudo dos algoritmos para a sua construção. Nesta dissertação consideramos o problema do fecho convexo de um conjunto de pontos no plano.

No estudo desses algoritmos procuramos compreender os algoritmos seqüenciais de complexidade $O(n \log n)$. Especialmente vimos a estratégia de divisão-e-conquista que serve no projeto de desenvolvimento dos algoritmos paralelos para esse problema. Outros algoritmos seqüenciais podem ser usados na fase de computação local em cada processador.

O principal objetivo desta dissertação foi estudar os algoritmos paralelos para o fecho convexo. Para isso, definimos o modelo de computação paralela que será usado. Apresentamos vários modelos de computação paralela, fazendo uma classificação dos modelos apresentados. Nesse trabalho, usamos os modelos PRAM e CGM para desenvolver os algoritmos.

No modelo PRAM procuramos descrever detalhadamente o algoritmo apresentado em [33], que consideramos ser mais importante dos algoritmos paralelos pioneiros. Sua complexidade de tempo é $O(\log n)$ usando $O(n \log n)$ operações. O algoritmo paralelo descrito mostra como o método de divisão-e-conquista pode ser usado para o projeto de desenvolvimento de um algoritmo paralelo, para o problema do fecho

convexo. Em Aggarwal et al [2] encontramos um outro algoritmo paralelo para o mesmo problema usando o paradigma de divisão-e-conquista.

Vimos também de modo sucinto alguns algoritmos paralelos mais recentes no mo- 
delo CGM. O algoritmo de Dehne et al [15] visa a eliminar os pontos que estão no interior de cada fecho convexo calculado em cada processador. O algoritmo proposto é escalável, probabilístico e independente da arquitetura. Ele tem, com alta probabilidade, um número constante de rodadas de comunicação e complexidade de tempo $(k+2)\left(\frac{T_{1}(n)}{p}+O\left(\frac{n}{p}\right)\right)$ para a computação local e $(k+1)\left(T_{p S u m}(p)+T_{\text {compr }}(p, n)\right)$ para a comunicação, onde $k=\left\lceil\frac{1}{2 \epsilon}+\frac{1}{2}\right\rceil$ é uma constante e $\epsilon>0$ uma constante fixa. $T_{1}(n)$ denota a complexidade de tempo seqüencial e $T_{p S u m}(p)$ é a complexidade paralela para calcular a soma parcial de $p$ números cada um armazenado em um processador. $T_{\text {compr }}(p, n)$ é o tempo para comprimir um subconjunto de dados de tamanho $n^{\prime} \leq n$ em $p^{\prime} \leq p$ processadores. Em [18], Diallo et al descrevam um algoritmo paralelo determinístico, também escalável e independente da topologia de interconexão para o problema do fecho convexo no plano. $\mathrm{O}$ algoritmo requer somente um número constante de rodadas de comunicação e tem a complexidade de tempo de computação local $O\left(\frac{n \log n}{p}+T_{s}(n, p)\right)$ onde $n$ é o tamanho do problema, $p$ o número de processadores e $T_{s}(n, p)$ refere a complexidade de tempo de ordenação de $n$ pontos armazenados em $p$ processadores. Zhou, Deng e Dymond, em um trabalho ainda não publicado, propõem um algoritmo paralelo para o fecho convexo de um conjunto de $n$ pontos no plano, de complexidade de tempo local $\left(O\left(\frac{n \log n}{p}\right)\right)$ com o número de rodadas de comunicação ótimo.

Vários artigos relatam algoritmos para o problema do fecho convexo [7, 21, 27, 35, 38, 41]. O artigo de Goodrich [28] mostra técnicas probabilísticas para o problema no modelo $B S P$. Atallah et al [8] trata do método de divisão-e-conquista em cascata como um método para o desenvolvimento de algoritmos paralelos.

Neste trabalho foi proposta a paralelizão do algoritmo seqüencial Quickhull. A idéia é eliminar os pontos que estão no interior dos quatro pontos extremos. Sua complexidade de tempo de computação local é $\left(\frac{n}{p} \log n\right)$ com um número constante de rodadas de comunicação.

Dentre os algoritmos estudados, implementamos na máquina paralela Parsytec PowerXplorer o algoritmo de Dehne e o algoritmo proposto. O desempenho obtido mostra que o algoritmo de Dehne é melhor, pois ele consegue eliminar os pontos que estão no interior de cada fecho convexo calculado em cada processador. 


\section{Implementação}

Na proposta de nossa dissertação, sugerimos a implementação de um algoritmo paralelo probabilístico. Por isso, implementamos o algoritmo Quickhull paralelo. Neste apêndice listamos o código fonte como descrito no capítulo 6 do trabalho.

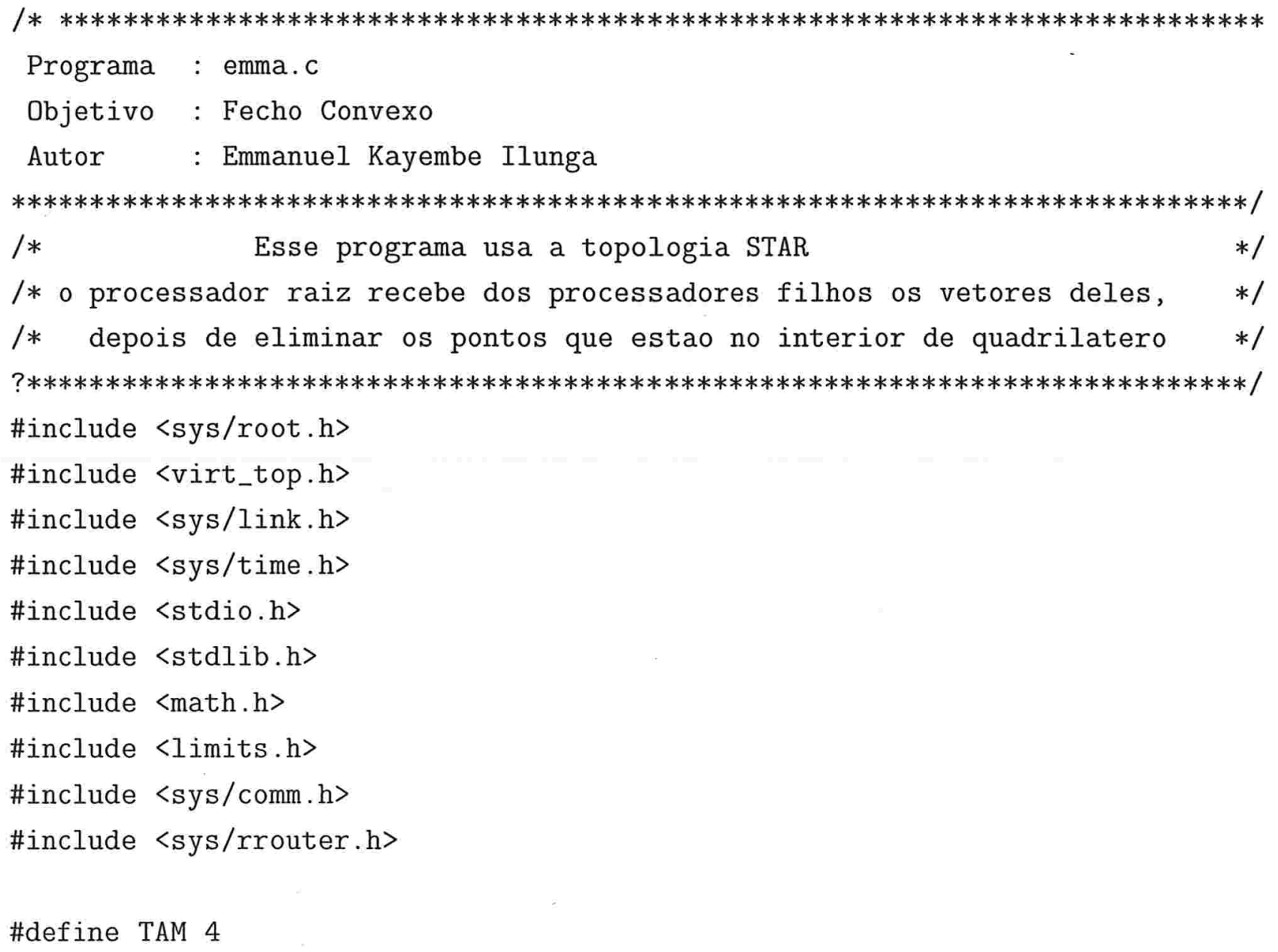




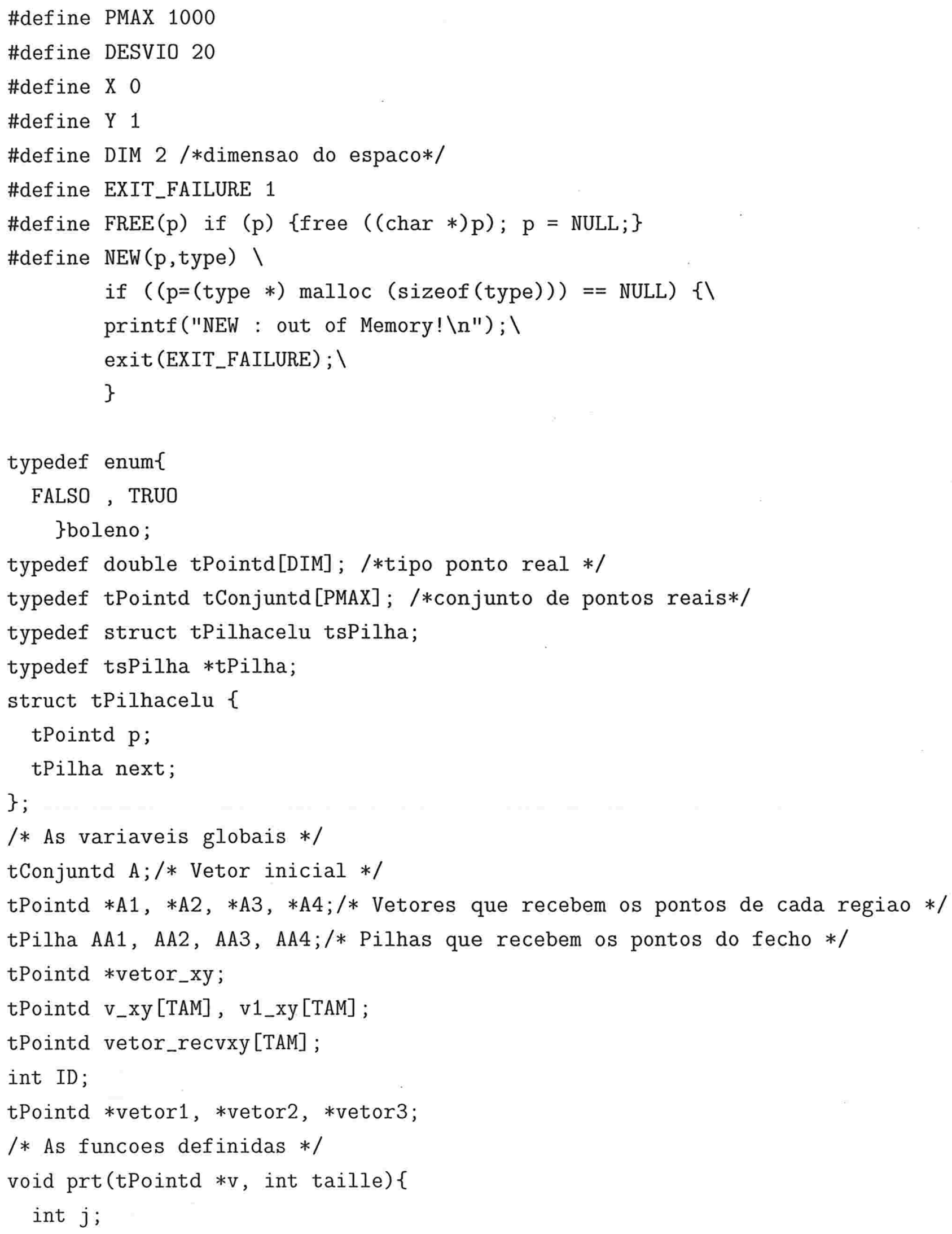




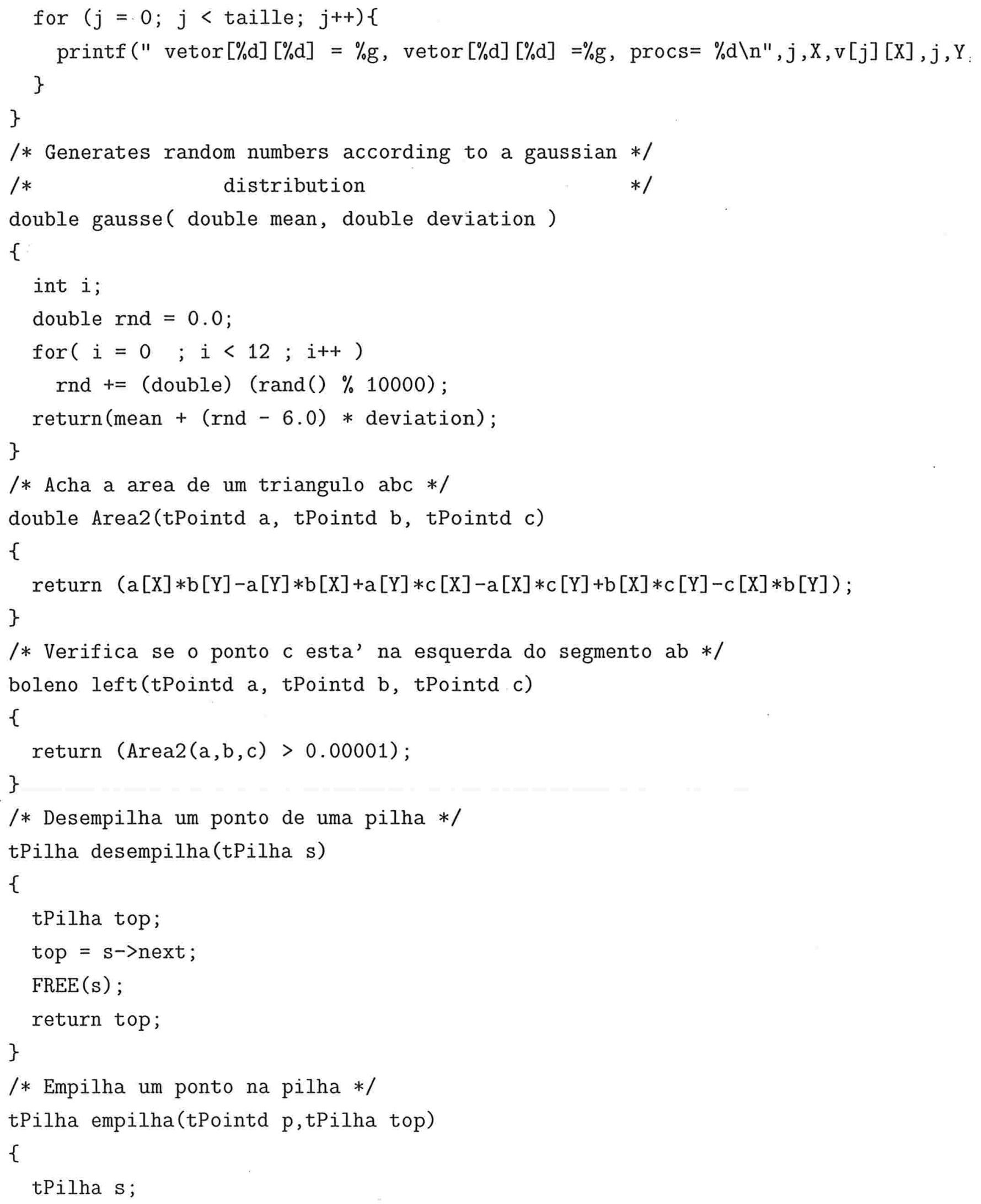




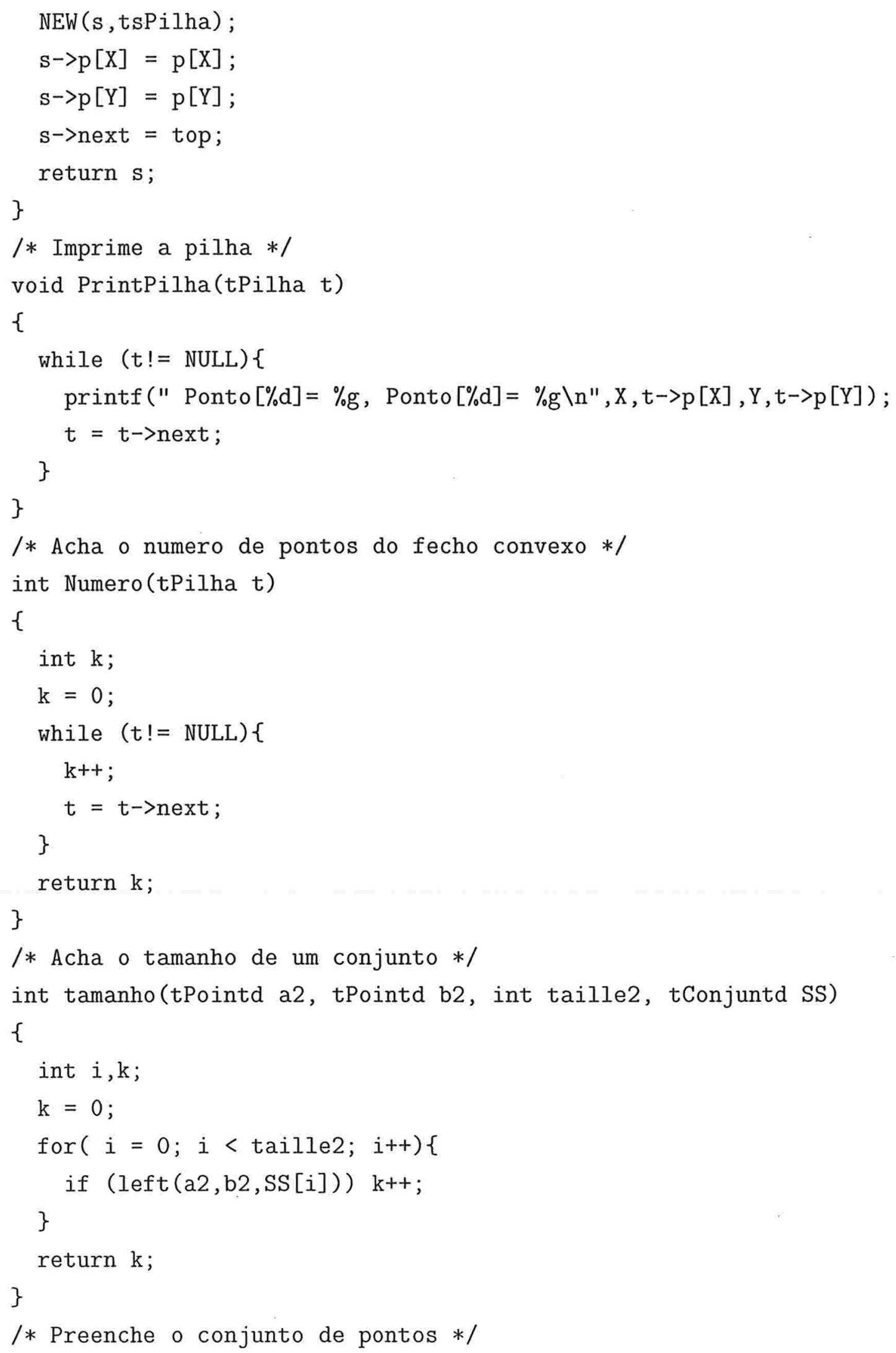




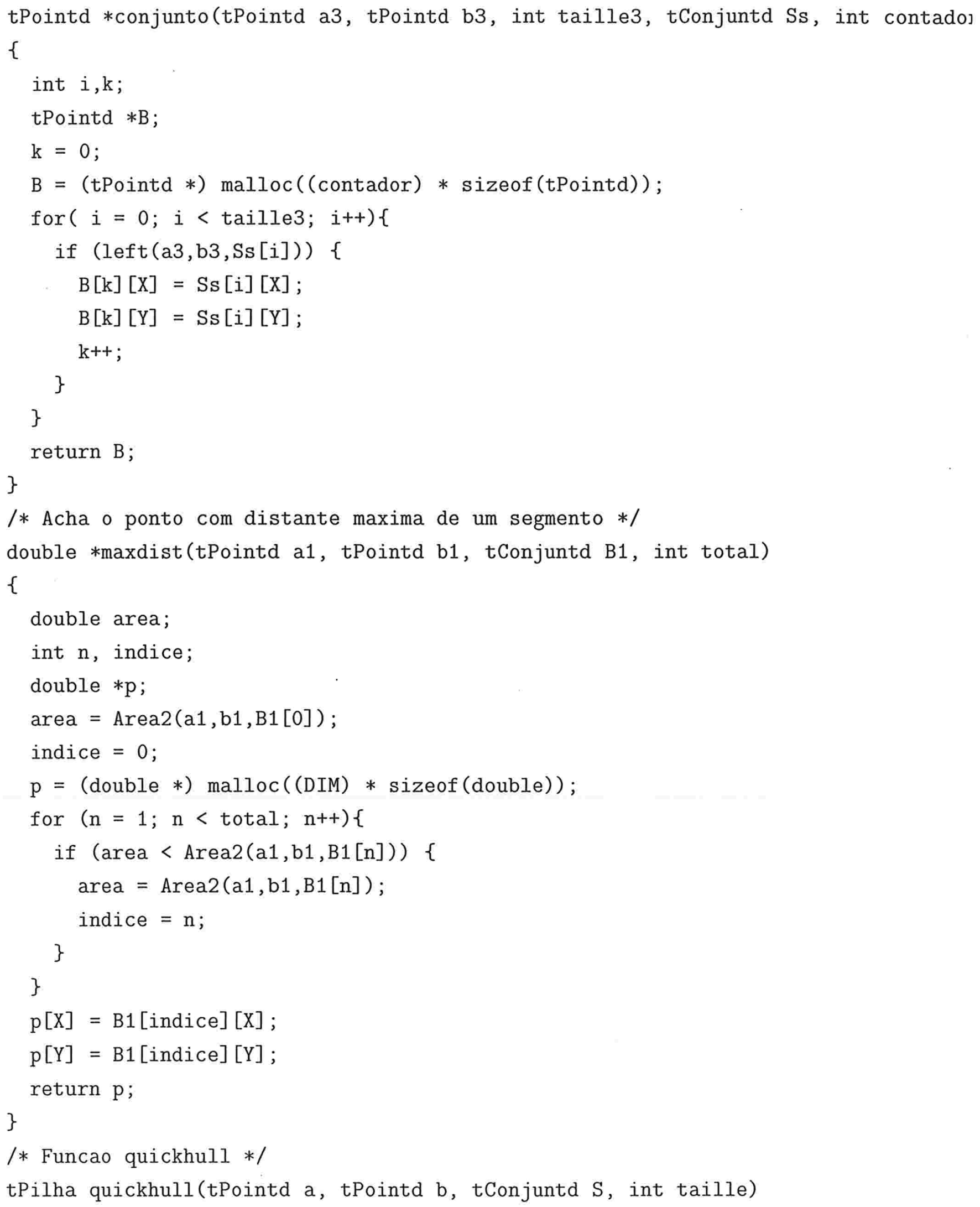




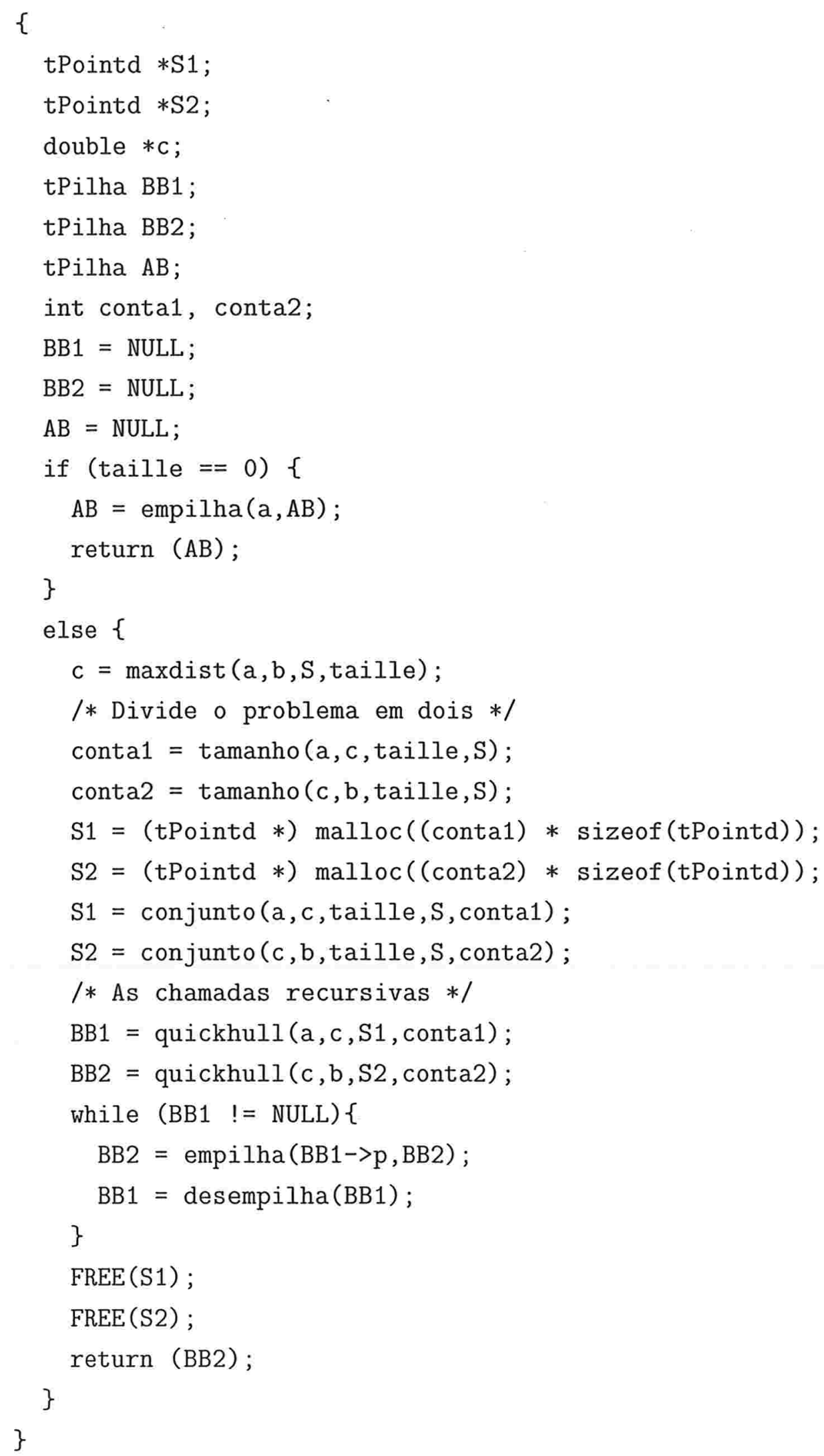




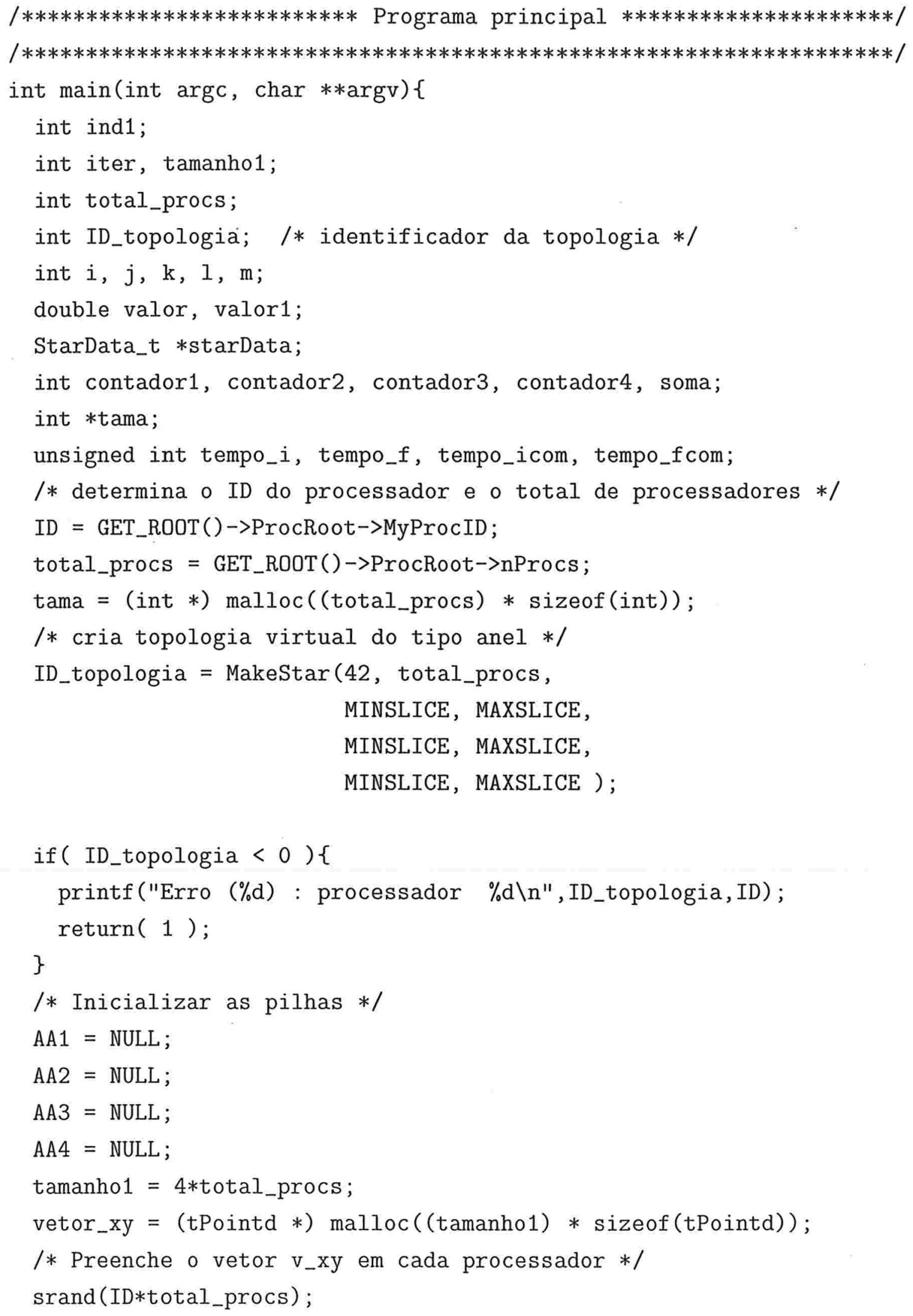




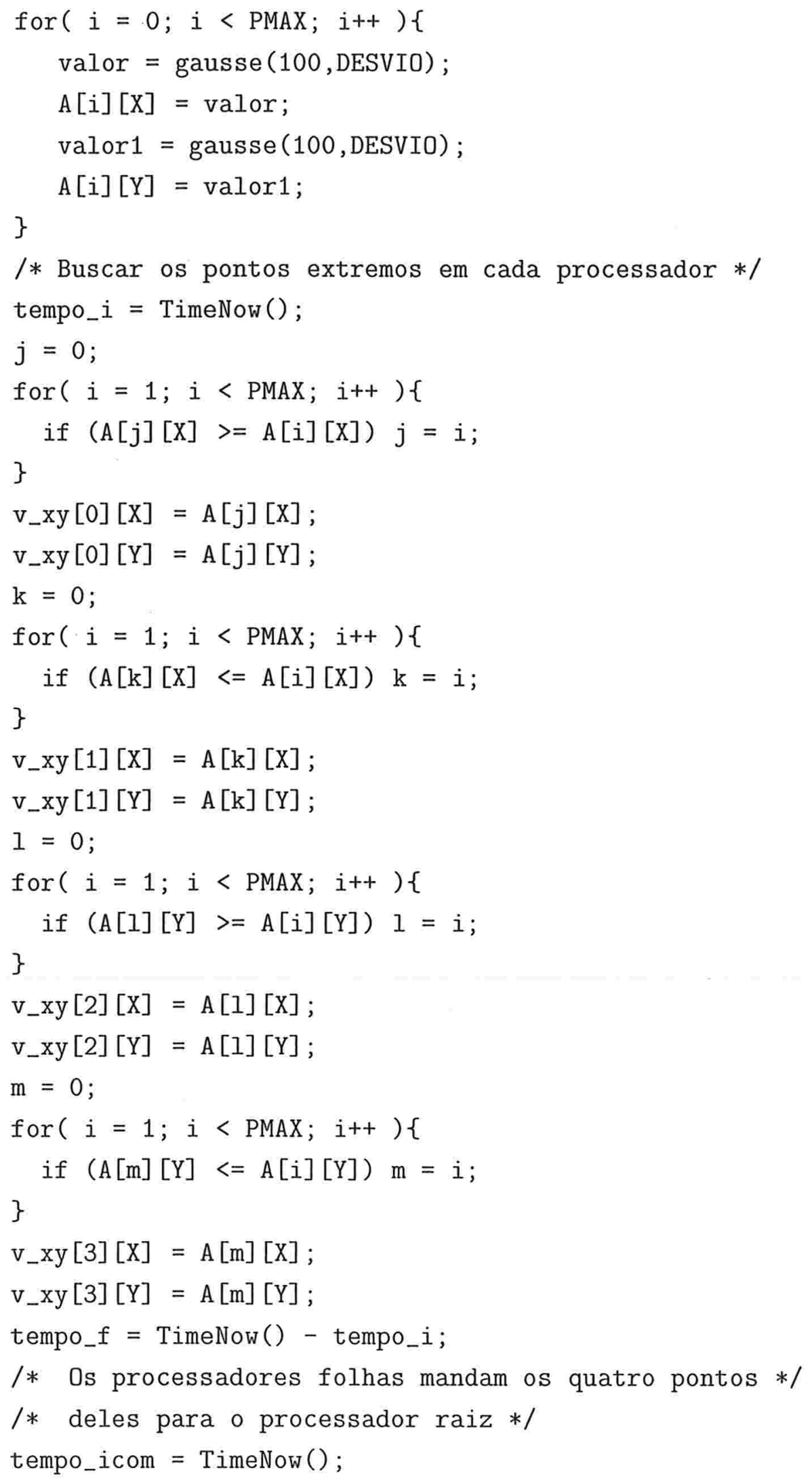




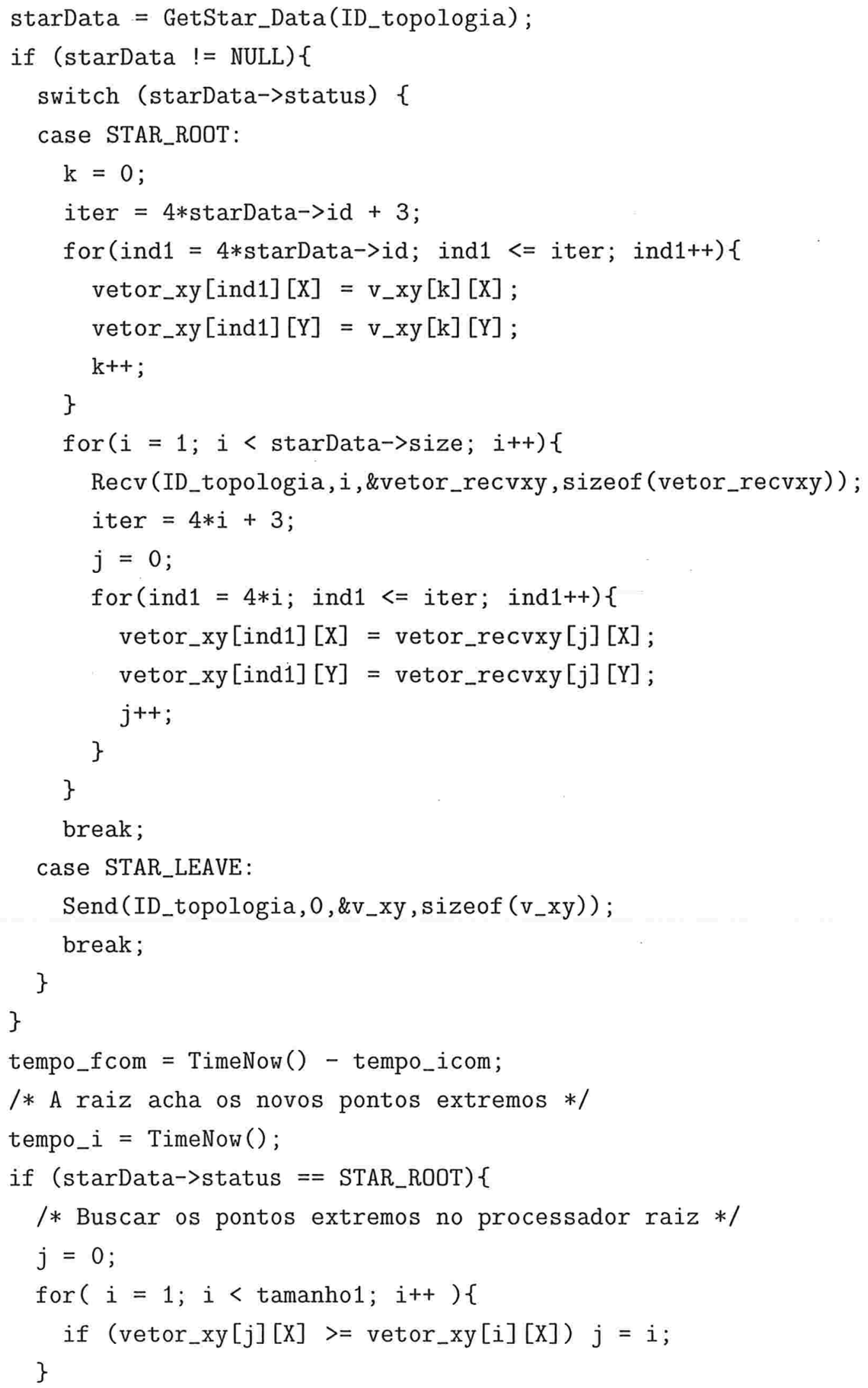




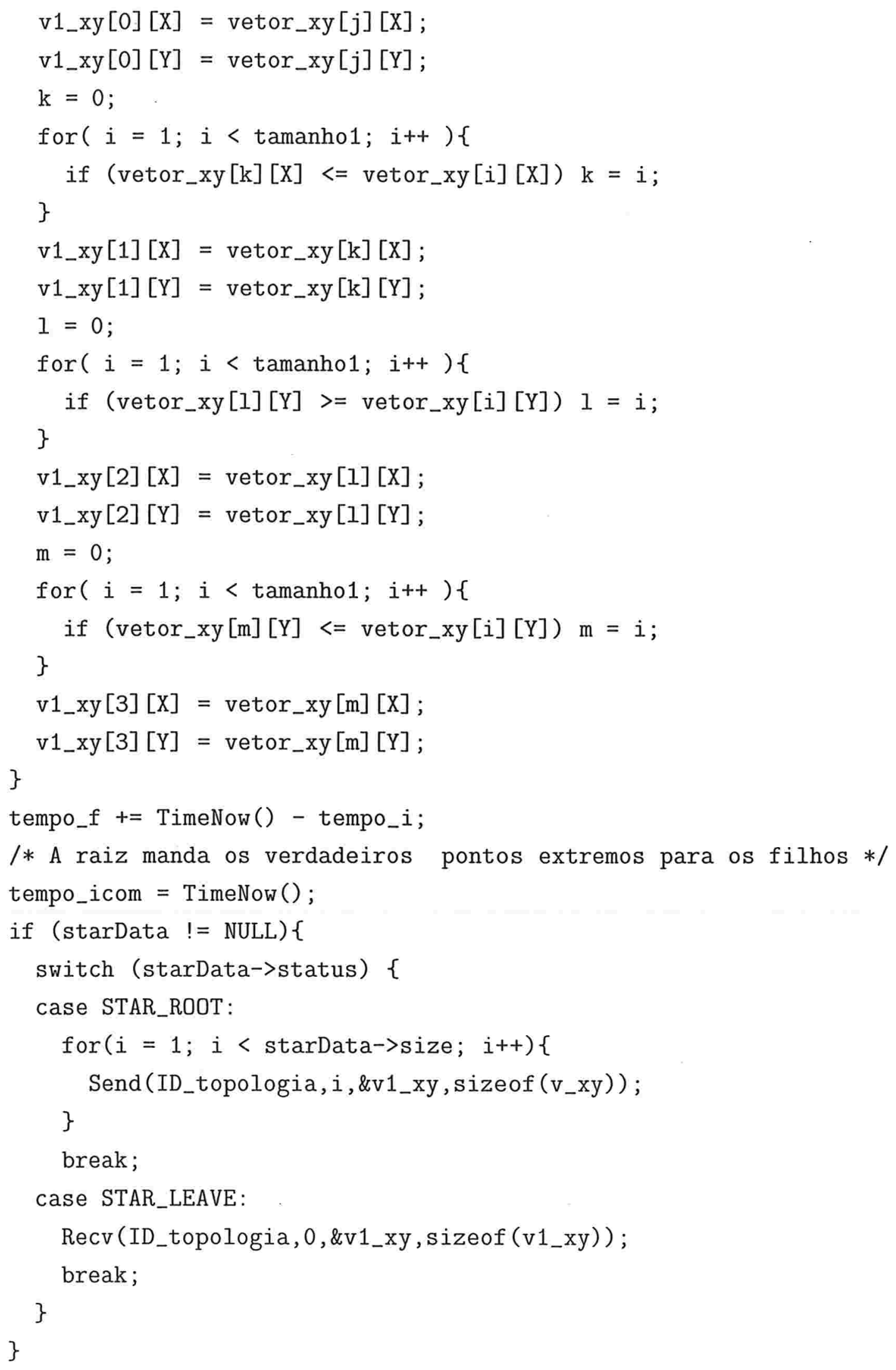




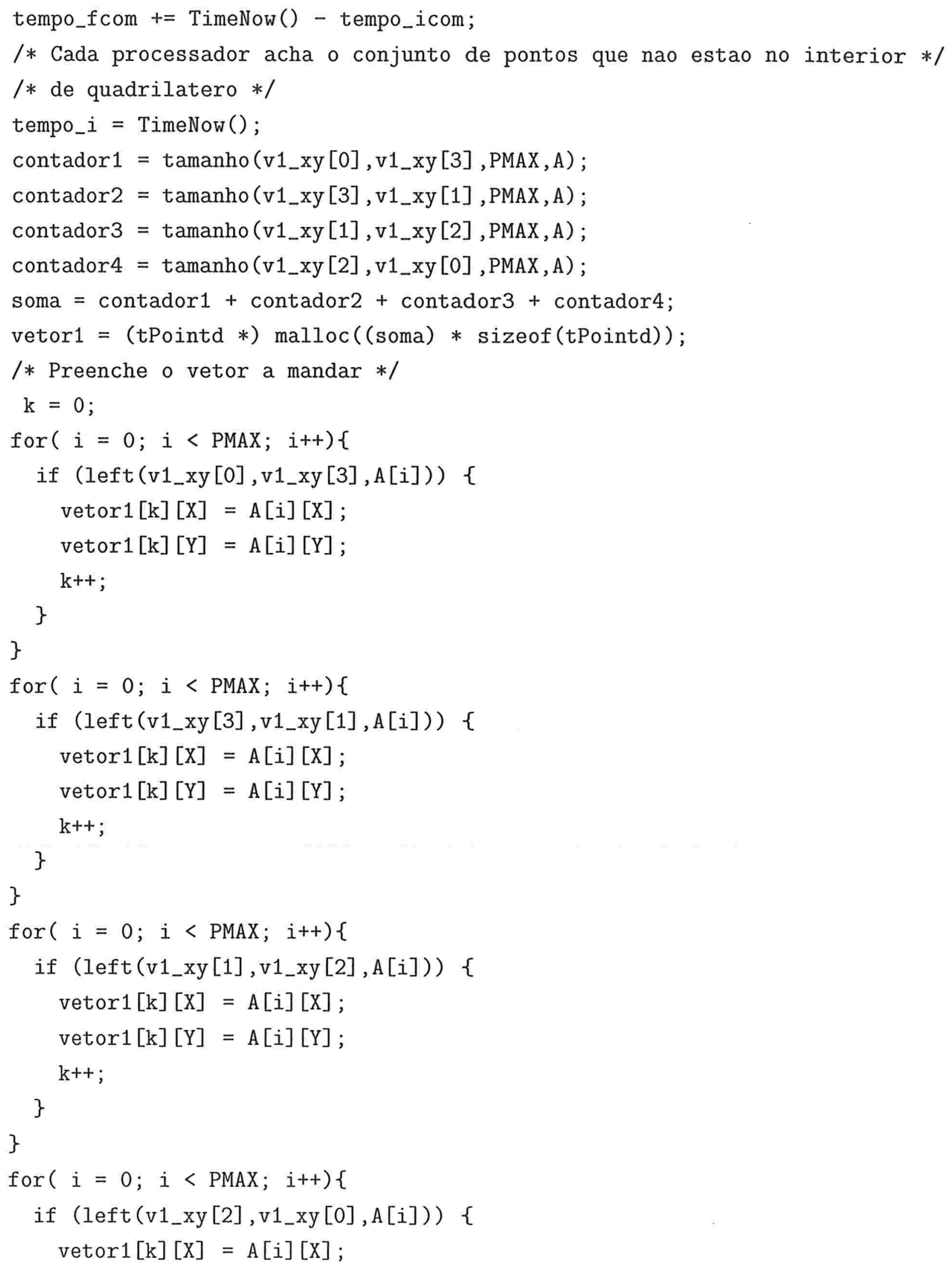




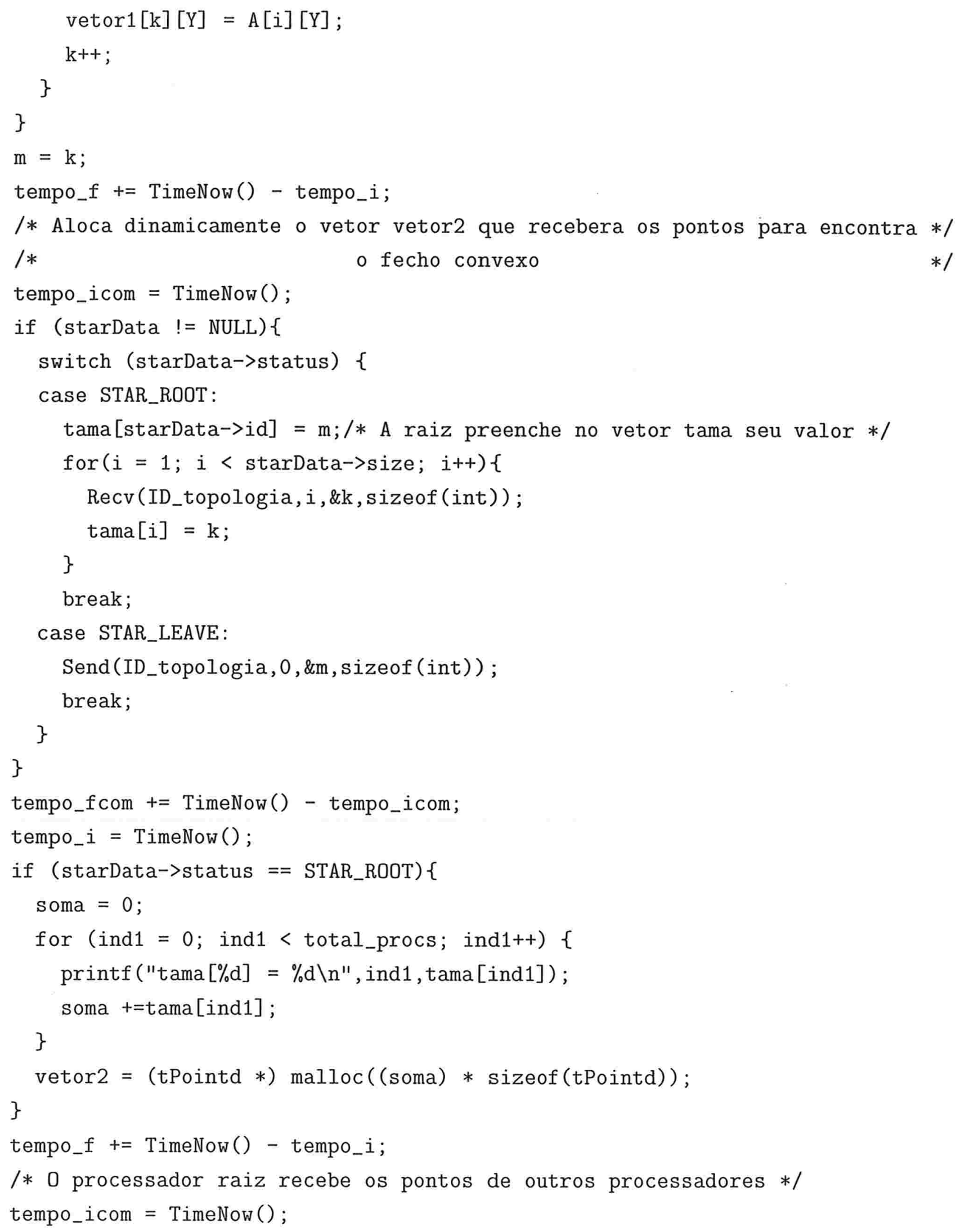




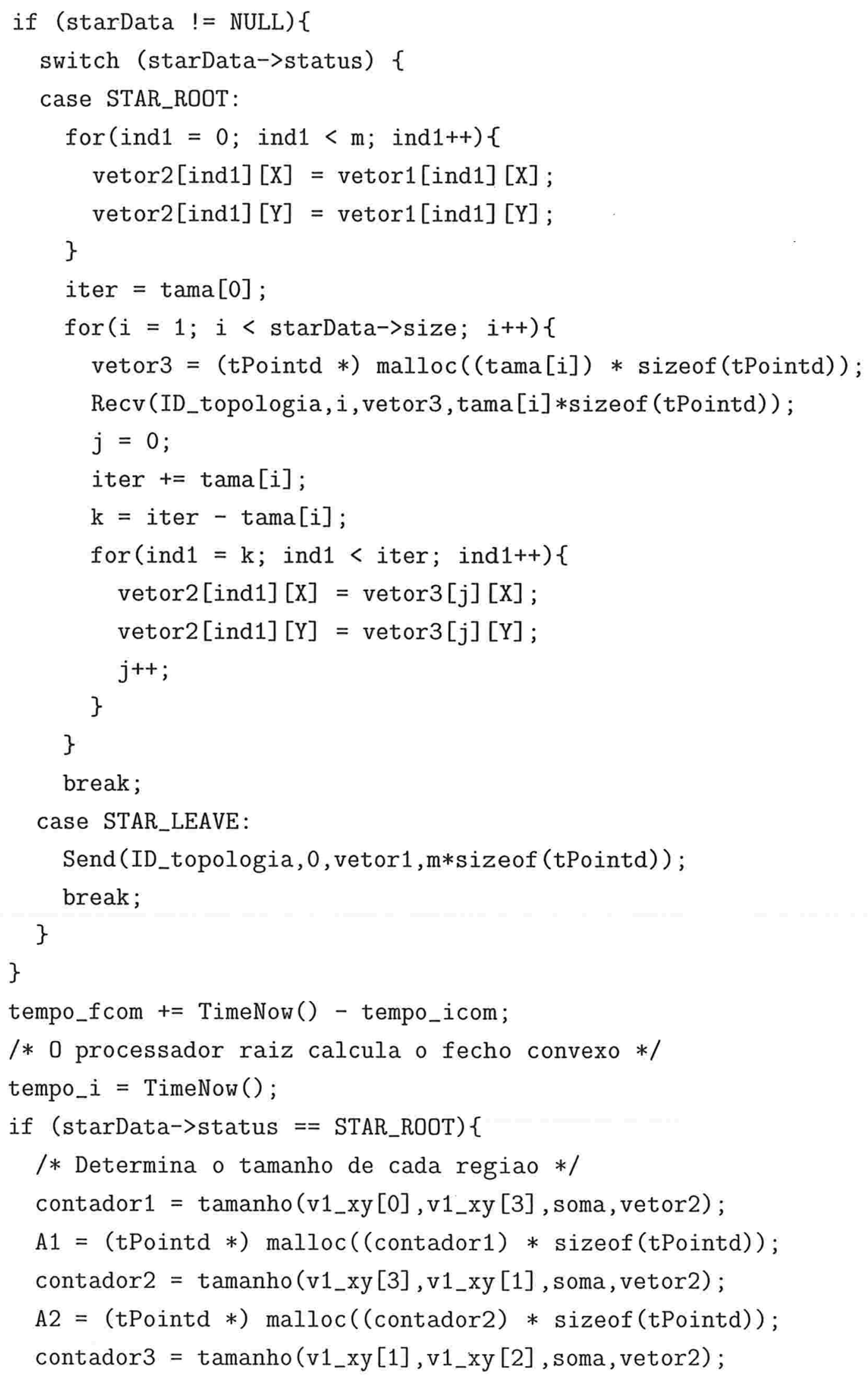




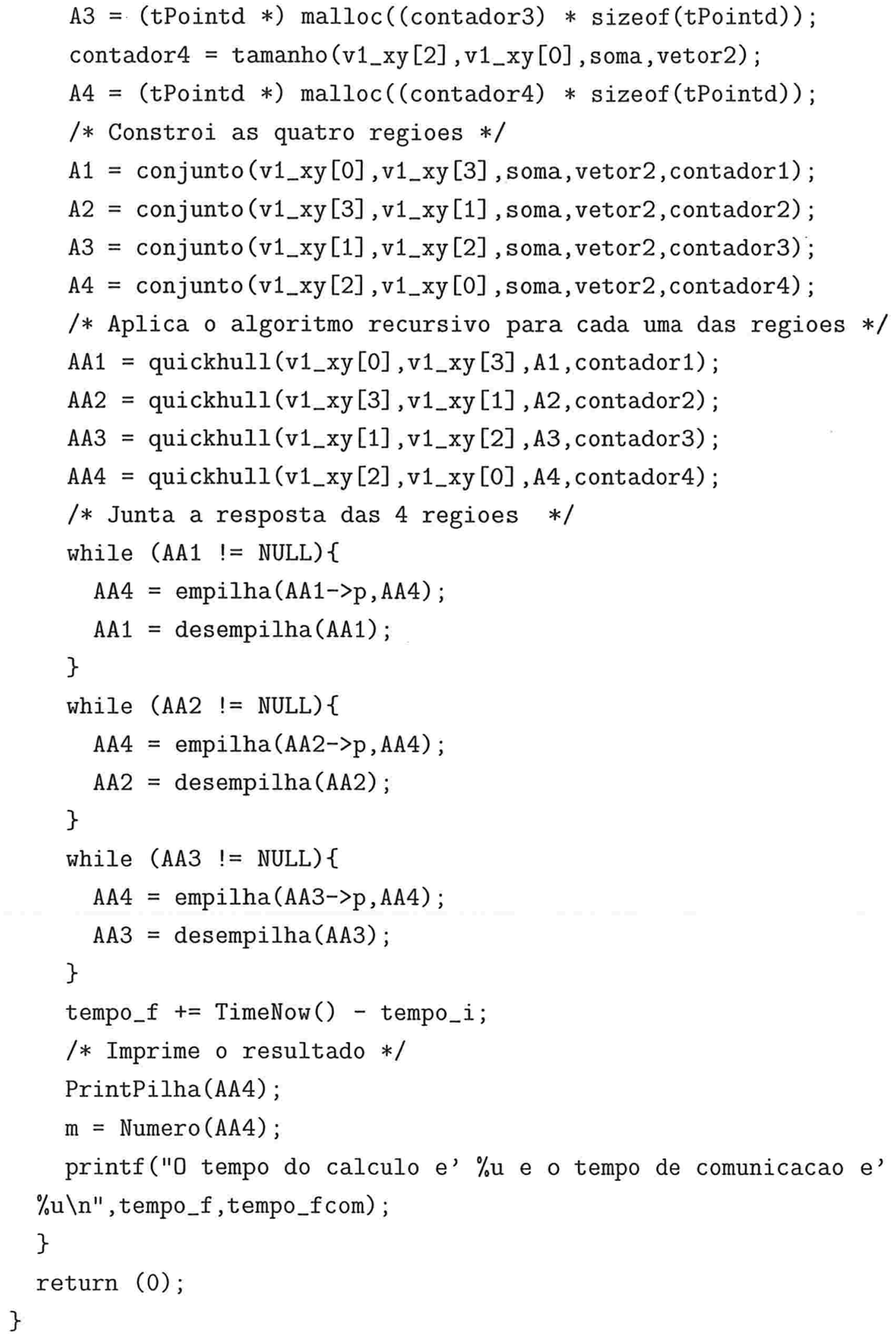




\section{Referências Bibliográficas}

[1] Conception et mise en oeuvre d'application parallèles irreguliéres de grande taille, Groupes thématiques de PRS, Capa - Rumeur- Exec, CNRS, 1997.

[2] A. Aggarwal, B. Chazelle, L. J. Guibas, C. O’Dunlaing and C. K. Yap, Parallel computational geometry, Algorithmica (1988), no. 3, 293-327.

[3] S. G. Akl, A constant-time parallel algorithm for computing convex hulls, BIT 22 (1982), 130-134.

[4] S. G. Akl, The Design and Analysis of Parallel Algorithms, ch. 12 - Traversing Combinatorial Spaces, pp. 310-340, Prentice-Hall International, Engelwood Cliffs, NJ, 1989, pp. 310-340.

[5] S. G. Akl and K. Lyons, Parallel computational geometry, Prentice Hall, 1993.

[6] S. G. Akl and G. T. Toussaint, Efficient convex hull algorithms for pattern recognition applications, Proc. 4th International Joint Conf. on Pattern Recognition, Kyoto, Japan (1979), 483-487.

[7] N. M. Amato, M. T. Goodrich and E. A. Ramos, Parallel algorithms for higherdimensional convex hulls, Proc. 35th IEEE Symp. on Foundations of Computer Science (FOCS), 1994, pp. 683-694.

[8] M. J. Atallah, R. Cole and M. T. Goodrich, Cascading divide-and-conquer: A technique for designing parallel algorithms, SIAM Journal on Computing 18 (1989), no. 3, 499-532. 
[9] T. H. Axford, The divide-and-conquer paradigm as a basis for parallel language design, Advances in Parallel Algorithms (L. Kronsjö and D. Shumsheruddin, eds.), Blackwell, London, UK, 1992, pp. 25-65.

[10] A. Bykat, Convex hull of a finite set of points in two dimensions, Information Processing Letters 7 (1978), no. 6, 296-298.

[11] A. L. Chow, A parallel algorithm for determining convex hull of sets of points in two dimension, Proc. of the Nineteenth Annual Allerton Conf. on Communication, Control and Computing (1981), 214-222.

[12] T.H. Cormen, C.E. Leiserson and R.L. Rivest, Introduction to algorithms, The MIT Press, MacGraw-Hill Book Company, 1990.

[13] F. Dehne, X. Deng, P. Dymond, A. Fabri and A. A. Kokhar, A randomized parallel 3D convex hull algorithm for coarse grained multicomputers, In Proc. ACM Symposium on Parallel Algorithms and Architectures (1995), 27-33.

[14] F. Dehne, A. Fabri and C. Kenyon, Scalable and architecture independent parallel geometric algorithms with high probability optimal time, In Proc. 6th IEEE Symposium on Parallel and Distributed Processing (1994), 586-593.

[15] F. Dehne, A. Fabri and A. Rau-Chaplin, Scalable parallel computational geometry for coarse grained multicomputers, In Proc. ACM 9th Annual Computational Geometry (1993), 298-307.

[16] F. Dehne and S. W. Song, Randomized parallel list ranking for distributed memory multiprocessors, ACSC: Asian Computing Science Conference, LNCS, 1996.

[17] X. Deng and N. Gu, Good algorithm design style for multiprocessors, In Proc. 6th IEEE Symposium on Parallel and Distributed Processing, Dallas, USA (October 1994), 538-543.

[18] A. Diallo, A. Ferreira, A. Rau-Chaplin and S. Ubéda, Scalable 2D convex hull and triangulation algorithms for coarse grained multicomputers, Proc. 7th IEEE Symposium on Parallel and Distributed Processing (SPDD'95) (1995).

[19] R. O. Duda and P. E. Hart, Pattern classification and scene analysis, WileyInterscience, New York, 1973. 
[20] W. F. Eddy, A new convex hull algorithm for planar sets, ACM Transactions on Mathematical Software 3 (1977), no. 4, 398-403.

[21] D. J. Evans and Shao-wen Mai, Two parallel algorithms for the convex hull problem in a two dimensional, Parallel Computing 2 (1985), no. 4, 313-326.

[22] W. Feller, An introduction to probability theory and its applications, John Wiley \& Sons, 1950.

[23] A. Ferreira, Parallel and communication algorithms on hypercube multiprocessors, Handbook of Parallel and Distributed Computing (Albert Y. Zomaya, ed.), McGraw-Hill, New York, 1995.

[24] L. H. Figueiredo and P. C. P. Carvalho, Introdução a geometria computacional, 18 Colóquio Brasileiro de Matemática, IMPA, 1991.

[25] H. Freeman, Computer processing of line-drawing images, Comput. Surveys 6 (1974), 57-97.

[26] H. Freeman and R. Shapira, Determining the minimum-area encasing rectangle for an arbitrary closed curve, Communications of the ACM 18 (1975), no. 7, 409-413.

[27] M. T. Goodrich, Finding the convex hull of a sorted point set in parallel, Information Processing Letters 26 (1987), no. 4, 173-179.

[28] _ Randomized fully-scalable BSP techniques for multi-searching and convex hull construction (preliminary version), Proceedings of the Eighth Annual ACM-SIAM Symposium on Discrete Algorithms (New Orleans, Louisiana), 5-7 January 1997, pp. 767-776.

[29] R. L. Graham, An efficient algorithm for determining the convex hull of a finite planar set, Information Processing Letters 1 (1972), 132-133.

[30] P. J. Green and B. W. Silverman, Constructing the convex hull of a set of points in the plane, The Computer Journal 22 (1979), no. 3, 262-266.

[31] S. E. Hambrusch, Models for parallel computation, ICPP: 25th International Conference on Parallel Processing, 1996.

[32] R. A. Jarvis, On the identification of the convex hull of a finite set in the plane, Information Processing Letters 2 (1973), 18-21. 
[33] J. JáJá, An introduction to parallel algorithms, Addison-Wesley Publishing Company, 1992.

[34] B. M. Maggs, L. R. Matheson and R. E. Tarjan, Models of parallel computation: a survey and synthesis, Proceedings of the 28th Hawaii International Conference on System Sciences (HICSS), vol. 2, 1995, pp. 61-70.

[35] S. N. Maheshwari and P. C. P. Bhatt, Parallel algorithms for the convex hull problems in two dimensions, Conf. Analy. Prob. Classes Program. Parallel Comput., Lecture Notes in Computer Science, vol. 111, Springer-Verlag, 1981, pp. 358-372.

[36] E. W. Mayr and R. Werchner, Divide-and-conquer algorithms on the hypercube, Theoretical Computer Science 162 (1996), no. 2, 283-296.

[37] R. Miller and Q. Stout, Computational geometry on a mesh-connected computer (preliminary version), Proc. of the 1984 International Conference on Parallel Processing (1984), 236-271.

[38] _ Efficent parallel convex hull algorithms, IEEE Transactions on Computers 37(12) (1988), 1605-1618.

[39] J. O'Rourke, Computational geometry in c, Cambridge University Press, Cambridge, 1993.

[40] C. H. Papadimitriou, Computational complexity, Addison-Wesley, New York, 1994.

[41] W. Preilowski, E. Dahlhaus and G. Wechsung, New parallel algorithms for convex hull and triangulation in 3-dimensional space, Proceedings of MFCS '92. Mathematical Foundations of Computer Science (MFCS '92) (Berlin, Germany) (Ivan M. Havel and Vaclav Koubek, eds.), LNCS, vol. 629, Springer, August 1992, pp. 442-450.

[42] F. P. Preparata and S. J. Hong, Convex hulls of finite setes os points in two and three dimensions, Commun. ACM (1977), no. 20, 87-93.

[43] F. P. Preparata and M. I. Shamos, Computational geometry: An introduction, texts and monographs in computer science, Springer-Verlag, New York, 1985.

[44] J. H. Reif, Synthesis of parallel algorithms, Morgan Kaufmann, San Mateo, 1993. 
[45] A. Rosenfeld, Picture processing by computers, Academic Press, New York, 1969.

[46] J. Sklansky, Measuring concavity on a rectangular mosaic, IEEE Trans. Comp. C-21 (1972), 1355-1364.

[47] L. Valiant, A bridging model for parallel computation, Communications of the ACM (1990), no. 33, 103-111. 